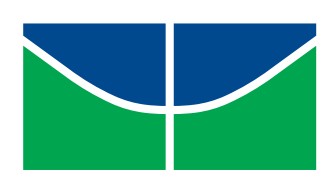

Universidade de Brasília

Faculdade de tecnologia

Departamento De Engenharia Mecânica

Programa de Pós-Graduação em Ciências Mecânicas

WESLY JEAN

\title{
ESTUDO DE UM SISTEMA FOTOVOLTAICO-EÓLICO PARA UMA COMUNIDADE ISOLADA NO HAITI
}

DISSERTAÇÃO DE MESTRADO

\author{
Brasília-DF \\ 14 de Março de 2017
}


WESLY JEAN

\section{ESTUDO DE UM SISTEMA FOTOVOLTAICO-EÓLICO PARA UMA COMUNIDADE ISOLADA NO HAITI}

Dissertação de Mestrado apresentada ao Programa de Pós-Graduação em Engenharia Mecânica (PCMEC) da Faculdade de Tecnologia da Universidade de Brasília como parte dos requisitos necessários para obtenção do título de mestre em Ciências Mecânicas.

Orientador: Antonio C. P. Brasil Junior

Brasília-DF

14 de Março de 2017 


\section{FICHA CATALOGRÁFICA}

\section{Wesly Jean}

ESTUDO DE UM SISTEMA FOTOVOLTAICO-EÓLICO PARA UMA

COMUNIDADE ISOLADA NO HAITI/ Wesly Jean. - Brasília-DF, 27 de Março de 2017- 114 p. : il. (algumas color.) ; $30 \mathrm{~cm}$.

Orientador: Antonio C. P. Brasil Junior

Dissertação de mestrado - Universidade de Brasília-

UnB Faculdade de Tecnologia

Departamento De Engenharia Mecânica

Programa de Pós-Graduação em Ciências Mecânicas, 27 de março de 2017.

1. comunidades isoladas. 2. sistemas híbridos de energia. 3. Programa HOMER.

4. sustentabilidade. I. Orientador. II. Universidade de Brasília. III. Faculdade de Tecnologia.

\section{REFERÊNCIA BIBLIOGRÁFICA}

Jean, W. (2017). ESTUDO DE UM SISTEMA FOTOVOLTAICO-EÓLICO PARA UMA COMUNIDADE ISOLADA NO HAITI. Dissertação de Mestrado em Ciências Mecânicas, Publicação ENM.DM-253 A/2017, Departamento de Engenharia Mecânica, Universidade de Brasília, Brasília - DF, 114p.

\section{CESSÃO DE DIREITOS}

NOME DO AUTOR: Wesly Jean.

TÍTULO DA DISSERTAÇÃO DE MESTRADO: ESTUDO DE UM SISTEMA FOTOVOLTAICO-EÓLICO PARA UMA COMUNIDADE ISOLADA NO HAITI GRAU/ANO: Mestre/2017.

É concedida à Universidade de Brasília permissão para reproduzir cópias dessa dissertação de mestrado e para emprestar ou vender tais cópias somente para propósitos acadêmicos e científicos. O autor reserva outros direitos de publicação e nenhuma parte dessa dissertação de mestrado pode ser reproduzida sem a autorização por escrito do autor.

\footnotetext{
Wesly Jean

Faculdade de Tecnologia

Universidade de Brasília (UnB), Brasília - DF weslyjean99@yahoo.com.br
} 
Universidade de Brasília

Faculdade de Tecnologia

Departamento de Engenharia Mecânica

\title{
ESTUDO DE UM SISTEMA FOTOVOLTAICO-EÓLICO PARA UMA COMUNIDADE ISOLADA NO HAITI
}

\author{
Wesly Jean
}

DISSERTAÇÃO SUBMETIDA AO DEPARTAMENTO DE ENGENHARIA MECÂNICA DA FACULDADE DE TECNOLOGIA DA UNIVERSID,.DE DE BRASÍLIA COMO PARTE DOS REQUISITOS NECESSÁRIOS PARA OBTENÇÃO DO GRAU DE MESTRE EM CIÊNCIAS MECÂNICAS.

Aprovada por:

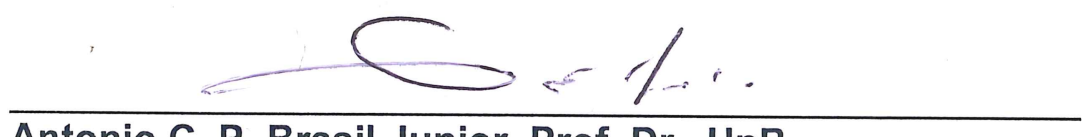

Antonio C. P. Brasil Junior, Prof. Dr., UnB

(Orientador)

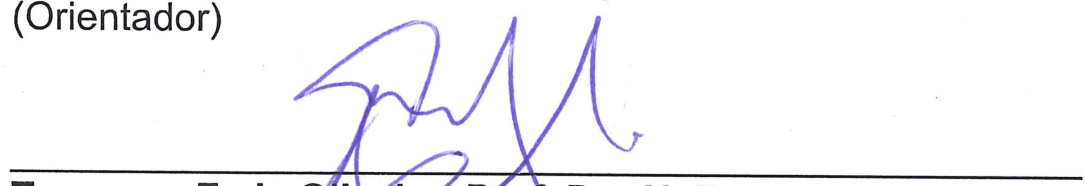

Taygoara F. de Qlive "ra, Prot. Dr., UnB

(Examinador interno)

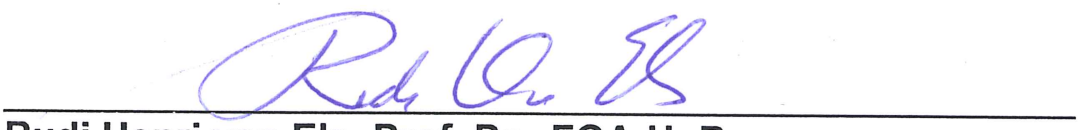

Rudi Henri van Els, Prof. Dr., FGA-UnB

(Examinador externo)

Brasília, 27 de Março de 2017. 
Ao meu grande DEUS, por estar sempre comigo todos os dias e em todos os momentos da minha via.

Aos meus irmãos por acreditaram em mim e por todos os tipos de incentivos.

Ao meu orientador professor Dr. Antonio C. P. Brasil Junior por ter me proporcionado o crescimento científico.

Aos meus pais, in memoriam. 


\section{Agradecimentos}

Agradeço primeiramente a Deus por ter me dado saúde, força e inteligência para superar todas as dificuldades e conseguir chegar onde hoje estou.

Aos meus irmãos Jean Marie Jeancilien Jean, Jean Robert Jeancilien Jean e Wismy Jean que mesmo de longe, sempre são exemplos de companheirismo e cumplicidade e que me apoiaram para que esse trabalho fosse realidade.

A Universidade de Brasília (UnB), por ter me dado a oportunidade de realizar este curso e pelo ambiente criativo e amigável que proporciona.

Agradeço a este meu orientador, professor Antonio C. P. Brasil Júnoir, pela paciência, dedicação e ensinamentos que possibilitaram que eu realizasse este trabalho.

Meus agradecimentos aos amigos Donald Manigat, Geslin Mars, Barnet Joseph, Kerby Myrthil, Lilise Lima e Marcelo Perreira por estarem do meu lado em todos os momentos durante essa caminhada.

Agradeço aos senhores Pastores Léonel Raphael e Gérard Toussaint Paul por terem me dado a oportunidade de estar aqui.

Agradeço meus companheiros e irmãos de trabalhos da LEA na amizade que fizeram parte da minha formação e que vão continuar presentes em minha vida com certeza.

Enfim, agradeço a todas as pessoas que fizeram parte dessa etapa importante em minha vida. 
"Descobrir consiste em olhar para o que todo mundo está vendo e pensar uma coisa diferente". (Roger Von Oech) 


\section{Resumo}

A eletrificação das comunidades isoladas e/ou áreas rurais tem sido uma grande preocupação de muitos governos e instituições não governamentais nos últimos anos. As fontes renováveis de energia vêm sendo uma das alternativas mais promissoras utilizadas nas últimas décadas para enfrentar esse grande desafio. Este presente trabalho consiste em usar os recursos locais (solar e eólico) para projetar e simular um sistema híbrido de energia por meio do programa HOMER numa comunidade isolada no Haiti. A comunidade possui uma igreja, uma escola e algumas residências, portanto, o projeto deve atender as cargas elétricas de todas essas unidades. No trabalho foi feita análises de viabilidade econômica e técnica da implantação do projeto. É um projeto que pode entrar no programa "Banm limyè, banm lavi" do governo haitiano que tem por objetivo de levar energia elétrica para todas as comunidades do país.

Primeiramente, foi feita uma revisão de literatura sobre os principais temas envolvendo o trabalho, onde foram descritas as relações entre energia e comunidades, energia e pobreza, energia e sustentabilidade, sistemas híbridos e ferramentas de simulação. Depois, foi feita a caracterização da comunidade, apresentando os seus aspectos geográficos, econômicos, populacional e climáticos, assim como, a sua caracterização energética. Em seguida, foi apresentado o estado da arte do programa em questão, com sua descrição geral, sua formulação energética e os principais recursos usados nesse trabalho. E por último foi realizado a simulação através da ferramenta computacional HOMER para determinar se o projeto é tecnicamente e financeiramente viável, neste, para fins de análises, foi comparado algumas configurações encontradas na simulação e que nesse trabalho são denominadas de configurações intensivas. Analisando os resultados, foi possível determinar qual foi a configuração intensiva que melhor atende a comunidade visando equilibrar os detalhes técnicos e econômicos. As conclusões mostraram que projetos de energias deste tipo podem contribuir para abastecer comunidades isoladas usando os recursos locais e assim, fazendo a inclusão social destas pessoas desprovidas das necessidades mais básicas. 


\begin{abstract}
The electrification of isolated communities and/or rural areas is a major concern of many governments and non-governmental institutions around the world. Recently, one of the most promising alternatives to meet this great challenge is the use of renewable energy sources. This work consists of using the local resources (solar and wind) to design and simulate a hybrid energy system through the HOMER program in an isolated Haitian community. This community has a church, a school and some residences, thus the project must meet the electric charges of all these entities. The economic and technical feasibility analyzes of the project implemented were made as part of this work. This research project could enter into the "Banm limyè, banm lavi" program of the Haitian government that aims to bring electricity to all communities in the country.
\end{abstract}

Firstly, a literature review was carried out on the main themes involving the work, where the relations between energy and communities, energy and poverty, energy and sustainability, hybrid systems and simulation tools were described. Afterwards, the community was characterized by presenting its geographic, economic, population and climatic aspects, as well as its energy characterization. Next, the state of the art of the program in question was presented by underlining the general description, energetic formulation and the main resources used in this work. Finally, the simulation through the HOMER program was performed to determine if the project is technically and financially viable. For analysis purpose, we compared some of the configurations found in the simulation, which are called intensive configurations. The intensive configuration which well serves the community in order of balancing the technical and economic details was determined through the results analysing. This work shows that energy projects of this type can contribute to supply energy to the isolated communities using local resources and make the social development of these people devoid of the most basic needs. 


\section{Lista de ilustrações}

Figura 1 - As três dimensões do desenvolvimento sustentável. . . . . . . . . . 31

Figura 2 - Modelo de sistema híbrido de energia. . . . . . . . . . . . . 34

Figura 3 - Carta da República do Haiti. . . . . . . . . . . . . . . . 40

Figura 4 - Localização e distâncias das residências no vilarejo. . . . . . . . . . 41

Figura 5 - Instituição de ensino do vilarejo. . . . . . . . . . . . 43

Figura 6 - Condições de vida das pessoas do vilarejo. . . . . . . . . . . 43

Figura 7 - Danos causados por catástrofes naturais no vilarejo. . . . . . . 44

Figura 8 - Gráfico reproduzido da média anual de temperatura e precipitações nas proximidades da comunidade em estudo. . . . . . . . . 45

Figura 9 - Média da irradiação solar global no Haïti. . . . . . . . . . . . . 46

Figura 10 - Média mensal de radiação solar do vilarejo em estudo. . . . . . . . . 47

Figura 11 - Irradiação solar da cidade de port-de-paix e do vilarejo em estudo. 47

Figura 12 - Velocidade média de vento no Haiti, altura $80 \mathrm{~m}$. . . . . . . . . 48

Figura 13 - Velocidade média do vento na região do vilarejo. Fonte: (WINDFINDER, 2016) . . . . . . . . . . . . . . . . . . 49

Figura 14 - Arquitetura do sistema fotovoltaico-eólica simulado . . . . . . 53

Figura 15 - Exemplo da curva de potência de uma turbina eólica. . . . . . . . . 59

Figura 16 - Curva de vida para o modelo de bateria de ciclo profundo US-250. . 61

Figura 17 - Sistema proposto para o vilarejo . . . . . . . . . . . . 65

Figura 18 - Desenho do painel solar . . . . . . . . . . . . . . 66

Figura 19 - Modelo de painel usado no projeto . . . . . . . . . . . . 66

Figura 20 - Desenho do modelo de turbina simulado no sistema . . . . . . . . 68

Figura 21 - a) Energia da Turbina no sistema. b) desempenho da turbina no sistema. . . . . . . . . . . . . . . . 68

Figura 22 - Profundidade de descarga $x$ ciclos da bateria . . . . . . . . 70

Figura 23 - Temperatura de trabalho $x$ vida útil da bateria . . . . . . . . . . 70

Figura 24 - Modelo de Bateria para o sistema em estudo . . . . . . . . . . 71

Figura 25 - Modelo de conversor para o sistema . . . . . . . . . . . . . 72

Figura 26 - Desenho do controlador de carga . . . . . . . . . . . . . . . . 75

Figura 27 - Modelo de controlador de carga MPPT escolhido para o sistema . . 76

Figura 28 - Média de irradiação solar do vilarejo $\left(\mathrm{kW} / \mathrm{m}^{2} / \mathrm{dia}\right) \ldots \ldots$. . . . . 77

Figura 29 - Média mensal da velocidade do vento $(\mathrm{m} / \mathrm{s}) \ldots \ldots \ldots$. . . . . 77

Figura 30 - Perfil diária do consumo de eletricidade do vilarejo . . . . . . . . 78

Figura 31 - Diferentes configurações do sistema para o vilarejo. . . . . . . . . 80

Figura 32 - Média mensal da produção elétrica do sistema $(\mathrm{C} 1) \ldots \ldots$. . . . 82

Figura 33 - Média mensal de produção elétrica do sistema (C2) . . . . . . . . . 82 
Figura 34 - Média mensal de produção elétrica do sistema (C3) . . . . . . . . 83

Figura 35 - Média mensal de produção elétrica do sistema (C4) . . . . . . . . . 83

Figura 36 - Comparação da produção elétrica mensal das quatro configurações. 84

Figura 37 - Comparação dos rendimentos totais de energia considerando as configurações intensivas. . . . . . . . . . . . . . . . . . . 84

Figura 38 - Variação na demanda de carga não atendida e excesso de eletricidade anual. . . . . . . . . . . . . . . . . . .

Figura 39 - Produção dos painéis solares para cada hora do dia/mês (C1, C2 e C3). . . . . . . . . . . . . . . . . . 86

Figura 40 - Produção dos painéis solares para cada hora do dia/mês (C4). . . . 86

Figura 41 - Comparação no rendimento elétrico da FV para todas as configurações. 87

Figura 42 - Produção da turbina para cada hora do dia/mês (C1 e C3). . . . . . 88

Figura 43 - Produção da turbina para cada hora do dia/mês (C2) . . . . . . . . 88

Figura 44 - Produção da turbina para cada hora do dia/mês (C4). . . . . . . . 88

Figura 45 - Comparação do rendimento elétrico das turbinas para as quatro configurações. . . . . . . . . . . . . . . . 89

Figura 46 - Variação da taxa de descarga das baterias para cada hora/mês (C1, C2 e C4) . . . . . . . . . . . . . . . . . . . 90 90

Figura 47 - Variação da taxa de descarga das baterias para cada hora/mês (C3). 90

Figura 48 - Autonomia do sistema de baterias das diversas configurações. . . . 90

Figura 49 - Perdas no sistema de baterias das diversas configurações. . . . . . 91

Figura 50 - Entrada e Saída de Energia no banco de baterias das diversas configurações. . . . . . . . . . . . . . . . . . . 91

Figura 51 - Custos dos componentes para todas as configurações. . . . . . . 92

Figura 52 - Custos anuais dos componentes para todas as configurações. . . . 94

Figura 53 - Comparação dos custos NPC das quatro configurações. . . . . . . . 94

Figura 54 - Análise de sensibilidade de valores relativo à melhor estimativa . . . 103

Figura 55 - Variação no excesso de eletricidade . . . . . . . . . . . . . . . . 104

Figura 56 - Variação na carga não atendidade pelo sistema . . . . . . . . 105

Figura 57 - Variação na saída do banco de baterias . . . . . . . . . . . . . . . 105 
Lista de quadros 


\section{Lista de tabelas}

Tabela 1 - Ferramentas de Simulação de Sistemas Híbridos de Energia . . . . 38

Tabela 2 - Valores paramétricos simulados no HOMER . . . . . . . . . . 50

Tabela 3 - Fatores de eficiência dos componentes do sistema fotovoltaica . . 51

Tabela 4 - Recurso Solar do vilarejo em estudo . . . . . . . . . . . . . . . . 55

Tabela 5 - Recurso Eólico do vilarejo em estudo . . . . . . . . . . . . . . 56

Tabela 6 - Parâmetros estatísticos simulados pelo HOMER dovilarejo em estudo 56

Tabela 7 - Especificações Técnicas do painel . . . . . . . . . . . . . 65

Tabela 8 - Especificações da Turbina . . . . . . . . . . . . . . . . . . 67

Tabela 9 - Especificações das Baterias . . . . . . . . . . . . . . . 71

Tabela 10 - Especificações do Conversor . . . . . . . . . . . . . . . . 72

Tabela 11 - Tecnologia de controladores $X$ painéis e baterias . . . . . . . . . 74

Tabela 12 - Especificações do controlador de carga . . . . . . . . . . . . . 74

Tabela 13 - Parâmetros da demanda diária da comunidade . . . . . . . . . . . 79

Tabela 14 - Tabela das configurações em estudo. . . . . . . . . . . . . . . 80

Tabela 15 - Parâmetros relacionados a produção elétrica para cada configuração. 81

Tabela 16 - Valores da saída da matriz fotovoltaica para todas as configurações. 85

Tabela 17 - Valores da saída da(s) turbina(s) . . . . . . . . . . . . . . . 87

Tabela 18 - Indicadores do banco de baterias para todas as quatro configurações. 89

Tabela 19 - Custos de cada componentes para todas as configurações. . . . . . 92

Tabela 20 - Custos por tipo de custo para todas as configurações. . . . . . . . . 92

Tabela 21 - Custos de capitais anuais por tipo de custo das quatro configurações. 93

Tabela 22 - Custos de capitais anuais dos diversoscomponentes do sistema. . . 93 


\section{Lista de abreviaturas e siglas}

$\begin{array}{ll}\text { CA } & \text { Corrente Alternada } \\ \text { CC } & \text { Corrente Contínua } \\ \text { COE } & \text { Custo Normalizado de Energia } \\ \text { GD } & \text { Geração Distribuída } \\ \text { IDH } & \text { Índice de Desenvolvimento Humano } \\ \text { IEC } & \text { Comissão Eletrotécnica Internacional } \\ \text { IHSI } & \text { Instituto Haitiano de Estatística e Informática } \\ \text { LCD } & \text { Liquid Crystal Display } \\ \text { MPPT } & \text { Maximum Power Point Tracker } \\ \text { MTPTEC } & \text { Ministério dos Trabalhos Públicos, Transporte, Energia e Comunicação } \\ & \text { (Haiti) } \\ \text { NHS } & \text { Número Horas Solar } \\ \text { NPC } & \text { Custo Líquido Total } \\ \text { ONG } & \text { Organização não Governamental } \\ \text { PWM } & \text { Pulse Width Modulation } \\ \text { SH } & \text { Sistema Híbrido } \\ \text { SHE } & \text { Sistema Híbrido de Energia } \\ \end{array}$




\section{Lista de símbolos}
Ah
Ampere-hora
A
Ampere
$\mathrm{Cm}$
representa o consumo diária da comunidade
CRF
é o fator de recuperação de capital
$\boldsymbol{C}_{a n n, t o t}$
é o custo anualizado total
$\boldsymbol{C}_{N P C}$
custo líquido total atual
Ed
Energia consumida por dia pelo conjunto (casas, igreja e escola) em kWh/dia
Ee
designa o consumo mensal da igreja em $\mathrm{kWh} / \mathrm{mês}$
Ei
é o consumo mensal da escola em kWh/mês
$E m$
representa o consumo mensal de energia
$\boldsymbol{E}_{\text {def }}$
montantes totais de carga deferível
$\boldsymbol{E}_{\text {grid,sales }}$
é a quantidade de energia vendida à rede por ano
$\boldsymbol{E}_{\text {prim }}$
montantes totais de carga primária
$\boldsymbol{f}_{P V}$
é o fator de redução de energia fotovoltaica ou (desclassificação)
Ic, Is irradiação constante (que é a quantidade padrão de radiação utili- zada para classificar a capacidade da matriz fotovoltaica)
i
a taxa de juros real anual (taxa de desconto)
Im
irradiação do mês considerado
$\boldsymbol{I}_{T}$
a radiação solar global incidente na superfície da matriz fotovoltaica $(\mathrm{kW} / \mathrm{m} 2)$
Nc
representa o número de residências
Nd
é o numero de dias considerado no mês
NHS
número de horas solar
$N$
é o número de anos 

$N_{b a t t}$
é o número de baterias no banco de bateria
potência total do sistema $(\mathrm{kW})$
$\boldsymbol{Q}_{\text {lifetime }}$
a taxa de vida de uma única bateria
$\boldsymbol{Q}_{\text {thrpt }}$
a taxa de transferência de energia anual (o montante total de energia que percorre o banco de baterias em um ano)
$\boldsymbol{R}_{\text {batt }, f}$
a duração do flutuador da bateria (a vida máxima, independente- mente da vazão)
$\boldsymbol{R}_{p r o j}$
a vida útil do projeto
$\boldsymbol{Y}_{P V}$
a capacidade nominal da matriz fotovoltaica $(\mathrm{kW})$
$\boldsymbol{A}_{s}$
Autonomia do sistema
$\boldsymbol{C}_{b}$
Capacidade da bateria
$\boldsymbol{C}_{t c}$
Consumo total para todas as casas
$\boldsymbol{P}_{p 1}$
Unidade de painel
$\boldsymbol{P}_{t}$
Potência total do sistema (W ou kW)
$\boldsymbol{Q}_{b}$
Quantidade de bateria
$\boldsymbol{Q}_{t b}$
Quantidade de bateria total do sistema
$\boldsymbol{Q}_{t p}$
Quantidade de painéis necessários
$\boldsymbol{T}_{s}$
Tensão do sistema
$\boldsymbol{V}_{b}$
Voltagem da bateria
$\mathrm{kWh}$
Quilowatt-hora
$\mathrm{mph}$
Milha por hora
$\mathrm{m} / \mathrm{s}$
Metro por segundo
N.m
Newton $\mathrm{x}$ metro
$\boldsymbol{F}_{e}$
Fatores de eficiência (considerando eventuais perdas no sistema)
$\boldsymbol{P}_{u n}$
Potência de uma unidade de painel (Wp)
Wp
Watt-pico 
Sumário

INTRODUÇÃO $\ldots \ldots \ldots \ldots \ldots \ldots \ldots \ldots \ldots$

$1.1 \quad$ Conceito Comunidades Isoladas . . . . . . . . . . . 20

$1.2 \quad$ Energia e Sustentabilidade . . . . . . . . . . . . . 20

1.3 Geração Distribuída e Energias Renováveis . . . . . . . . . . 21

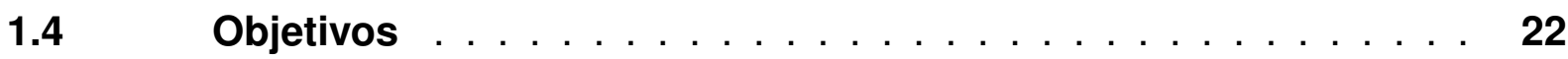

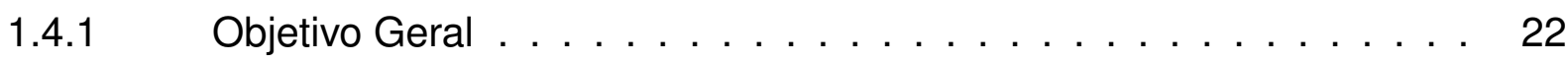

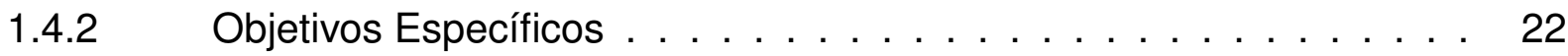

$1.5 \quad$ Organização da dissertação $\ldots \ldots \ldots \ldots \ldots \ldots \ldots$

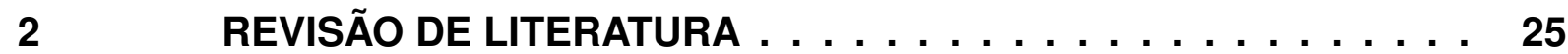

$2.1 \quad$ Energia e Comunidades $\ldots \ldots \ldots \ldots \ldots \ldots$

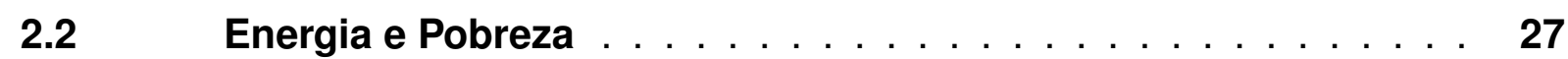

$2.3 \quad$ Energia e Sustentabilidade . . . . . . . . . . . . . . . 29

$2.4 \quad$ Sistemas Híbridos . . . . . . . . . . . . . . . . . 33

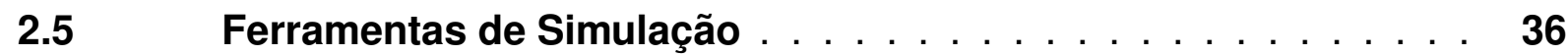

3 CARACTERIZAÇÃO DA COMUNIDADE EM ESTUDO $\ldots \ldots \ldots$

3.1 Aspectos Geográficos da Comunidade . . . . . . . . . . . . . 40

3.2 População, Economia Local e Indicadores Sociais . . . . . . . . 41

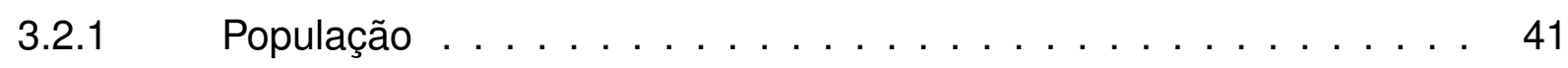

3.2.2 Economia Local . . . . . . . . . . . . . . . . . . . . . . . 41

3.2.3 Indicadores Sociais . . . . . . . . . . . . . . . . . . . 42

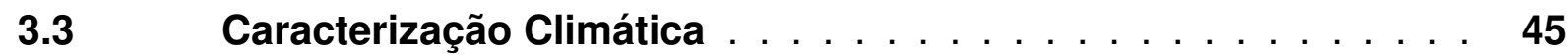

3.3.1 Recurso Solar . . . . . . . . . . . . . . . . . . . . . . 45

3.3.2 Recurso Eólico . . . . . . . . . . . . . . . . . . . . 48

3.3.3 Demanda Elétrica no Vilarejo . . . . . . . . . . . . . . . . . 50

$4 \quad$ PROGRAMA HOMER $\ldots \ldots \ldots \ldots \ldots \ldots \ldots$

$4.1 \quad$ Descrição Geral $\ldots \ldots \ldots \ldots \ldots$

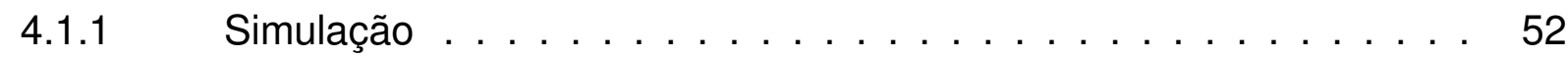

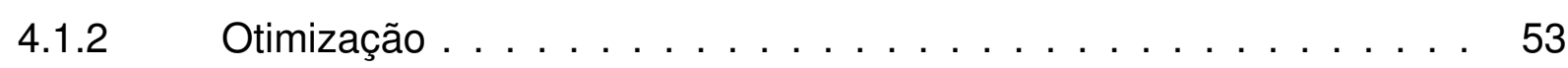

$4.1 .3 \quad$ Análise de Sensibilidade . . . . . . . . . . . . . . . . . 54

$4.2 \quad$ Formulação Energética . . . . . . . . . . . . . . . . 54

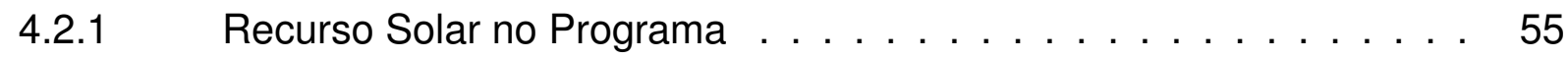

4.2.2 Recurso Eólico no Programa . . . . . . . . . . . . . . 55

$4.3 \quad$ Tecnologias e componentes do Programa . . . . . . . . . . 57 
4.3.1 Matriz Fotovoltaica . . . . . . . . . . . . . . . . 57

$4.3 .2 \quad$ Turbina Eólica . . . . . . . . . . . . . . . . . . . 58

4.3.3 Banco de Baterias . . . . . . . . . . . . . . . . . . . 59

4.3.4 Conversor . . . . . . . . . . . . . . . . . . 61

$4.4 \quad$ Modelo Econômico . . . . . . . . . . . . . . . . . . . 62

$5 \quad$ RESULTAdOS dA SIMULAÇÃo $\ldots \ldots 4$

$5.1 \quad$ Sistema Proposto . . . . . . . . . . . . . . . . . . 64

5.1.1 Especificações do Sistema Fotovoltaico . . . . . . . . . . . . . . . . 65

5.1.2 Especificações do Sistema Eólico . . . . . . . . . . . . . . . . . 67

5.1.3 Especificações do Banco de baterias . . . . . . . . . . . . . . . 69

$5.1 .4 \quad$ Especificações do Conversor . . . . . . . . . . . . . . . . . 71

5.1.5 Especificações do Controlador de carga . . . . . . . . . . . . . 72

$5.1 .6 \quad$ Dados do recurso solar do vilarejo . . . . . . . . . . . . . . . . . 76

5.1 .7 Dados do recurso eólico do vilarejo . . . . . . . . . . . . . 77

$5.1 .8 \quad$ Perfil de carga do vilarejo . . . . . . . . . . . . . . . . . . 78

$5.2 \quad$ Resultados . . . . . . . . . . . . . . . . . 79

5.2.1 Rendimento Energético . . . . . . . . . . . . . . . . . 81

5.2.1.1 Produção da matriz fotovoltaica . . . . . . . . . . . . . . . . . . 85

5.2.1.2 Produção da Turbina . . . . . . . . . . . . . . . . 87

5.2.1.3 Saída de Energia do Banco de Baterias . . . . . . . . . . . . . . . . . 89

$5.2 .2 \quad$ Custos do Sistema . . . . . . . . . . . . . . . . . . . . 91

5.2.2.1 Fluxo de caixa do sistema . . . . . . . . . . . . . . . . . . . . 91

5.2.2.2 Custos Anuais . . . . . . . . . . . . . . . . . . . . . . . . . . 93

$5.3 \quad$ Análise e Discussão . . . . . . . . . . . . . . . . . . 95

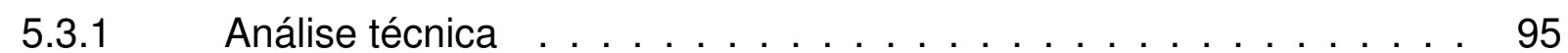

5.3.2 Análise Econômica . . . . . . . . . . . . . . . . . . . 101

5.3.3 Análise de Sensibilidade . . . . . . . . . . . . . . . . . . 102

6 CONCLUSÃo . . . . . . . . . . . . . . . . . . 106

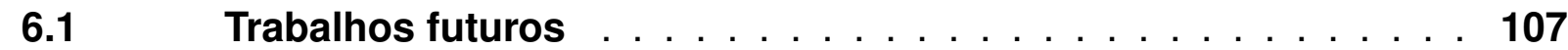

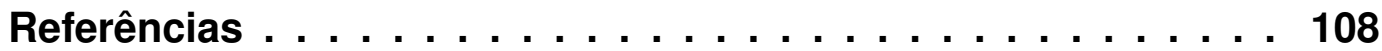




\section{Introdução}

Em meados do século XIX as iniciativas relacionadas a energia para comunidades já existiam. $O$ uso de recursos locais para produção energética já impulsionavam atividades industriais em pequena escala nas comunidades. Portanto, só no final da década de 1970 que as iniciativas de energia para comunidades começaram a se relacionar mais com as fontes renováveis de energia, onde começou em $1978 \mathrm{com}$ a associação de proprietários de turbinas eólicas dinamarquesa (REN21, 2016). Posteriormente, muitas comunidades visaram projetos voltados para produção local de energia renovável. Visando o crescimento das comunidades, a maioria desses projetos estava focado na geração de eletricidade.

Ao todo, estima-se que 1,2 bilhão de pessoas no mundo não tem acesso a eletricidade e ainda 2,8 bilhões usam algum tipo de biomassa e/ou madeira para cozinhar e se aquecer (IEA, 2013). De acordo com o banco mundial, a maior parcela dessa população se concentra nas áreas rurais de países subdesenvolvidos e em desenvolvimentos. $\mathrm{O}$ acesso a energia elétrica se torna uma grande preocupação nos últimos anos, pois a eletricidade é essencial para o desenvolvimento humano, do nível de qualidade de vida e para o desenvolvimento econômico de qualquer sociedade.

Por falta de interesses políticos e motivos técnicos como demanda, longas distâncias, as comunidades isoladas são excluídas do serviço de fornecimento de energia elétrica e assim estão às margens da sociedade. A oferta de eletricidade a estas comunidades permite não só seu desenvolvimento socioeconômico, mas pode trazer melhorias importantes na qualidade de vida dos seus habitantes, promovendo cidadania e justiça social.

Os projetos de energia renovável para comunidades estão desempenhando um papel importante na produção de eletricidade para comunidades remotas. A utilização de fontes de energia renováveis, se mostra como importante solução para comunidades rurais, e estímulo ao consumo energético não agressivo ao meio ambiente, evitando o uso de recursos fósseis que são potenciais poluidores.

A geração de eletricidade nas comunidades isoladas a partir do uso de recursos locais vem se destacando em vários lugares do mundo. Na América Latina, várias cooperativas de energia renovável estão desempenhando um papel importante na eletrificação de zonas rurais. A Costa Rica, por exemplo com seu ambicioso objetivo de se tornar neutra em carbono até 2021 , abriga quatro cooperaticas de energia com mais de 180.000 membros, controlando quase $15 \%$ do mercado de energia (REN21, 2016). $\mathrm{Na}$ África, os projetos de energia para comunidades foram iniciados em grande parte 
por ONGs internacionais, governos e instituições educacionais e religiosas, como a iniciativa SharedSolar desenvolvida pela Columbia University (REN21, 2016).

A energia gerada a partir de fontes renováveis é considerada como segura, limpa e confiável, não causa danos ao meio ambiente e ainda é de fácil uso. No desenvolvimento de comunidades remotas e/ou zonas rurais ela desempenha um papel fundamental que é o de atender as necessidades energéticas daquela comunidade e conseqüentemente contribuir para que ocorra uma integração social, onde a população possa gozar das suas necessidades básicas.

A falta de energia elétrica impede o desenvolvimento, sabe-se que quanto mais desenvolvida é uma região mais energia ela consome e um aumento na produção de bens demandaria um consumo maior de energia (BARROS et al., 2005). De acordo com OLIVEIRA (1991), o fornecimento de energia nas comunidades tem impactos positivos tais como, elevação na produção agrícola, aumento na oferta de alimentos, crescimento da industria rural, geração de emprego e aumento nas rendas das famílias e melhoria das condições de vida da população.

O uso de fontes alternativas de energia, principalmente solar e eólica vem crescendo cada vez mais na produção de energia descentralizada para abastecer áreas remotas e comunidades rurais. São sistemas economicamente viáveis, bem menos poluentes comparado às fontes convencionais de energia, requerem pouca ou nenhuma manutenção, pouca mão de obra e podem ser manuseados muito fácil. Além dos benefícios sociais e ambientais como poluição atmosférica local, impactos na saúde, mudanças climáticas, existem várias razões para a tendência ascendente das iniciativas comunitárias baseadas em energias renováveis. Estes são: grandes benefícios econômicos, maior controle sobre a geração de energia e benefícios sociais e ambientais. De acordo com o relatório REN21 (2016), o custo das tecnologias de energias renováveis (especialmente a energia solar fotovoltaica e a energia eólica) caiu tanto que a implementação tornou-se economicamente viável em muitos locais. As preocupações ambientais que vão desde a poluição atmosférica local e os impactos na saúde até as mudanças climáticas globais são, muitas vezes, motoras importantes para iniciativas comunitárias de energia. Outros benefícios sociais incluindo a melhoria do acesso à energia, a segurança e a confiabilidade do suprimento, o fortalecimento do senso da comunidade e a criação de empregos locais. O REN21 (2016) destacou que a energia (energia ou calor) que uma comunidade produz e usa localmente não está sujeita ao mesmo nível de perdas de transmissão e distribuição que ocorrem com sistemas mais centralizados. 


\subsection{Conceito Comunidades Isoladas}

Na sua pesquisa, os autores Hanley e Nevin (1999), destacaram o conceito de "comunidades isoladas" como grupos de baixa densidade populacional que ocupam uma área delimitada, distantes dos centros urbanos, possuem difícil acesso, com nível de atividades econômicas baixíssima e que são excluídos no atendimento de serviços energéticos pelas redes concessionárias. Geralmente, essas comunidades rurais vivem da agriculta e/ou da criação de gado, a indústria nessas regiões não está desenvolvida e, por conseguinte, a geração de renda é bastante precária.

Uma das características destas comunidades isoladas, é que elas estão às margens da vida social e econômica. Elas enfrentam grandes dificuldades para satisfazerem as suas necessidades básicas como educação, lazer, saúde e água potável. As suas propriedades são muito distantes dos centros urbanos, e na maioria das vezes sem estrada dificultando todos os meios de comunicação que lhes impedem de comunicarem com outras regiões. A falta de renda, demanda muito baixo de energia e dificuldades para transportar equipamentos em tais localidades fazem delas um mercado de altos custos e não rentável pelas concessionárias de energia.

\subsection{Energia e Sustentabilidade}

Estudos têm demonstrado que o "bem-estar" tem dimensões econômicas, sociais, culturais, políticas e ambientais. O objetivo de bem-estar sustentável pode implicar em melhora as dimensões acima citadas. Este é um desafio que inclui não só a meIhora de forma sustentável da qualidade de vida nos países subdesenvolvidos e em desenvolvimento, mas também pode transformar em sustentável um ambiente insustentável que sustenta o padrão de vida de países industrializados (HOLDREN, 2007). Portanto, nenhuma parte desse desafio é mais complexa ou mais exigente do que sua dimensão energética. Isso porque o suprimento de energia está diretamente ligado com a segurança nacional e internacional e com muitos dos problemas ambientais mais prejudiciais e perigosos como a qualidade do ar e às mudanças climáticas global, bem como a capacidade de satisfazer às necessidades básicas humanas, de combustível e o crescimento econômico.

O crescimento contínuo da população e a rápida expansão da riqueza em várias partes do mundo estão impulsionando uma taxa de aumento no uso de energia que tem implicações notáveis. A energia é tão essencial para o funcionamento do sistema econômico global quanto a gasolina é para um carro ou eletricidade para uma lâmpada (AYRES et al., 2007). Hoje um terço da produção de energia mundial vem do petróleo seguido por carvão e gás natural. Porém esse caminho não é sustentável e leva ao desastre, a dependência dos combustíveis fósseis é muito perigoso, pois gera altera- 
ções climáticas muitas vezes irreversíveis. Daí às grandes procuras de aumentos na disponibilidade per capita de serviços energéticos, obrigam a uma transição para um caminho diferente. Uma das alternativas importantes para conter esse problema seria a necessidade de aumentar potencialmente os investimentos públicos e privados para melhorar as tecnologias de fornecimento de energia como, por exemplo, melhorar a acessibilidade do aproveitamento direto da luz solar para as necessidades energéticas da sociedade (HOLDREN, 2007).

\subsection{Geração Distribuída e Energias Renováveis}

As grandes preocupações com as alterações climáticas globais, o efeito de estufa e a qualidade do ambiente criaram um enormemente interesse nos sistemas de "Energia Renovável" para a "Geração Distribuida (GD)". Os recentes avanços tecnológicos têm posicionado algumas tecnologias de energia renovável em um status de custo competitivo com as tecnologias convencionais. Existem muitas novas tecnologias que utilizam recursos de energia renovável. No entanto, nesse momento, os que se mostram mais promissores para aplicações de "GD" são os sistemas de conversão de recursos renováveis em energia como por exemplo, eólica, sistemas geotérmicos, sistemas solares térmicos, sistemas fotovoltaicos e células de combustível (RAMAKUMAR; CHIRADEJA, 2002).

Na visão dos autores acima citados, fenômenos recentes têm criado um novo ambiente para a infra-estrutura de energia elétrica. Entre esses, destacam-se:

1) Sensibilização de instituições governamentais e não governamentais para o meio ambiente, impactos da geração de energia elétrica;

2) Crescente aumento da demanda de energia elétrica em várias partes do mundo;

3) Avanços significativos em várias tecnologias de geração que são muito mais benignas do ponto de vista ambiental (geração eólica, microturbinas, células de combustível e fotovoltaicas) do que as centrais convencionais de carvão, óleo e gás;

4) Aumentar do desejo mundial de promover tecnologias "verdes" baseadas em fontes de energia renováveis.

De acordo com Ackermann et al. (2001), geralmente, o termo geração distribuída é usado em combinação com uma determinada categoria de tecnologia geralmente de energias renováveis. Segundo COGEN (2013), entende-se por GD (Geração Distribuída), fonte de geração elétrica gerada em locais em que não seria possível instalar 
usinas geradoras de energia elétrica de fontes convencionais devido a diversos fatores, contribuindo dessa forma para aumentar a distribuição geográfica energética em tais localidades.

Devido à conscientização sobre o esgotamento dos recursos não renováveis pelas usinas convencionais que utilizam combustível fóssil, a GD tem sido usada como uma ferramenta de estratégia importante, com o propósito de incentivar o uso de recursos renováveis disponíveis localmente. Para fins ambientais, na utilização da GD, os recursos energéticos distribuídos podem contribuir na redução das emissões de gases de efeito estufa e para amenizar a mudança climática (BARBOSA FILHO; AZEVEDO, 2014).

Os recursos de energia renovável geralmente não estão sujeitos ao esgotamento, como o calor e a luz do sol, a força do vento, a matéria orgânica (biomassa), a queda de água e o calor geotérmico. Estes recursos podem ser aproveitados localmente para fornecer energia de forma descentraliza onde existe grandes dificuldades de implantar sistemas de energia de fontes convencionais sem a necessidade de linhas de transmissão, transporte de combustíveis provenientes de fontes fósseis, muitas vezes pouca manutenção ou sem manutenção dos equipamentos. E por fim, considerando aspectos sociais, ambientais, econômicos e técnicos, a GD com uso de recursos renováveis se apresenta como a melhor alternativa para fornecer soluções energéticas para comunidades isoladas. Na verdade isso já está sendo feito em diversos lugares do mundo, principalmente nos países subdesenvolvidos e em desenvolvimentos, caso do sistema Fotovoltaico-Eólico de Joanes do município de Salvaterra do estado do Pará (BARBOSA, 2006).

\subsection{Objetivos}

\subsubsection{Objetivo Geral}

Esse trabalho propõe por meio da ferramenta computacional HOMER (LAMBERT et al., 2006), simular e projetar um sistema fotovoltaico-eólico para suprimento energético aproveitando os recursos solar e vento disponíveis de uma comunidade isolada no Haiti. Especificamente, ele busca avaliar a viabilidade técnica e econômica da implantação desse sistema híbrido analisando a oferta e a demanda de carga assim como os custos envolvidos.

\subsubsection{Objetivos Específicos}

i) Descrever os recursos energéticos disponíveis na localidade;

ii) Caracterizar a demanda de carga da comunidade em estudo; 
iii) Analisar as configurações simuladas pelo programa comparando custo presente líquido;

iv) Analisar a viabilidade técnica (detalhes como: autonomia do sistema, perdas, rendimento anual, excesso de energia, etc.) das configurações apresentadas pelo programa;

v) Avaliar os dados do desempenho econômico do sistema;

vi) Avaliar a relação de demanda de carga e a oferta do sistema;

vii) Discutir o desempenho e a importância de cada tecnologia no sistema;

viii) Identificar o melhor número de componentes para o sistema;

ix) Analisar o desempenho do banco de bateria;

x) Realizar análise de sensibilidade do sistema.

\subsection{Organização da dissertação}

Esse trabalho está organizado em 6 capítulos.

No capítulo 1, é realizado uma introdução com abordagem do problema envolvendo os conceitos de comunidades isoladas, Energia e sustentabilidade (melhoria da qualidade de vida) e a relação entre geração distribuída e energias renováveis. São também apresentados os objetivos do trabalho.

O capítulo 2 apresenta a revisão de literatura do trabalho, onde são abordadas relações entre energia e comunidades isoladas, energia e sustentabilidade, energia e pobreza e a definição dos conceitos de sistemas híbridos e são citados algumas ferramentas de simulação de sistemas de energia.

Já no capítulo 3, são descritas as caracterizações da comunidade isolada em estudo. Nesta parte, são mostrados os aspectos geográficos e humanos, população, economia e os indicadores sociais. Ainda são descritas as caracterizações climática e a caracterização energética, onde são mostrados os recursos disponíveis na localidade e que são usados neste estudo (recurso solar e recurso eólico) e a demanda de carga elétrica da comunidade.

O estado da arte do programa HOMER é mostrado no capítulo 4. Nele é feito a descrição geral da ferramenta, a sua formulação energética, apresentando os recursos solar e eólica e as tecnologias modeladas para calcular a potência total do sistema. $\mathrm{E}$ por fim, são descritas o método de otimização e sensibilidade do programa.

O capítulo 5 é apresentado os resultados obtidos através das simulações feitas. São realizadas depois análises desses resultados. 
Por fim, o capítulo 6 apresenta a conclusão do trabalho e possíveis pesquisas que poderão ser realizadas no futuro. 


\section{Revisão de Literatura}

\subsection{Energia e Comunidades}

Quando se refere a "comunidade isolada, aparece o que se amplia no meio rural os espaços socialmente vazios" (WANDERLEY; NAZARETH, 2001 apud BARROS et al., 2005, p. 5). Se a estrutura fundiária inibe o acesso à terra de grande parcela da população que trabalha na atividade agrícola, também dificulta qualquer meta que tente aproximar-se da paridade social, tornando a população rural vítima da pobreza, do isolamento e da submissão política (WANDERLEY; NAZARETH, 2001, p. 34).

Atribui-se a comunidades remotas ou isoladas, grupo de habitantes com densidade populacional baixa, que não possui condições de usar as tradicionais fontes de energia, sem infra-estrutura urbana, atividades econômicas pouco rentáveis, difícil acesso e distância dos mercados consumidores (ROSÁRIO; ELS; BRASIL JÚNIOR, 2005 apud ATHAYDE; MARTINS FILHO; BRASIL JÚNIOR, 2008). O isolamento dessas comunidades que geralmente se encontram nos países de terceiro mundo, casos de países da América latina, Ásia e África, é caracterizado por:

a) Falta ou inexistência de serviços públicos, como saúde, educação, lazer, etc.;

b) Grandes distâncias em relação ao mercado consumidor e fornecedor;

c) Isolamento dos principais meios de comunicação;

d) Não existência de serviços energéticos;

e) Meios de transportes praticamente inexistentes e seus custos são elevados.

As comunidades isoladas em sua maioria encontram-se às margens da vida econômica e socialmente são excluídas. Elas são desprovidas de serviços essenciais como energia elétrica além da falta de condições básicas para que seja conferida a cidadania para seus habitantes. Por falta de energia elétrica, os habitantes dessas comunidades enfrentam grandes dificuldades para retirar água do poço, não podem realizar irrigações necessárias e isso afeta diretamente a sua produção que conseqüentemente afeta a falta de recursos financeiros. Com renda baixa, os pequenos agricultores não podem adquirir novos equipamentos na produção. Geralmente as propriedades destes pequenos produtores são muito distantes das redes elétricas e, de difícil acesso, muitas vezes sem estrada, constituindo um mercado que não compra e não cresce, cujo suprimento implica altos custos, sendo considerado pelas concessionárias como um mercado pouco rentável (COSTA et al., 2000 apud MARINI, 2001). Então isso inviabiliza 
a extensão de redes concessionárias. Para chegar a determinados lugares onde não há estrada, é necessário caminhar vários quilômetros ou utilizar barco, quando possível (FEDRIZZI, 2003 apud RIBEIRO et al., 2013). É difícil transportar equipamentos em tais comunidades, estes além, da grande distância podem gerar grandes custos, exemplo dos custos das linhas de transmissão. As demandas de energia elétrica são baixas já que é uma população que não tem grandes oportunidades de geração de renda, e ainda existe os obstáculos naturais de cerrado e/ou áreas florestais e grandes rios. Todos esses obstáculos fazem com que elas sejam excluídas do atendimento de energia elétrica.

O acesso à energia é um meio importante para a existência humana, uma vez que é necessária a satisfação das suas necessidades básicas como alimentação, vestuário, habitação, de mobilidade e comunicação. Um dos acessos à energia para suprimento de uma demanda cada vez mais crescente é a queima de combustíveis fósseis que afeta a estabilidade ecológica da Terra.

O consumo de energia nas comunidades está diretamente relacionado ao crescimento econômico, porque para aumentar a produção de bens e serviços e melhorar o padrão de vida dos habitantes é necessário mais energia, já que quanto mais desenvolvida é a localidade, mais energia ela consome (BARROS et al., 2005). Alguns aspectos importantes da implementação do uso da energia nas comunidades: elevação na produção e produtividade agrícolas com aumento na oferta de alimentos e redução do êxodo rural fazendo com que o homem fique ao campo por meio do aumento da geração de emprego com o crescimento da industrialização rural e melhora nas condições de vida econômica e social (OLIVEIRA, 1991).

Alguns trabalhos ao serem avaliados mostram os impactos que a eletrificação nas comunidades causou em diferentes localidades principalmente nos países de terceiro mundo. A chegada da energia elétrica causa de início uma grande demanda por aparelhos elétricos, vindo a beneficiar a economia urbana (RAMANI, 1992 apud MARINI, 2001). A energia elétrica nas comunidades, além de gerar empregos, também gera certa demanda por equipamentos elétricos, como televisores, rádios, refrigeradores, ventiladores e outros, o que beneficia a economia das industrias (CORONADO, 1993 apud MARINI, 2001). A eletrificação das comunidades através de recursos locais (como solar e eólica) é um fator que tem um papel fundamental, ela proporciona o desenvolvimento social e econômico da própria localidade, os habitantes passam a ter iluminação e possam conservar seus alimentos dentre outros (SILVA et al., 2000). Na sua tese, MARINI mostrou que postos de saúde em áreas remotas são dotados de sistemas que alimentam geladeiras, iluminação e bombas d'água, proporcionando à população carente o acesso a vacinas, soros e medicamentos vitais para sua sobrevivência. Escolas rurais possibilitam a alfabetização noturna de adultos através do uso 
de módulos fotovoltaicos para iluminação de salas de aula (MARINI, 2001, p. 25).

O aproveitamento dos recursos locais como solar, eólico, biomassa e de pequenas quedas d'água tem sido uma importante alternativa para garantir eletricidade a essas comunidades e proporcionar melhor qualidade de vida, permitindo valorização e desenvolvimento econômico (RIBEIRO et al., 2013, p. 271). Ainda segundo estes autores, o sucesso dessas iniciativas contribui para diminuição do êxodo rural e conseqüentemente redução da pressão demográfica nas áreas urbanas. Essas tecnologias de aproveitamento de energia fornecem qualidade de serviço adequado por meio de infra-estrutura descentralizada.

\subsection{Energia e Pobreza}

Diversos estudos indicam as relações existentes entre a energia, pobreza, desnutrição, saúde, economia e diversas outras preocupações mundiais (REDDY et al., 1997). A energia é um fator fundamental para a existência da humanidade e, na atualidade, a energia elétrica tornou-se um vetor importantíssimo, portanto, ao fazer parte de um sistema social ela adquire outras dimensões. Quando a eletricidade chega as pessoas podem utilizar aparelhos eletrônicos e eletrodomésticos, o que facilita o caminho para mudanças sociocultural e melhoria das condições de vida (TRIGOSO, 2004, p. 66).

Petry (2007), na sua pesquisa mostrou que existem dois tipos de pobreza: relativa e absoluta. A pobreza relativa é relacionada com o modo de vida de uma determinada sociedade, onde se pode perceber certa desigualdade das necessidades culturalmente estabelecidas entre as nações. Portanto, haveria uma comparação interna o que dificultaria as comparações entre as nações. Já a pobreza absoluta fundamentase na idéia de subsistência ou ausência das condições básicas onde a pessoa carece da satisfação das necessidades como alimentação, vestimenta, habitação adequada, água potável e esgoto, educação. Este que só ocorre nos países subdesenvolvidos ultrapassa o tradicional critério de renda per capita, comparação empregada na classificação de países desenvolvidos e subdesenvolvidos (PETRY, 2007, p. 2).

A energização é fundamental para diminuir a pobreza, pois, uma elevação no padrão de vida de uma população com aumento de produção de bens e de serviços requeria mais energia, assim quanto mais desenvolvida é determinada região, mais energia ela consome (BARROS et al., 2005). A energia além de exercer um papel fundamental no desenvolvimento humano melhorando a qualidade de vida das pessoas, ela também mantém os elos entre os diversos aspectos das sociedades, tais como a economia ou as políticas públicas (GOLDEMBERG; JOHANSSON, 1995 apud TRIGOSO, 2004). O desenvolvimento socioeconômico e cultural para muitos passa em primeiro lugar pela disponibilidade de energia, já que o acesso à eletricidade permitiria 
a utilização de tecnologias modernas. Para os autores acima citados, neste caso, não haveria desenvolvimento sem acesso à energia elétrica e, então, seria necessário que o estado facilitasse a disposição deste serviço a todos os cidadãos, sem nenhuma exceção.

As necessidades de energia elétrica nas regiões pobres vão além do suprimento energético e precisam ser resolvidas de forma integrada. Numa residência pobre e/ou rural, por exemplo, faz se o uso de lenha para cocção de alimentos, que pode trazer uma série de problemas à saúde destes usuários (OLIVEIRA, 2003). A eletrificação por muitos é considerada como um facilitador do desenvolvimento socioeconômico, no entanto, ela por si só não é suficiente, ela deve acompanhar iniciativas e ações que abranjam educação, saúde, a produção e outros. De modo a expandir as oportunidades ela pode proporcionar, por exemplo, (TRIGOSO, 2004, p. 78):

- Iluminação residencial e pública, o que aumenta as horas de trabalho, estudo ou lazer;

- O uso de eletrodomésticos e aparelhos eletrônicos como rádio, televisão, liquidificadores, máquinas de lavar, computadores, aparelhos de comunicação, etc.;

- Eletrificação de escolas e de hospitais ou postos de saúde, acompanhada do uso de refrigeradores para vacinas, microscópios ou instrumentos médicos;

- Utilização de máquinas com a finalidade de aumentar à produção e conseqüentemente a renda;

Alguns autores verificaram o sucesso de programas de eletrificação em regiões que se encontram a margem da sociedade em países subdesenvolvidos e em desenvolvimentos. No Brasil, com o programa PROLUZ foi verificado o surgimento de propriedades como pequenos armazéns e bares que conseqüentemente geram novos empregos beneficiando a economia local (MARINI, 2001). Estes programas além de gerar emprego, aumentam a renda nas indústrias através do crescimento da demanda por equipamentos elétricos, como bombas d'água, televisores, rádios, refrigeradores, chuveiro elétrico, ventiladores e outros (CORONADO, 1993 apud MARINI, 2001).

Na sua pesquisa, Trigoso (2004) mencionou algumas barreiras pelas quais as comunidades pobres e isoladas não possuem energia elétrica. Dentre as barreiras identificadas, têm-se as barreiras econômicas e culturais, nas barreiras econômicas as pessoas dessas regiões possuem renda baixíssima e a falta de oportunidades para gerá-la, ou seja, estas pessoas estão a margem da economia daquele país e por isso não pode exercer a sua cidadania. Já as barreiras culturais estão relacionadas com a cultura empresarial, onde as autoridades consideram impossível atender uma região 
onde as pessoas não têm renda e por cima, uma baixíssima densidade de carga já que as pessoas não possuem eletrodomésticos e aparelhos eletrônicos.

Pesquisas apontam que nas regiões de renda mais baixa o percentual de domicílios sem eletricidade é maior. Portanto, a renda é o fator principal da demanda de energia elétrica em regiões pobres, tendo em vista que, a renda irá definir se o consumidor potencial tem condições de arcar com os custos de conexão à rede e pagar as contas de luz. E ainda, quanto aos usos domésticos da eletricidade, a renda determinará o poder de compra de eletrodomésticos e, conseqüentemente, o nível de consumo do domicílio (ROBERTO, 2003, p. 34).

As fontes de energias renováveis podem ser consideradas como instrumentos de inclusão social para as populações carentes e distantes. A implantação das energias renováveis contribui para os objetivos socioeconômicos que favorece a diversificação produtiva em regiões não desenvolvidas, melhorando o seu nível de competitividade e contribuindo para a redução das disparidades regionais de renda e assim melhorar a quantidade e a qualidade de emprego (RíO; BURGUILLO, 2007). Os benefícios socioeconômicos das energias renováveis estão ganhando cada vez mais atenção. A Comissão Européia numa comunicação recente afirmou que " uma parte substancial dos benefícios públicos prosseguidos pelas políticas de apoio as energias renováveis estão relacionadas com o emprego e as políticas sociais e de desenvolvimento rural (RÍO; BURGUILLO, 2007).

\subsection{Energia e Sustentabilidade}

O conceito de" sustentabilidade" desde que foi lançado em 1987 no debate público internacional pelo relatório Brundtland vem sendo muito discutidas por algumas matrizes discursivas (ACSELRAD, 1999). Entre as citadas por Acselrad na sua pesquisa, encontram-se a matriz de:

a) Autosuficiência, que pretende desligar os fluxos do mercado mundial das economias nacionais e sociedades tradicionais adotada para endossar a mestria de auto-regulação comunitária das disposições de reprodução da base material do desenvolvimento;

b) Escala, que estabelece um marco mensurável entre o crescimento econômico e à pressão que exerce sobre os recursos ambientais;

c) Ética, que estabelece uma certa harmonização do mundo material e os valores do bem e do mal, destacando todo tipo de convívio da base do desenvolvimento e das condições de seguimento da vida na terra. 
d) Eficiência, que tem por objetivo alinhar a racionalidade econômica ao espaço não mercantil do planeta e menosprezar todo tipo de desperdício da base material do desenvolvimento;

e) Equidade, que não é nada mais que a vinculação entre ecologia e justiça baseando em métodos analíticos.

Nos debates de diversos atores, o conceito vem ganhando cada vez mais espaço, de um lado das agências multilaterais e ideologistas do desenvolvimento e de outro lado no campo das ONGs. Para as ONGs, esta é uma ideia inovadora que vem para suceder o conceito "progresso", ele concentra um desenvolvimento voltado para o povo e ser para sociedade civil uma visão mobilizadora. Já na visão dos ideologistas de desenvolvimento e as agências multilaterais o conceito visa projetos mais verde $e$ readequação dos processos decisórios (ACSELRAD, 1999).

No meio acadêmico, a sustentabilidade vem sendo um tema bem discutido, pois, é devido a conscientização através de pesquisas científicas que o impacto ambiental promovido pela humanidade para o desenvolvimento humano pode se tornar o limite de tal desenvolvimento que é a base de danos tanto reversíveis custosos a longo prazo como também os irreversíveis a planeta terra (INATOMI; UDAETA, 2011). De acordo com os mesmos, a sustentabilidade se enquadra em diversas esferas: política, social, técnico-econômica e por último ambiental e, a parte de energia está diretamente relacionada a todas elas, já que ela causar quanto impactos positivos como negativos. No que diz respeito ao sistema de energia, pode ser interpretado como conceito da energia misturada com a otimização dos recursos locais, planejamento urbano e industrial com a otimização de transporte e a utilização das fontes de energias renováveis (H.AFGAN et al., 2002).

Segundo Río e Burguillo (2007), numa visão de sustentabilidade, a dimensão territorial do desenvolvimento sustentável exige o uso de uma abordagem mais operativa que diretamente está ligado aos contextos territoriais regionais ou locais. Segundo estes pesquisadores, dois grandes marcos conceituais que podem ser destacados para avaliar a sustentabilidade específica de projetos de desenvolvimento em locais específicos: sustentabilidade substantivo e sustentabilidade processual. A sustentabilidade processual é considerada como um projeto específico que contribui para melhoria das condições econômicas, sociais e ambientais de um determinado território e conseqüentemente para o bem estar da população desse território. Já a sustentabilidade substantiva tenta fornecer um quadro analítico para identificar como um projeto específico de energia renovável pode influenciar nas dimensões econômicas, sociais e ambientais de um território específico conforme mostrado na Figura 1 abaixo. 


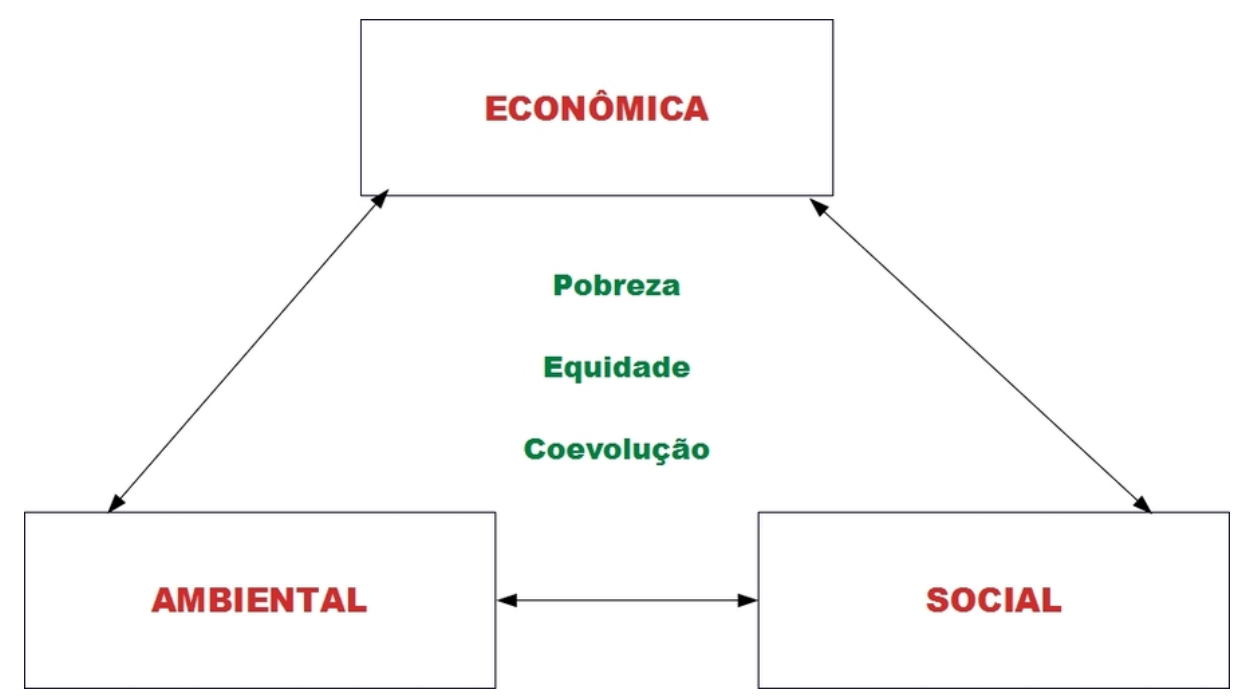

Figura 1 - As três dimensões do desenvolvimento sustentável.

Os autores ainda destacaram, no objetivo de aumentar a qualidade de vida dos cidadãos, uma política de desenvolvimento sustentável deve abordar todas as três dimensões da sustentabilidade. O desenvolvimento sustentável na verdade tem sido definido como o desenvolvimento que satisfaz as necessidades da geração presente sem comprometer a capacidade das gerações futuras satisfazerem as suas necessidades. Ele é uma necessidade mundial, uma ferramenta para que as gerações do futuro tenham condições de sobreviver. Para ser bem claro entre desenvolvimento sustentável e sustentabilidade, o primeiro tem como objetivo à preservação do ecossistema, mas também atender às necessidades socioeconômicas das comunidades e manter o desenvolvimento econômico. Já o segundo visa estabelecer um equilíbrio entre o que a natureza pode nos oferecer, o limite de consumo dos recursos naturais e a melhora na nossa qualidade de vida. Na verdade, a sustentabilidade não necessariamente está relacionada ao termo desenvolvimento, porém considera alternativas viáveis, ambientalmente corretas e culturalmente e socialmente justas para a construção da sociedade. Os três níveis de sustentabilidade da Figura 1 são apresentados abaixo:

a) Econômico: Melhoria ou criação do abastecimento de energia, aumento na renda per capita regional e melhoria na qualidade de vida dos moradores da localidade.

b) Social: Diminuir o desemprego, melhorar a qualidade de emprego, aumentar a coesão regional reduzindo os níveis de pobreza, incentivo a implantação de energias renováveis são ações locais para alcançar a sustentabilidade.

c) Ambiental: Reduzir a poluição local, a exploração de recursos naturais e manutenção da resiliência (capacidade de se adaptar a alterações), a integridade e a estabilidade do ecossistema. 
O ser humano precisa buscar um equilíbrio entre geração de energia elétrica para seu desenvolvimento e degradação do meio ambiente. A questão de que a Terra para se manter em equilíbrio necessita dos recursos naturais faz com que o homem se preocupa e se conscientiza cada vez mais com os efeitos dos impactos ambientais.

Os recursos energéticos desempenham um papel fundamental na construção da sociedade humana, porém a produção e o consumo de energia provocam danos colaterais tanto para os humanos quanto para o meio ambiente (BASSETTO, 2010). "Os níveis de suprimento energético e a sua infra-estrutura interagem biunivocamente com o desenvolvimento sócio-econômico, e conseqüentemente impactam o meio ambiente e, portanto a sua sustentabilidade" (UDAETA, 1997 apud INATOMI; UDAETA, 2011, p. 2). Os autores mostraram que estes impactos ambientais gerados através da obtenção de energia interferem fortemente no desenvolvimento sustentável e seu entendimento é de grande importância no planejamento e implementação de projetos de energia.

No início do século XX, principalmente logo após a revolução industrial, as agressões antropogênicas ao meio ambiente passaram a ser mais significativas particularmente nos países industrializados devido ao aumento no consumo per capita e ao aumento da população (GOLDEMBERG; VILLANUEVA, 2003 apud INATOMI; UDAETA, 2011). Depois da revolução industrial as atenções eram voltadas no alcance do crescimento econômico, tecnológico e aumento da oferta no mercado, por isso houve uma grande exploração de recursos naturais no âmbito de obter energia sem se preocupar com as conseqüências que poderiam afetar o meio ambiente. De acordo com os autores Inatomi e Udaeta, as conseqüências deste desenvolvimento são conhecidas com os impactos ambientais gerados que são alvos de discussões internacionais para que sejam contidos e se possível reparados.

As fontes renováveis de energia podem contribuir para a sustentabilidade dos territórios possibilitando uma ampla variedade de benefícios socioeconômicos e ambientais reduzindo as emissões de vários poluentes como as emissões de CO2. Uma região sustentável é aquela que, para uma mesma oferta de serviços, minimiza o consumo de energia fóssil e de outros recursos materiais, explorando ao máximo os fluxos locais e satisfazendo o critério de conservação de estoques e de redução do volume de rejeitos (ACSELRAD, 1999, p. 82). Para os países do OCDE (Organização de Cooperação e Desenvolvimento Econômico), a política de implantação das energias renováveis é uma das alternativas mais importante para ajudá-los a cumprir as metas do protocolo de Quioto para diminuir os impactos ambientais (RíO; BURGUILLO, 2007).

As energias renováveis desempenham um papel importante especificamente no desenvolvimento das zonas rurais que geralmente possuem altos índices de desemprego e uma população em declínio. Na visão do desenvolvimento sustentável, os fatores fundamentais da disponibilidade de energia nas comunidades são: a criação de 
políticas de estabilização da população local e melhoria de qualidade de vida através do estímulo dos fatores de renda, educação e saúde (ATHAYDE; MARTINS FILHO; BRASIL JÚNIOR, 2008). Para Río \& Burguillo, a participação das comunidades locais na implementação bem sucedida bem como a existência de benefícios socioeconômicos para estas comunidades são elementos necessários para o longo prazo da sustentabilidade. As comunidades podem beneficiar de sistemas produtivos locais em que a organização, evolução e competitividade da estrutura produtiva local não dependem apenas de investimento e do processo técnico, mas está integrado nas instituições, na cultura local, nos hábitos e nas ações sociais do território local onde o processo de produção se encontra. Os projetos de energias renováveis têm potencial para alcançar essa integração entre esses elementos (sociais, produtivos e territoriais) e colocar as comunidades no caminho de desenvolvimento sustentável.

\subsection{Sistemas Híbridos}

Como vimos anteriormente, a eletrificação pela rede convencional nas comunidades isoladas é algo que não existe. Essa inexistência de fornecimento de energia se deve à fatores, tais como as dificuldades de acesso, os elevados custos de construção de subestações, longos circuitos de transmissão e distribuição, pouca demanda pontual e poucas unidades consumidoras. Alternativas de energias renováveis vêm sendo aplicadas para suprir a ausência de energia elétrica nessas comunidades remotas. Muitas dessas áreas apresentam variadas fontes de energias renováveis e estas podem ser combinadas em um único sistema. Essa combinação se chama de sistema híbrido de energia (PINHO et al., 2008).

Os Sistemas Híbridos de Energia (SHE) ou simplesmente sistemas híbridos (SH) combinam dois ou mais dispositivos de conversão de energia, ou dois ou mais combustíveis para o mesmo dispositivo, que, quando integrados, superam limitações inerentes a qualquer um. Estas limitações podem ser abordadas em termos de flexibilidade de combustível, eficiência, confiabilidade, emissões e/ou economia (BURCH, 2001, p. 3). O termo amplamente SHE descreve um sistema autônomo de energia, que combina fontes de energia renováveis e convencionais com banco de bateria para armazenamento e condicionamento de potência e um controlador (NEMA et al., 2013). $\mathrm{O}$ controlador e o condicionamento de potência são usados para manter a qualidade da potência. $O$ armazenamento de bateria serve para atender a demanda quando a demanda é demanda de carga de pico ou fonte de energia renovável não é disponível.

O objetivo dos SHs é potencializar o uso de energias renováveis, resultando em um sistema com emissões mais baixas do que as tecnologias convencionais alimentadas a combustíveis fósseis e manter a confiabilidade e a qualidade da energia fornecida evitando efeitos colaterais ao meio ambiente. 
De maneira geral, os sistemas híbridos incorporam tecnologia de conversão de fontes convencionais (grupo geradores a diesel, gasolina ou a gás), tecnologias de conversão de fontes alternativas (módulos fotovoltaicos, aerogeradores, biomassa, turbinas hidráulicas), subsistema de armazenamento de energia (banco de bateria) e equipamentos do sistema de condicionamento de potencia (inversores de tensão e retificares e controladores de carga), (PINHO et al., 2008). Os autores, no seu livro destacaram que para o atendimento das cargas, os equipamentos são conectados por meio de cabeamento e dispositivos de proteção (chaves, relés e disjuntores) e por fim a dois barramentos, um de corrente contínua (CC) e outro de corrente alternada (CA). A figura 2 abaixo mostra exemplo de um $\mathrm{SH}$.

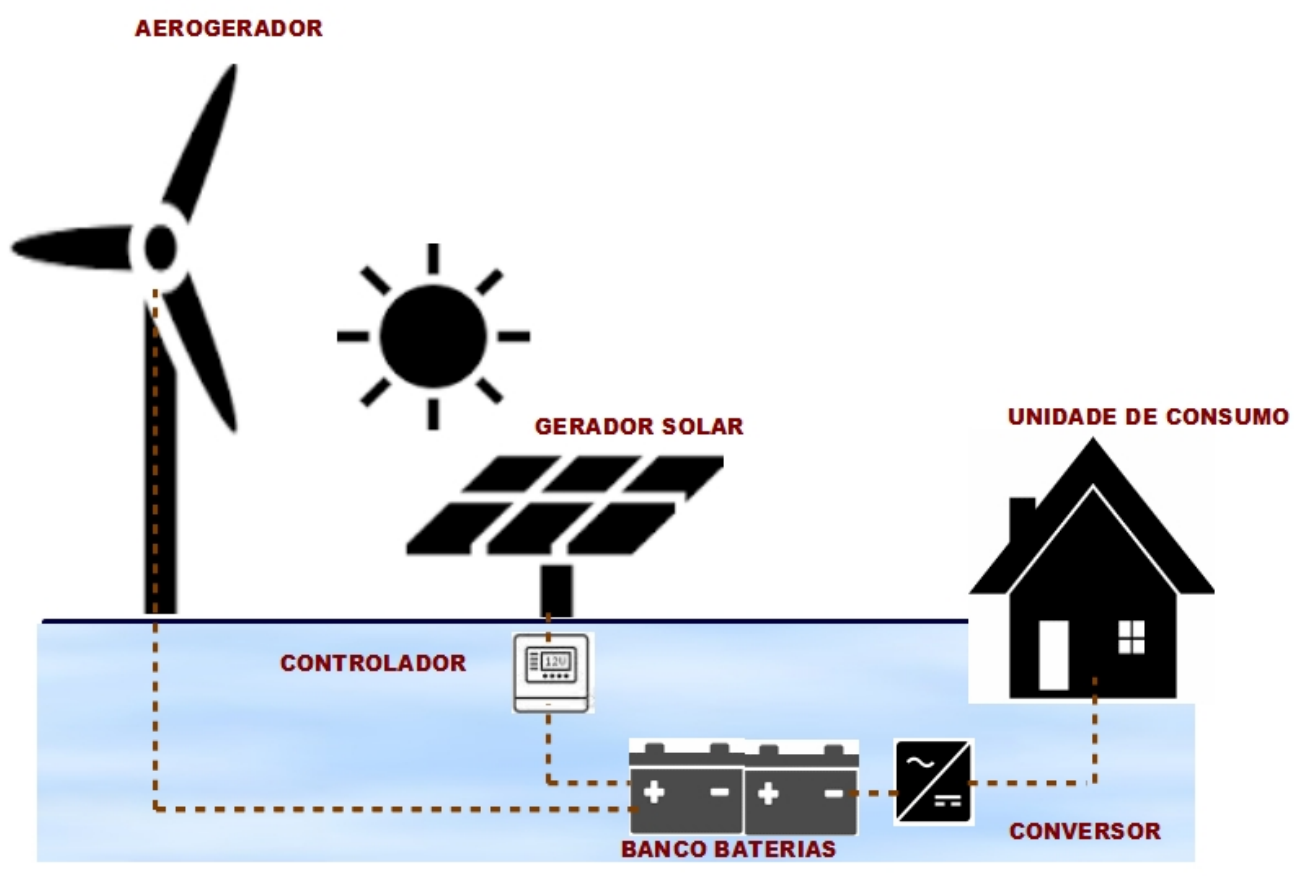

Figura 2 - Modelo de sistema híbrido de energia.

Nas duas últimas décadas, muitos sistemas híbridos de energia foram instalados em vários países no mundo, resultando no desenvolvimento de sistemas que podem competir com fontes de alimentação convencionais de combustíveis de área remotas baseadas em várias aplicações (NEMA et al., 2013). Estes sistemas são fontes importantes de energia em lojas, escolas, hospitais em comunidades de aldeias, especialmente em áreas remotas. Eles estão se tornando parte integrante do processo de fornecimento de energia para abastecer áreas remotas anteriormente não eletrificadas como na Índia, na Tailândia, na Espanha, na África do Sul (WICHERT, 1997). Para áreas remotas, SHE são freqüentemente as formas mais rentáveis e confiáveis de produzir energia (DESHMUKHA; DESHMUKH, 2008). Eles podem fornecer eletricidade a um preço comparativamente econômico em muitas áreas remotas. Para obter eletricidade a partir desses sistemas de forma fiável e a um preço econômico, seu design 
deve ser ótimo em termos de operação e seleção de componentes (ASHOK, 2007).

Na sua pesquisa, Wichert, destacou que, o estado atual da tecnologia do SHE é o resultado de uma série de pesquisa de várias áreas, tais como (WICHERT, 1997, p. 210):

- Os avanços na conversão de energia elétrica através da disponibilidade de novos dispositivos semicondutores eletrônicos de potência, resultaram em maior eficiência, qualidade do sistema e confiabilidade;

- Desenvolvimento de software de simulação de sistemas híbridos versáteis (HOMER, VIPOR, Hybrid 2, etc.);

- Avanços contínuos no processo de fabricação e eficiência dos módulos fotovoltaicos;

- O desenvolvimento de controladores automáticos personalizados, que melhoram o funcionamento dos sistemas de energia híbridos e reduzem os requisitos de manutenção;

- Desenvolvimento de baterias melhoradas de ácido-chumbo de ciclo profundo e outros tipos para sistemas de energia renovável;

- Disponibilidade de aparelhos CA e CC mais eficientes e fiáveis, que podem recuperar o seu custo adicional ao longo da sua vida operacional prolongada.

Na implementação dos SHEs, impactos ambientais e socioeconômicos devem ser considerados. Por se tratarem de sistemas de pequeno e médio porte, os impactos são geralmente mais benéficos do que prejudiciais. Os impactos ambientais estão relacionados ao descarte das baterias, ruídos dos aerogeradores e dos geradores diesel e eventual vazamento de óleo, por tanto, deve haver um programa a fim de evitar esses problemas como, por exemplo, programa de reciclagem das baterias e instalação dos aerogeradores longe das residências. Os impactos socioeconômicos ocorrem geralmente quando os SHs são instalados em comunidades, as pessoas passam a substituir as mais diversas fontes de energia que antes usavam, ocorre substituição de pilhas, querosene, óleo diesel, etc., outro impacto é a diminuição do êxodo rural e por fim, o aumento das atividades produtivas com o surgimento de pequenos negócios que conseqüentemente aumenta a renda das famílias (PINHO et al., 2008).

Os principais tipos sistemas híbridos de energia são:

- Eólico-diesel;

- Fotovoltaico-diesel; 
- Fotovoltaico-eólico;

- Fotovoltaico-eólico-diesel.

\subsection{Ferramentas de Simulação}

Com o avanço da tecnologia de computação, simulação computacional e modelagem têm sido amplamente utilizadas para fornecer uma avaliação precisa e detalhada do desempenho de sistemas energéticos (SAMAAN et al., 2016). É a forma de projetar um modelo de um sistema físico real ou teórico, executar o modelo em um computador digital e analisar a saída de execução.

A simulação consiste no processo de construção de um modelo que replica o funcionamento de um sistema real ou idealizado (ainda a ser construído) e na condução de experimentos computacionais com este modelo com o objetivo de melhor entender o problema em estudo, testar diferentes alternativas para sua operação e assim propor melhores formas de operá-lo.

Desta forma, podemos resumir as principais etapas numa aplicação prática de simulação em:

1) Desenho ou construção do modelo

2) Transformação deste modelo conceitual em um modelo computacional próprio ao processo de experimentação (execução do modelo);

3) Teste experimental de alternativas de ação para escolha das mais adequadas (análise do modelo);

Os sistemas elétricos baseados no hibridismo de geração renovável e não renovável, com a acumulação de energia feita em baterias, representam hoje uma alternativa madura para o suprimento de energia, devido especialmente a desenvolvimento de programas computacionais para simulação e análise desses sistemas híbridos. Os programas de simulação computacional são instrumentos analíticos eficazes para a construção de pesquisas energéticas e avaliação do desenho arquitectónico do sistema.

A primeira aparição dos programas de simulação energéticos nos estados unidos por SANDIA Laboratories e pela Universidade de Arizona, usando FORTRAN como linguagem de programação (KEATING, 1991). Mais tarde, foram desenvolvidos novos programas para computadores pessoais, possibilitando acesso para mais usuários (VERA, 2004). Segundo Krenzinger (1994), entre esses "softwares" destacaram-se PVFORM da SANDIA Laboratories, ASHLING da University College CORK (Irlanda) e HERMINES da L'école des MINES de Paris. 
De acordo com Vera (2004), os programas de simulação podem ser valiosos, permitindo fornecer o melhor planejamento possível de sistema híbrido de energia a projetar conforme as demandas do usuário. Entre as ferramentas de simulação mais usuais para projetar sistemas de energia híbridos que estão no mercado, destacam-se: Hybrid 2, PV*SOL Pro, RETScreen, Inseldi, Modes, SolSim, PV-Design Pro, PVS 2001, SolarPro e HOMER. Foram extraídas da publicação de Knaupp, W. (2003) a maioria das informações aqui prestadas.

Hybrid 2: Desenvolvido pelo NREL e a Universidade Masachusetts em 1996 tem como principal papel a realização de simulação detalhada de instalações híbridas de energia. Ele engloba sistemas que pode conter: módulos fotovoltaicos, aerogeradores ou turbinas eólicas, geradores a diesel e banco de baterias.

PV*SOL Pro: Desenvolvido em 1998 pela Di Valentin Energy software, ele realiza simulação e análise de sistemas de energia conectados à rede ou isolados.

RETScreen: Pacote de softwares de análise de projetos de energia limpa. É o mais avançado que serve como suporte à tomada de decisão nesse setor. Ele permite aos tomadores de decisão e profissionais do setor avaliar e determinar a viabilidade técnica e econômica de projetos de energias renováveis, potenciais de eficiência energética ou cogeração.

Inseldi: Este é um dos programas de energia mais antigo no mercado, ele foi desenvolvido pela Universidade Ossietzky d'Oldenburg da Alemanha. Este software tem embutido blocos para área de esfriamento e aquecimento solar. Para configuração do sistema desejado o modelador pode construir um diagrama de blocos com ajuda de um editor gráfico.

Modes: MODES (software de Modelos de Sistemas de Energia) é um programa de otimização técnica e financeira de sistemas energéticos. Além de realizar simulações de fontes de energias renováveis, ele também simular sistemas de geração de energia elétrica e térmica.

SolSim: Este como a maioria é um programa que permite fazer análise técnica e econômica de sistemas fotovoltaicos. Ele foi desenvolvido no objetivo de fazer simulação, análise e otimização de sistemas fotovoltaicos conectados ou não a rede. Ele permite a realização de sistemas híbridos com turbinas, biomassa e plantas de biogás.

Homer: HOMER (Hybrid Optimization Model for Electric Renewable). É um software que permite modela comportamento físico de um sistema de microenergia e seu custo de ciclo de vida, que é o custo total de instalação e operação do sistema ao longo de sua vida útil e ainda, permite ao modelador comparar muitas opções de design diferentes com base em seus méritos técnicos e econômicos. Ele também auxilia na compreensão e quantificação dos efeitos da incerteza ou mudanças nos insumos. A 
análise e o projeto de sistemas de microenergias podem ser desafiadores, devido ao grande número de opções de projeto e à incerteza em parâmetros-chave, como tamanho de carga e preço futuro do combustível (GILMAN; LILIENTHAL, 2006). Os mesmos autores ainda argumentam que, fontes de energia renováveis aumentam a complexidade porque a sua produção de energia pode ser intermitente, sazonal e não descartável, e a disponibilidade de recursos renováveis pode ser incerta. A ferramenta HOMER foi projetada para superar esses desafios.

Para limitar a complexidade de entrada e permitir uma computação rápida o suficiente para tornar a análise de otimização e sensibilidade prática, a lógica de simulação do HOMER é menos detalhada do que a de vários outros modelos de simulação de séries temporais para sistemas de microenergia, como os acima citados. Em compensação, HOMER é mais detalhado do que os modelos estatísticos como o RETScreen, que não realizam simulações de séries temporais. De todos estes modelos, HOMER é o mais flexível em termos da diversidade de sistemas que pode simular (GILMAN; LILIENTHAL, 2006).

Tabela 1 - Ferramentas de Simulação de Sistemas Híbridos de Energia

\begin{tabular}{|c|c|c|}
\hline $\begin{array}{l}\text { Ferra- } \\
\text { menta }\end{array}$ & Língua & Site \\
\hline Hybrid 2 & $\begin{array}{l}\text { Inglês } \\
\text { Inglês, }\end{array}$ & http://www.ecs.umass.du/mie/labs/rerl/hy2/intro.htm \\
\hline $\begin{array}{c}\mathrm{PV}^{*} \mathrm{SOL} \\
\text { Pro }\end{array}$ & $\begin{array}{l}\text { Espanhol, } \\
\text { Francês e } \\
\text { Alemão }\end{array}$ & http://www.valentin.com/ \\
\hline $\begin{array}{l}\text { RETS- } \\
\text { creen }\end{array}$ & $\begin{array}{c}\text { Francês e } \\
\text { Inglês }\end{array}$ & http://www.nrcan.gc.ca/energy/software-tools/7465 \\
\hline Inseldi & $\begin{array}{l}\text { Inglês e } \\
\text { Francês }\end{array}$ & http://www.dllfixis.com/inselDi.dll.html \\
\hline Modes & Alemão & http://www.ewis.fh-konstanz.de/modes.htm \\
\hline SolSim & $\begin{array}{l}\text { Alemão e } \\
\text { Inglês }\end{array}$ & http://www.ewis.fh-konstanz.de/solsim.htm \\
\hline Homer & Inglês & http://www.homerenergy.com/HOMER_pro.html \\
\hline
\end{tabular}

A sustentabilidade envolve questões como, constante luta pela melhoria da qualidade de vida dos cidadãos, a promoção da igualdade de oportunidades, restrição ao uso de fontes tradicionais de energia e o uso cuidadoso das energias renováveis. Como vimos nos capítulos anteriores, não há desenvolvimento sem energia, o desenvolvimento futuro depende de que se disponha dela por muito tempo, em quantidades cada vez maiores e de fontes seguras, confiáveis e adequadas ao meio ambiente. Por isso, só há desenvolvimento sustentável com energia vinda de fontes limpas. O uso das fontes tradicionais de energia traça uma trajetória ao declínio, não só pela sua caracte- 
rística efêmera, mas por que é uma ameaça ao meio ambiente. Na luta pela questão de sustentabilidade, as energias alternativas ganham cada vez espaço maior. Além de solucionar grandes problemas ambientais, como o efeito estufa, mudanças climáticas, poluição do ar, água e solo e manter a biodiversidade, as energias renováveis ajudam a combater a pobreza e desigualdade social principalmente nas regiões isoladas. Elas ajudam na criação de novas oportunidades de emprego, facilitam o acesso à água potável, alimentos cozidos, educação, segurança, mídia e comunicação e ainda contribuem para evitar o desmatamento.

A participação das fontes alternativas em projetos de sistemas energéticos pode ser importante no objetivo de promover a sustentabilidade. Estes projetos de fontes renováveis de energia e híbridos estão cada vez ganhando mais espaço. Eles apresentam grau de complexidade elevado e os problemas são diversos, devido ao grande número de opções de projetos e a incerteza nos parâmetros-chave, como tamanho de carga e preço futuro do combustível por exemplo. Fontes renováveis de energia aumentam a complexidade porque sua produção de energia pode ser intermitente, sazonal e não descartável, e a disponibilidade de recursos renováveis pode ser incerta. As ferramentas de simulação computacional de sistemas de energia foram projetadas para superar todos esses desafios e daí a importância de usar sistemas computacionais para a sustentabilidade. 


\section{Caracterização da Comunidade em Estudo}

\subsection{Aspectos Geográficos da Comunidade}

O presente trabalho está direcionado a comunidade isolada "Paulin/La corne" do departamento de Noroeste da república do Haiti. Essa comunidade é um pequeno vilarejo com superfície de aproximadamente $70,74 \mathrm{~km}^{2}$ de acordo com dados do "Institut Hal̈tien de Statistique et d'Informatique (IHSI, 2015)", e se encontra a cerca de $5 \mathrm{~km}$ da cidade de "Port-de-paix" do departamento de Noroeste. É uma comunidade que possui baixíssima densidade populacional com 1,88 Hab./ $/ \mathrm{km}^{2}$. Esse pequeno vilarejo isolado é situado ao norte pelo Rio "Les Trois Rivières" que o separa da cidade causando o seu isolamento para muitos, o sul pela comunidade de "Deux Garçons" e à leste e oeste respectivamente pelas comunidades de "Aubert" e "Gros Bassin" com as distâncias de 10 e $30 \mathrm{~km}$ aproximadamente. É uma comunidade de difícil acesso dos mercados consumidores e está isolada de praticamente todos os meios de comunicação, as pessoas usam pequenos barcos sem estrutura como meio de transporte para ir na cidade. Ele possui as seguintes coordenadas geográficas: $19^{\circ} 56^{\prime} 16^{\prime \prime} \mathrm{N}$ de latitude, $72^{\circ} 49^{\prime} 55^{\prime \prime} \mathrm{L}$ de longitude, altura de 36 metros e por fim com os ângulos $97,90^{\circ}$ de azimute, $12,34^{\circ}$ de elevação e - 68,63 de inclinação. As Figuras 3 e 4 a seguir mostram a localização da comunidade. As residências entre si são próximas, com uma distância de aproximadamente $400 \mathrm{~m}$ como pode ser observada na Figura 4, o que pode facilitar a implantação de um sistema centralizado.

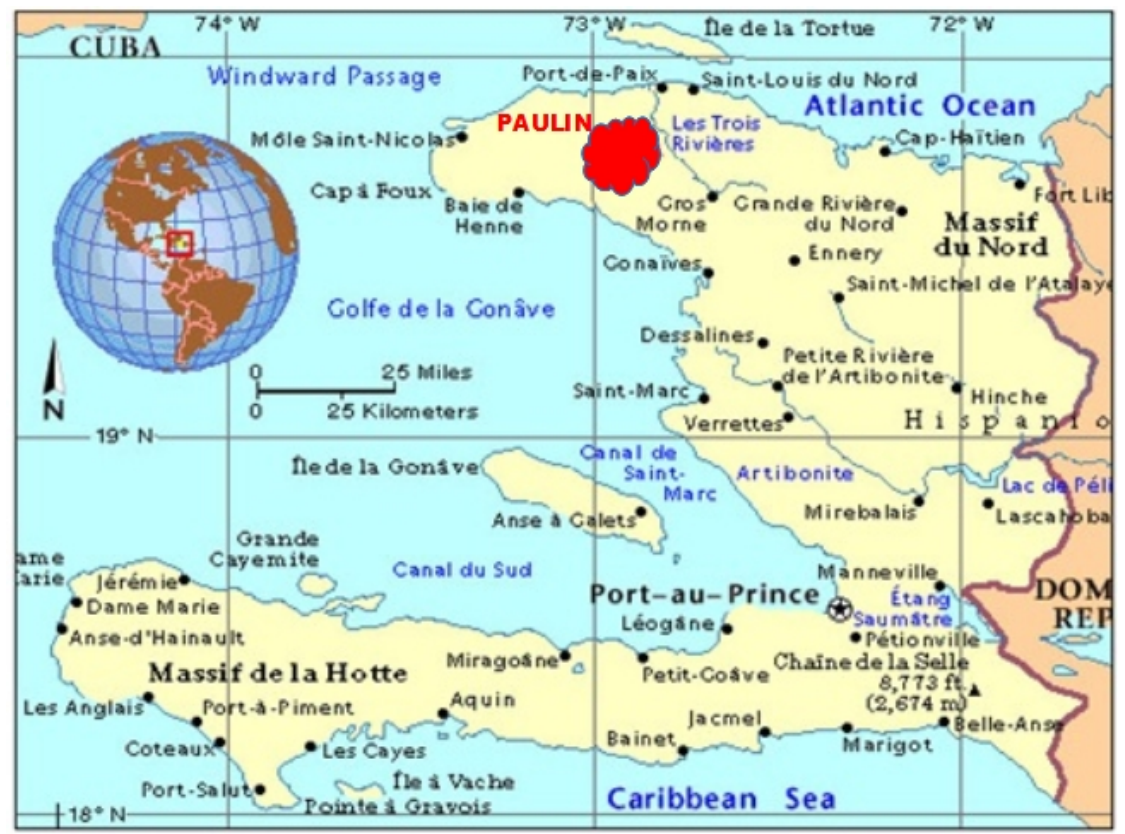

Figura 3 - Carta da República do Haiti. 


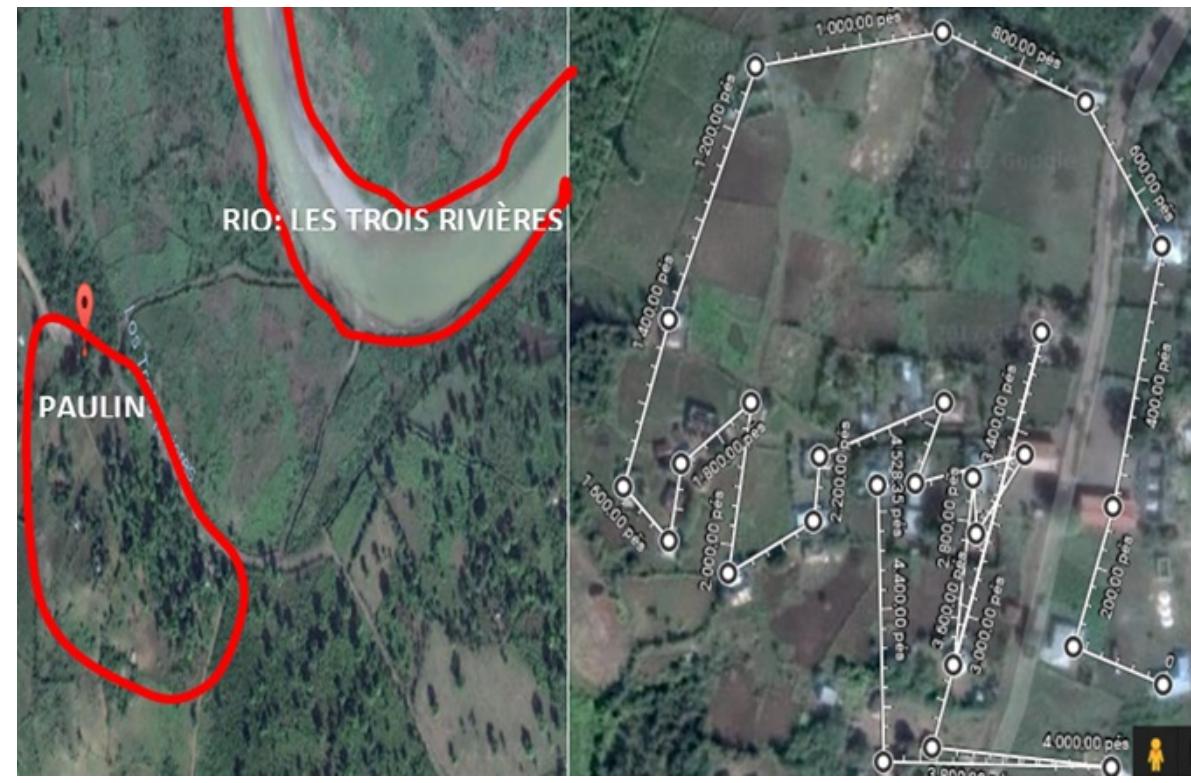

Figura 4 - Localização e distâncias das residências no vilarejo.

\subsection{População, Economia Local e Indicadores Sociais}

\subsubsection{População}

De acordo com IHSI, o número de habitantes no vilarejo é de 133 pessoas agrupadas em 26 famílias. As residências são um pouco distantes uma da outra neste. No relatório de "IHSI", as mulheres com uma porcentagem de 51,87\% representam uma proporção maior e os homens representam $48,12 \%$ dessa população considerando adultos e crianças. Ainda, segundo a classificação da IHSI, essa comunidade é considerada como comunidade rural isolada.

\subsubsection{Economia Local}

Pesquisas destacam que mais de $3 / 4$ da população rural do país tem dificuldade para satisfazer as suas necessidades de alimentos (DUFOUR, 2011). Isto não é diferente para essa pequena comunidade isolada em estudo. A economia desse pequeno vilarejo é formada basicamente pela agricultura tradicional, pecuária e pesca fluvial. A agricultura se baseia em atividades agrícolas como o plantio de feijão, banana e milho e destaca-se ainda algumas plantações de plátanos, cana de açúcar e mandioca doce. Como atividade pecuária, tem-se criação de porcos, ovelhas, cabras e alguns bois (MARNDR, 2015).

O nível de produção da agricultura é muito fraco, o sistema de irrigação é inexistente, o desmatamento de árvores para satisfazer necessidades como produção de carvão, a falta de conhecimento de técnicas de produção e a falta de acesso a insumos agrícolas básicos limitam e muito a produtividade dos agricultores. E ainda, 
esta produção é bem instável por falta de mão de obra. Apesar da disponibilidade de matérias-primas como palmitos, bambu, cabaça, o artesanato é muito pouco desenvolvido, isto é, principalmente devido à falta de capital, infra-estrutura deficiente (eletricidade, comunicação, estradas para movimentar os produtos para outras regiões) e por fim a falta de potenciais investidores.

A atividade de pesca fluvial é realizada no período de agosto até outubro que antecedem o defeso da reprodução dos peixes. Os pescadores enfrentam problemas de falta de treinamento e equipamentos de trabalho. Para capturar os peixes, o pescador usa simplesmente caniço simples, linha de mão e anzol. A pesca é uma atividade secundária da comunidade. A comercialização dos peixes representa um obstáculo muito grande para os pescadores, pois não há mercado formal no vilarejo, e ainda não há meios de conservação (eletricidade, freezer, etc.). Então, eles são forçados a vender localmente a preços muito baixos. Instabilidades meteorológicas e eventos como enchentes, causam danos às plantações e dificultam a pesca.

Para cozinhar as pessoas usam a biomassa tradicional usando galhos de árvores para fazer fogo. Os seus alimentos praticamente são: banana, mandioca, feijão, peixe, arroz, carne bovina e suína tudo em pequena proporção. Enfim, a população rural dessa localidade sofre não só com a falta de renda, mas também a falta de estruturas de instalações. Eles vivem apenas dos seus ativos mais importantes que é a terra.

\subsubsection{Indicadores Sociais}

Esta comunidade encontra-se às margens da vida econômica e enfrenta graves problemas sociais. Por sua vez, o Índice de Pobreza Multidimensional (IPM), que indica os níveis de pobreza de acordo com dez indicadores, reflete que os setores de energia elétrica, saneamento e energia para cozinhar alimentos, são os três que mais sofrem, particularmente nas áreas rurais do Haiti (OXFORD, 2010 apud DUFOUR, 2011). As pessoas vivem na pobreza absoluta, ou seja, elas carecem da satisfação das necessidades como alimentação, vestimenta e habitação adequada. A situação da infra-estrutura social desse pequeno vilarejo isolado é agravada pela escassez ou ausência de serviços públicos básicos como educação, saúde ou assistência médica, eletricidade, lazer e água potável. As casas não possuem eletrodomésticos como geladeira, televisão, máquina de lavar, rádio, liquidificador, etc.

O sistema de iluminação das casas é feito por meio de biamassa tradicional e de lamparina de querosene que forcene uma iluminação de pouca intensidade. Adicionado a isso é a falta ou a insuficiência de infra-estrutura física rural: estradas e outros meios de comunicação. Não existe posto de saúde, não existe farmácia, possui uma escola de ensino fundamental (Figura 5) com poucas estruturas, não há meios de comunicação como telefones, etc... 
As deficiências de saúde vêm diretamente de condições de vida, muitas vezes medíocres, onde a pobreza, as condições insalubres e a desnutrição fazem parte da vida de muitos adultos e crianças não vacinadas. As doenças infecciosas e parasitárias florescem na comunidade pois a população vive em situações que não lhes permitem a respeitar os princípios mais básicos de higiene, veja a Figura 6 abaixo. Todas estas deficiências possuem como efeito a promover o desenvolvimento da medicina tradicional que ainda tem o apoio de uma grande fração da população. Sem negar seus méritos, deve-se reconhecer que esta medicina é incapaz de lidar com a complexidade de alguns casos de doenças que exigem conhecimentos e técnicas mais apropriadas. Assim, tantas mortes são muitas vezes devido às manobras de alguns "médecinsfeuilles" ou charlatães que, por tanto, são tolerados no meio e ainda continuam a dar assistência. A água potável é outro problema na comunidade. Existe um poço de água no vilarejo, os moradores usam a água desse poço ou do rio, que podem resultar em conseqüências como risco de doenças intestinais (JHON, 1999).

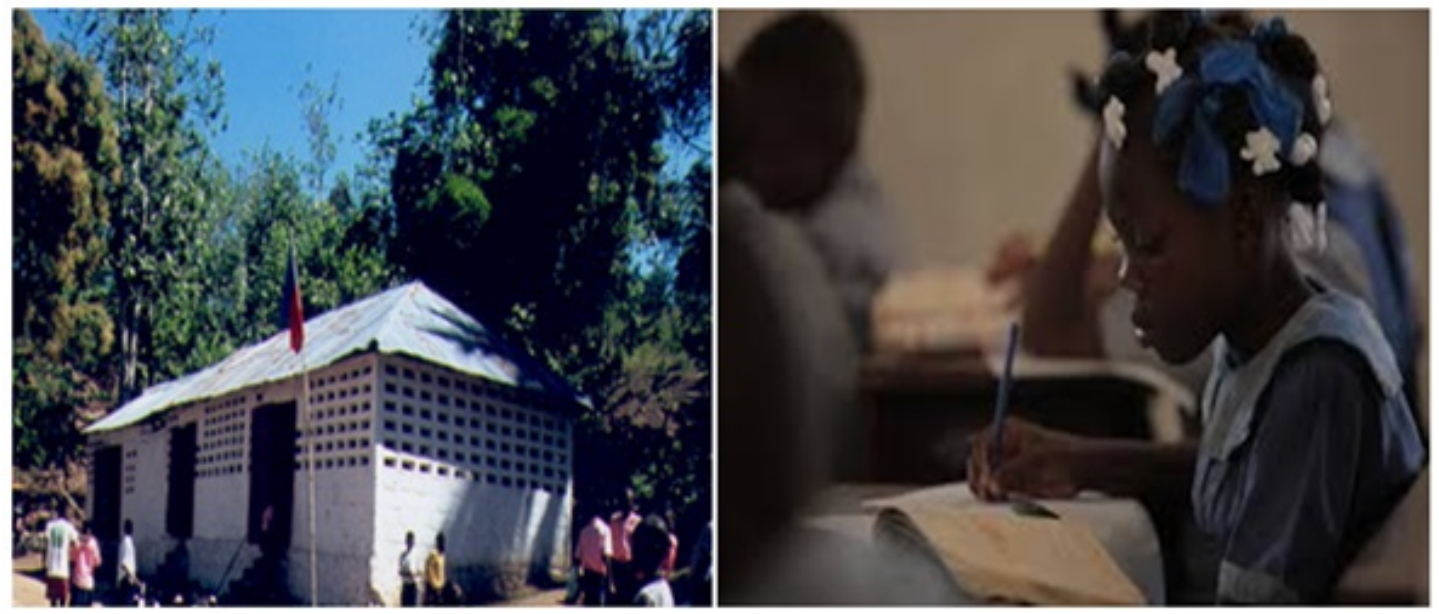

Figura 5 - Instituição de ensino do vilarejo.

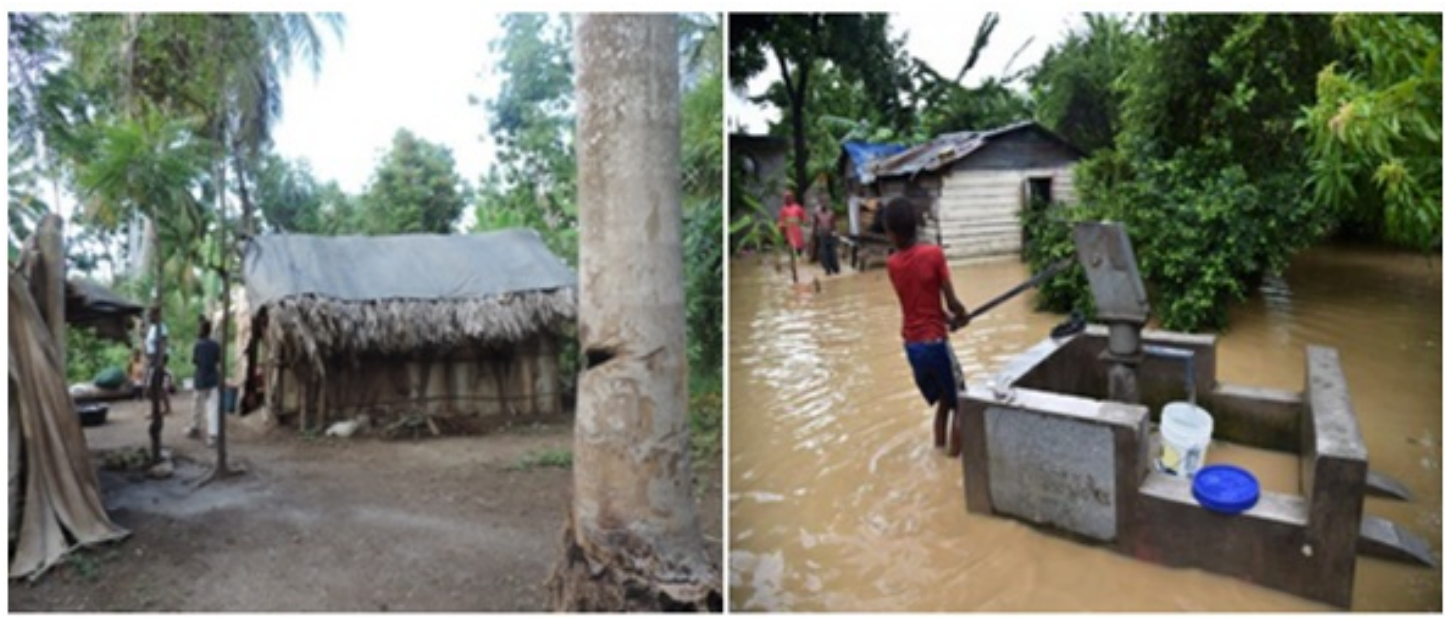

Figura 6 - Condições de vida das pessoas do vilarejo. Fonte: (RICHARD GUILLANDE SIGNALERT sarl, 2015) 
A organização racional e sistemática de entretenimento, especialmente em áreas remotas do país, é um dos principais pontos fracos, apesar de todos sabem a função e o poder de entretenimento saudável na vida social. Nessa comunidade não é diferente, pouca variedade de lazer. As brigas de galo chamado "gaguères", de longe, representam a mais importante atividade de lazer no vilarejo e sempre atrai um público importante. Os "gaguères" funcionam praticamente todos os dias. No entanto, esta programação caótica e sem lei desmobiliza demasiado freqüentemente muitas mão-de-obra cujo engajamento em atividades produtivas teria sido mais benéfico. A principal festa local "Notre Dame du Perpetuel Secours" é celebrada no dia 27 de Junho de cada ano.

Sujeito aos caprichos de qualquer espécie para sobreviver, esta população se vê obrigado a destruir seu próprio ambiente. Esta tendência está a incentivar o desmatamento e, geralmente, a deterioração dos recursos naturais (água, solo, floresta). Entre os fatores que contribuíram para agravar a pobreza e a miséria dessa população rural, vale à pena mencionar a freqüência de desastres naturais. Exemplos recentes de grandes catástrofes incluem inundações, secas, furacões e terremotos. A partir daí pode ter uma idéia da extensão dos danos causados por catástrofes naturais que não só destruíram colheitas, gados e casas, mas também resultaram na perda de vidas e cicatrizes deixadas que ainda não foram apagadas de uma população condenada à fome, observe a Figura 7.

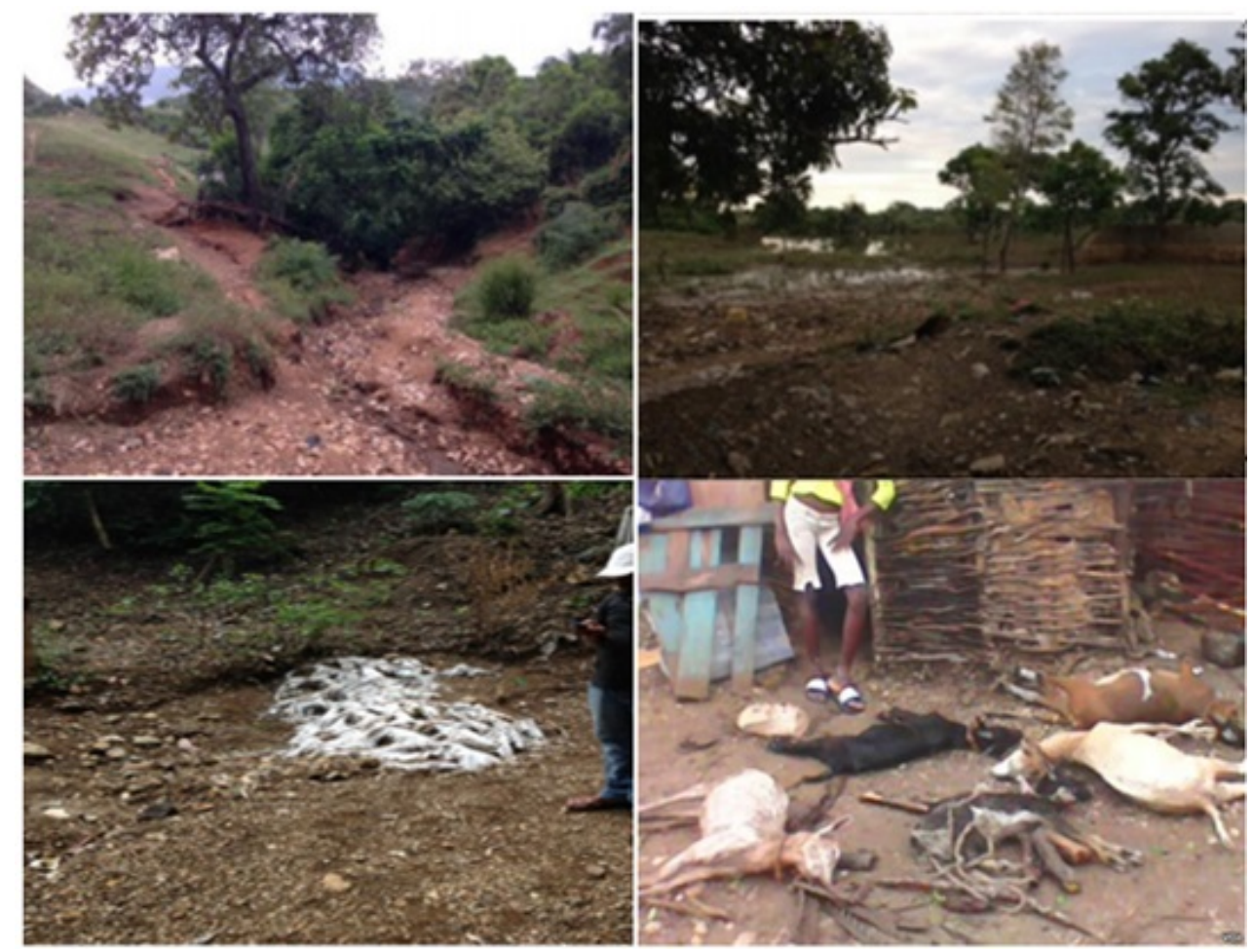

Figura 7 - Danos causados por catástrofes naturais no vilarejo.

Fonte: (RICHARD GUILLANDE SIGNALERT sarl, 2015) 
Enfim, todos esses fatores agravam o desemprego e a pobreza e ainda acelerar a migração, bem como a outros países e cidades causando êxodo rural, onde muitos migrantes engrossar as filas dos desempregados e subempregados.

\subsection{Caracterização Climática}

O pequeno vilarejo possui um clima praticamente de cerrado, com um inverno seco de acordo com a classificação climática de Köppen. As precipitações nessa comunidade são muito maiores no verão do que no inverno. Ao longo do ano, a temperatura média é de $26,9{ }^{\circ} \mathrm{C}$ e as precipitações são em médias $711,4 \mathrm{~mm}$. Precipitações médias de 19,9 mm fazem do mês de julho o mais seco do ano, já em outubro as precipitações são as mais importantes do ano com uma média de 120,7 mm. Em julho, mês mais quente do ano, a temperatura média é de $29{ }^{\circ} \mathrm{C}$ e janeiro considerado mês mais frio do ano, a temperatura média é de $24 \stackrel{\circ}{\mathrm{C}}$. O recorde de temperatura registrado nas proximidades do vilarejo foi no mês de julho de 1983 quando os termômetros marcaram $39 \stackrel{\circ}{\circ} \mathrm{C}$, enquanto a sexta-feira dia 22 de junho de 1979 foi o mês mais frio quando foi registrado uma de temperatura de $7 \stackrel{\circ}{\circ} \mathrm{C}$ nas proximidades dessa comunidade (PLANIFICATEUR, 2016). A Figura 8 mostra o comportamento das médias de temperatura e precipitações ao longo do ano nas proximidades da comunidade.

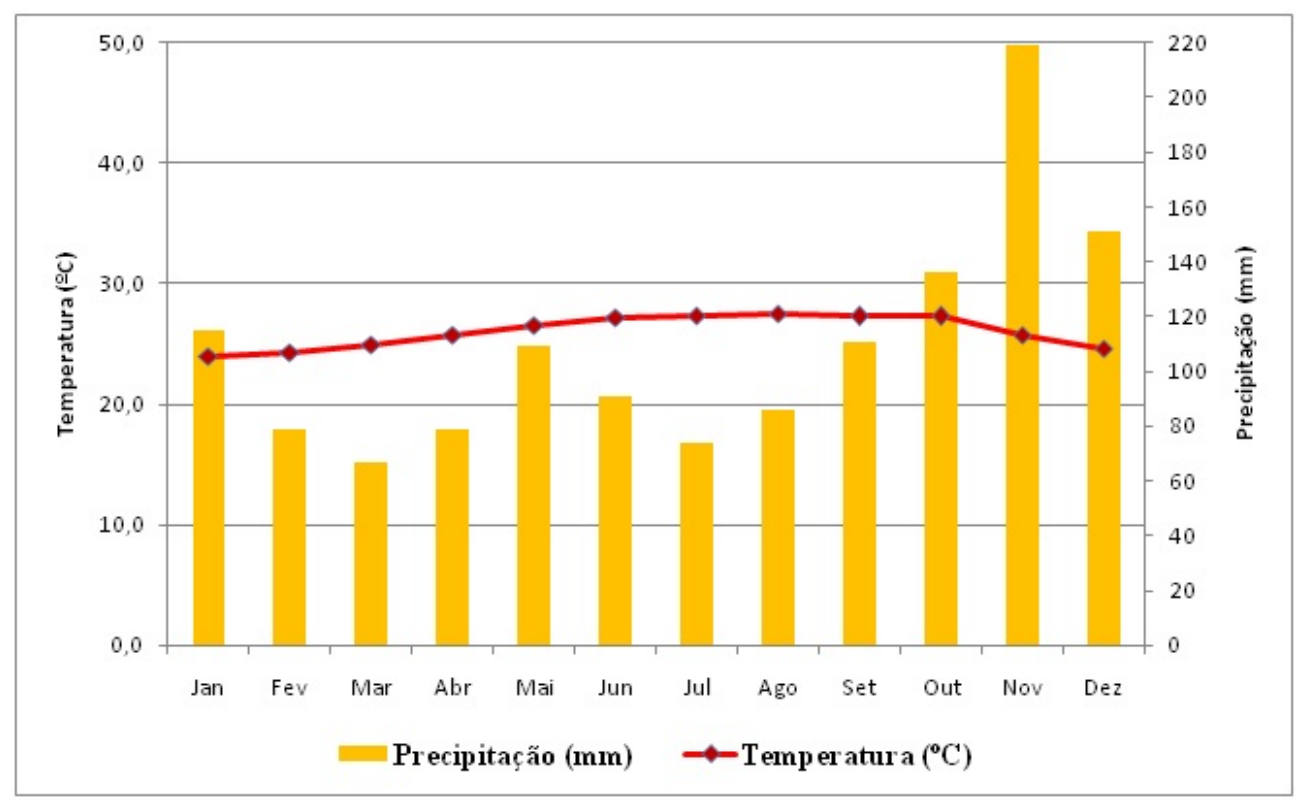

Figura 8 - Gráfico reproduzido da média anual de temperatura e precipitações nas proximidades da comunidade em estudo.

Fonte: (Climate, 2016)

\subsubsection{Recurso Solar}

O potencial de energia solar no Haiti é extremamente forte em todo o território nacional e se mantém durante todo o ano, mesmo no inverno ((WORLDWATCH, 2014). 
Na maior parte do país a irradiação global na horizontal varia de 5 à $7 \mathrm{kWh} / \mathrm{m}^{2} / \mathrm{dia}$ e se aproxima de 8 à $9 \mathrm{kWh} / \mathrm{m}^{2}$ em certas regiões (Figura 9).

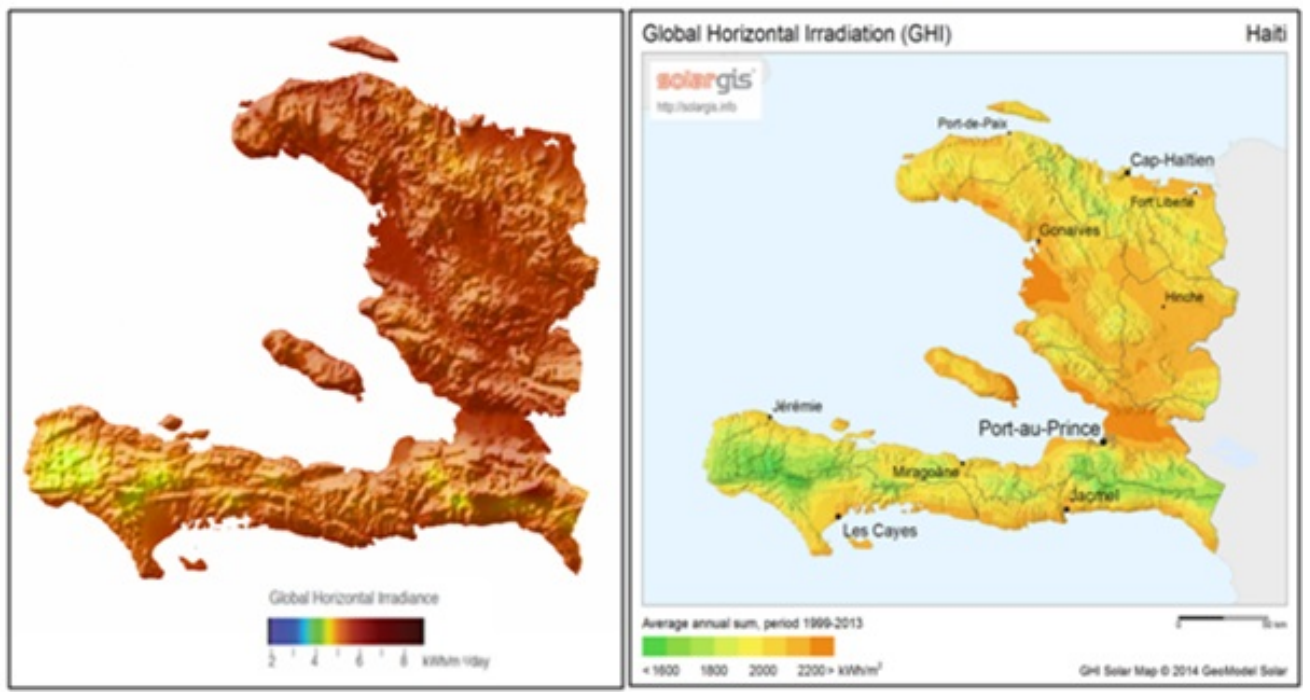

Figura 9 - Média da irradiação solar global no Haïti.

Fonte: (Global Solar Ir. . , 2016; Solargis (imaps..., 2016)

Como pode ser observado na Figura 10, no vilarejo em estudo, a média da irradiação mensal se mantém relativamente forte e uniforme o tempo todo, com uma pequena variação durante o período de novembro a fevereiro, julho é o mês com maior irradiação. O valor médio da irradiação no vilarejo é de $5,26 \mathrm{kWh} / \mathrm{m}^{2} / \mathrm{dia}$, isto é, a região apresenta um potencial elevado para aproveitamento de energia solar. Segundo Worldwatch e MTPTEC, país como Alemanha renomado pela produção de energia elétrica através do aproveitamento de fonte solar apresenta média de irradiação de 3 a $3,5 \mathrm{kWh} / \mathrm{m}^{2} /$ dia. Os dados de radiação solar global do vilarejo foram obtidos por meio do programa METEONORM 7 que disponibiliza a radiação com base nas coordenadas geográficas de determinadas localidades. Conforme informado anteriormente, o vilarejo fica a 36 m do nível do mar, 195' 16” N e 72ํ4' 55” E. 


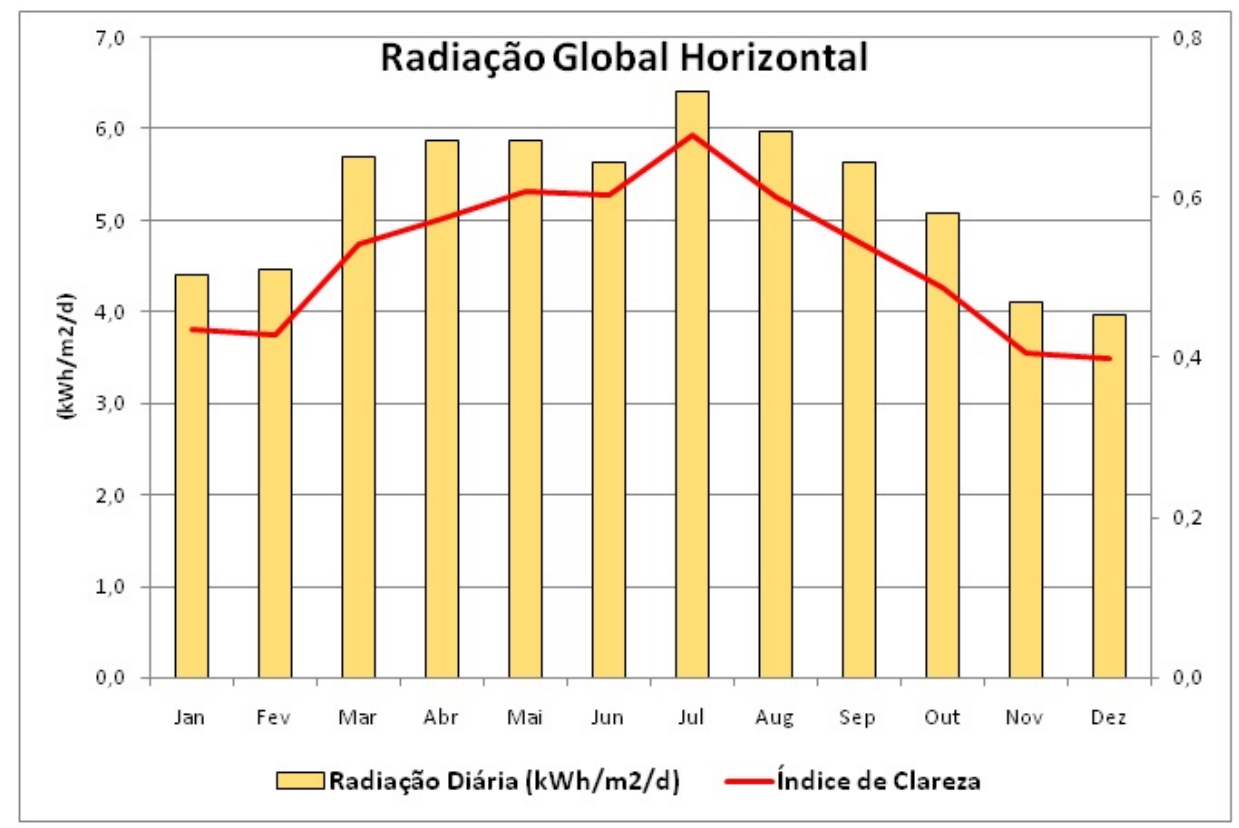

Figura 10 - Média mensal de radiação solar do vilarejo em estudo.

Fonte: (METEONORM 7, 2016)

Só para comparação, os dados da irradiação solar da localidade em estudo foram comparados com a pesquisa realizada por Worldwatch e MTPTEC na cidade de Port-de-Paix que fica a cerca de $5 \mathrm{~km}$ do vilarejo. $O$ que foi deduzido é que não houve alterações significativas nos resultados dos dois estudos, as médias de radiação mensais tendem aos mesmos valores o que significa que os resultados simulados pelo programa METEORONORM 7 são válidos, veja a Figura 11 a seguir.

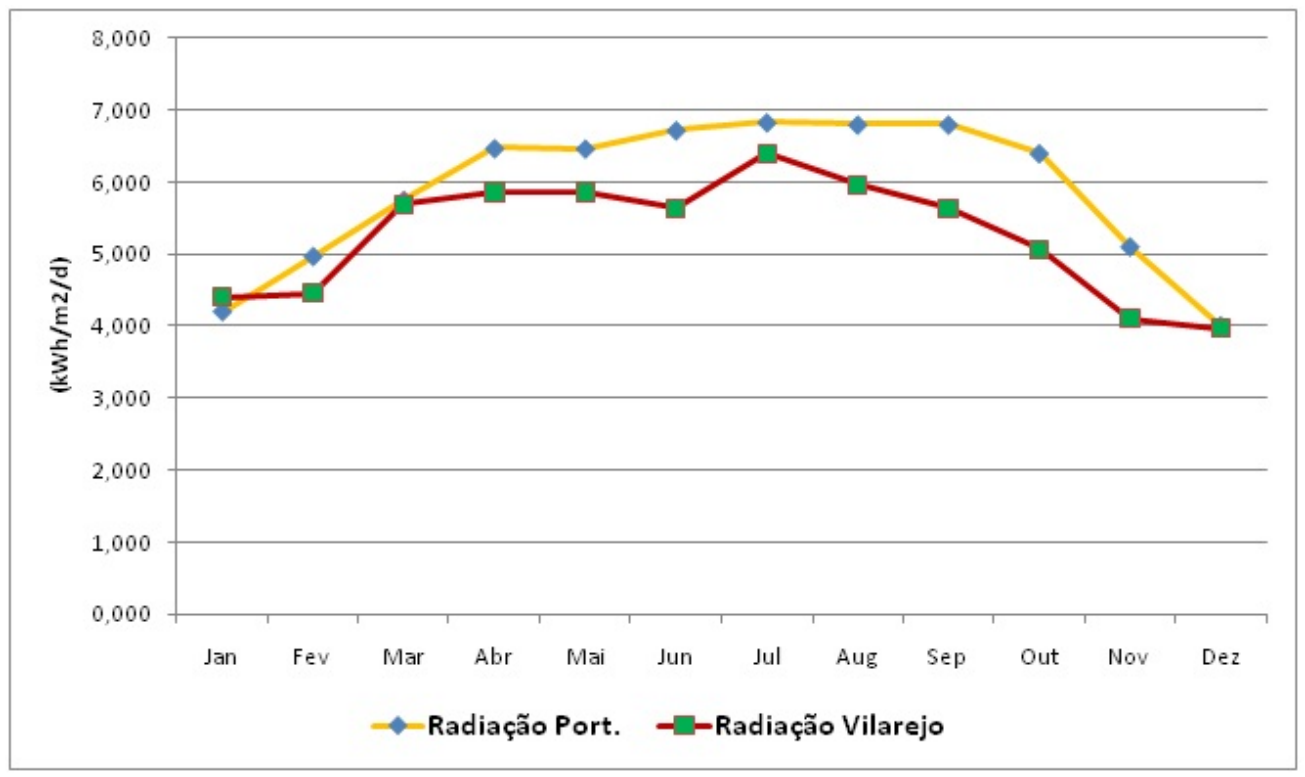

Figura 11 - Irradiação solar da cidade de port-de-paix e do vilarejo em estudo.

Fonte: (Global Solar Ir. . . 2016) \& METEORONORM 7 


\subsubsection{Recurso Eólico}

Como em todo o caribe, Haiti possui um potencial de ventos constantes durante todo o ano que penetra a região nordeste. De acordo com a pesquisa do "Worldwatch e MTPTEC", a maior parte do país possui locais onde a velocidade média do vento é ao menos 6 m/s numa altura de 80 metros, veja a Figura 12 abaixo. Estudos mostram que nos locais já medidos no mundo, somente $13 \%$ possuem vento com velocidade de $7 \mathrm{~m} / \mathrm{s}$ ou mais, que é geralmente um índice de que o desenvolvimento de energia eólica com baixo custo é possível (WORLDWATCH, 2014).
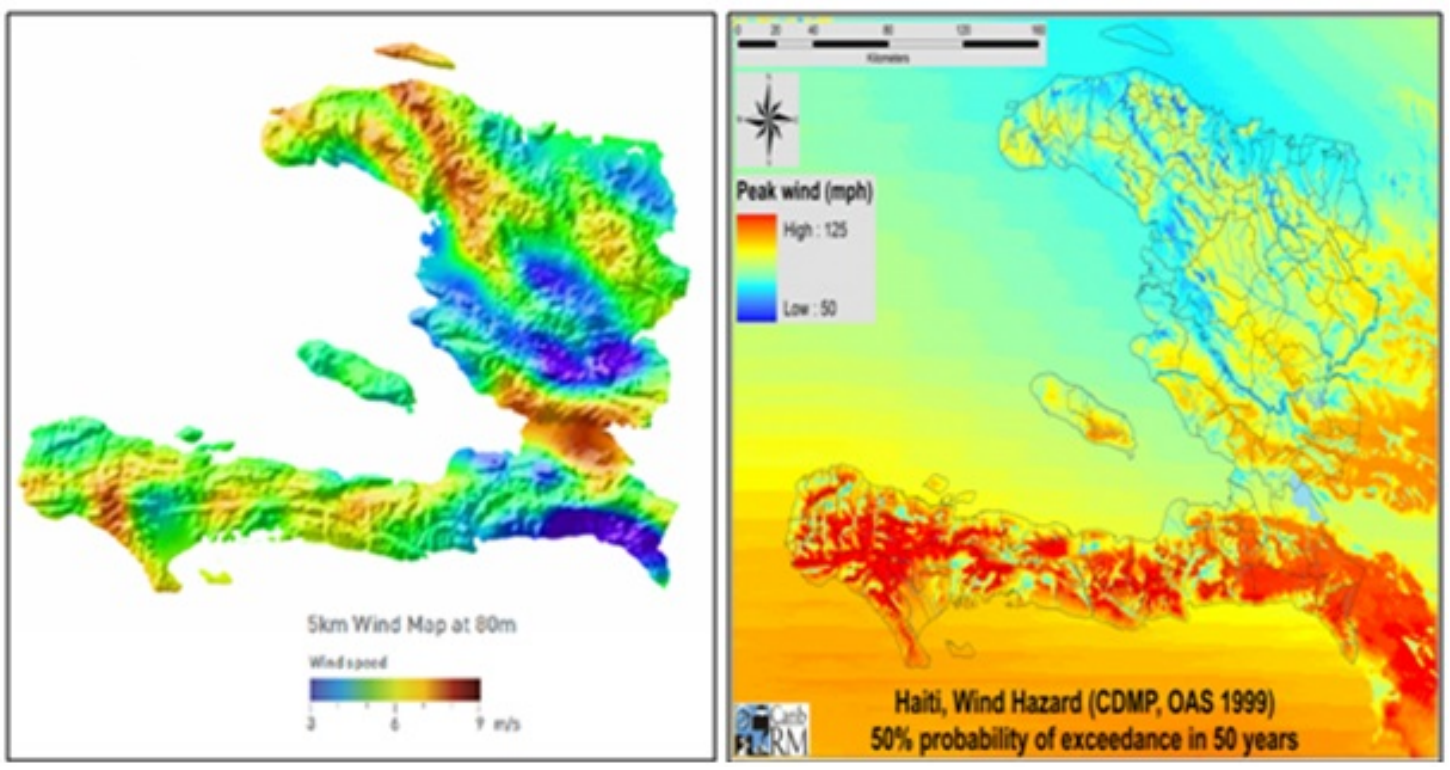

Figura 12 - Velocidade média de vento no Haiti, altura $80 \mathrm{~m}$.

Fonte: (Global Solar Ir. . , 2016)

Os dados de velocidade do vento da comunidade em questão foram obtidos através de uma estação meteorológica da região. Na Figura 13 são apresentadas as médias da velocidade de cada mês considerando um período de 20 anos (1997 a 2016). A média geral para todos os meses é de $6,04 \mathrm{~m} / \mathrm{s}$, setembro e outubro são respectivamente os meses com maior e menor velocidade média de vento com valores de $7,74 \mathrm{~m} / \mathrm{s}$ e $5,38 \mathrm{~m} / \mathrm{s}$, o que indica que a região possui um potencial de vento forte que é favorável ao desenvolvimento de energia eólica. 


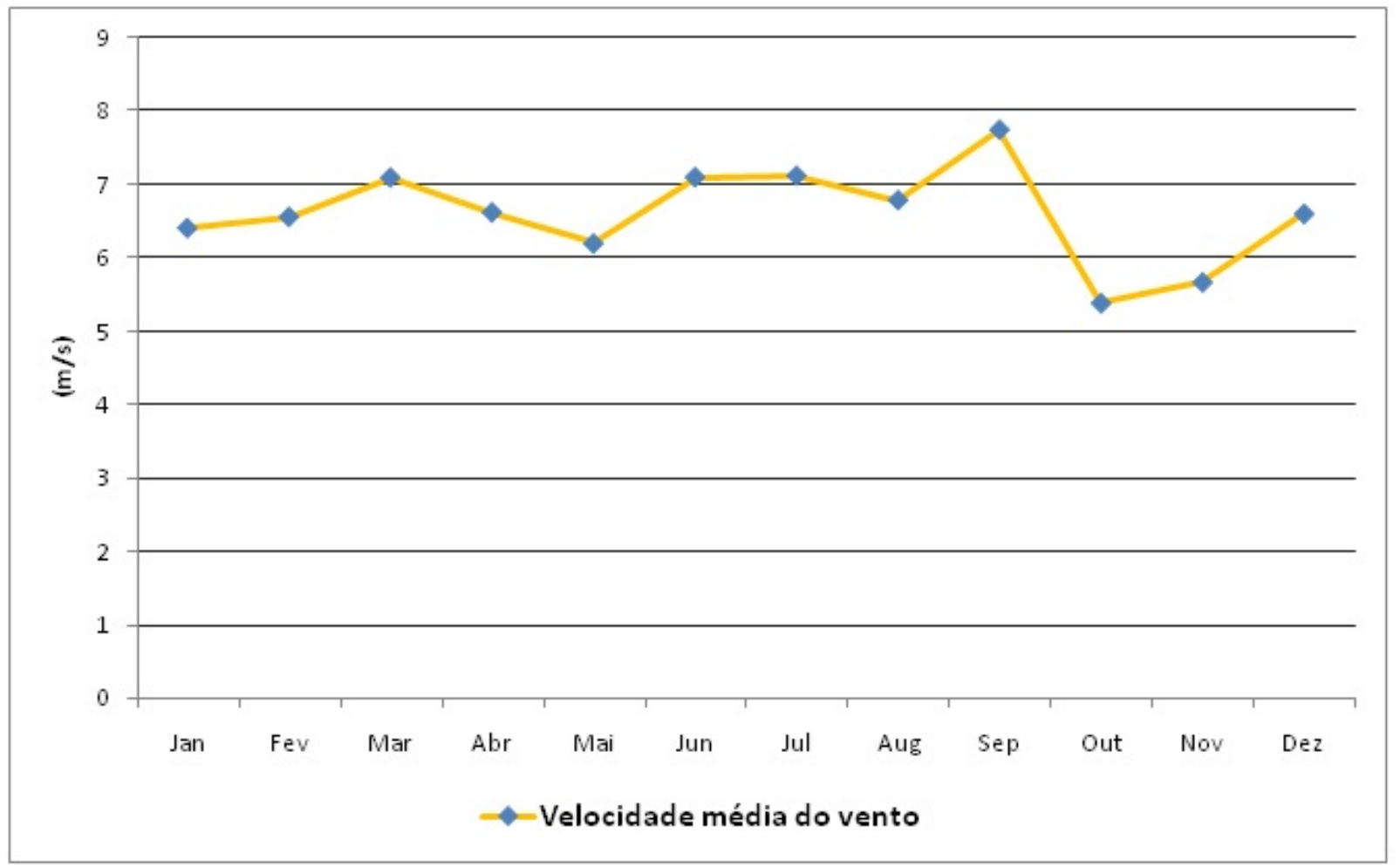

Figura 13 - Velocidade média do vento na região do vilarejo. Fonte: (WINDFINDER, 2016)

Simulando os valores no HOMER, resultados da Tabela 2, obtém-se 0,85 que representa o fator de autocorrelação, este valor alto indica que a velocidade do vento em uma hora tende a depender fortemente da velocidade do vento anterior. A força diurna padrão é 0,25 que é a medida de quão fortemente a velocidade do vento depende da altura do dia. $E \mathrm{k}=2$, fator de forma (Weibull) que representa a distribuição de velocidade do vento ao longo do ano. $O$ valor de $k$ é inversamente relacionado à variância da velocidade do vento em torno da velocidade média, o que implica em baixas variâncias se k é alto e vice-versa. Quanto menor a oscilação da velocidade, menor é o desvio padrão, maior é o fator de forma (k) e mais "estreito" é o gráfico da distribuição de frequência. $O$ valor de $k=2$ na localidade em estudo, é considerado alto e representa um melhor ajuste para curva de distribuição de frequência de Weibull já que ele implica em baixas variâncias, ou seja, os valores das velocidades do vento tendem a estar próximas do valor médio. Valores semelhantes de $\mathrm{k}$ a este foram encontrados por JUSTUS, HARGRAVES e YALCIN (1976) nos Estados Unidos e por Gupta (1986) na Índia. 
Tabela 2 - Valores paramétricos simulados no HOMER

\begin{tabular}{cc}
\hline Altitude $(\mathrm{m})$ & 36 \\
Altura do Anemômetro $(\mathrm{m})$ & 10 \\
Weibull k & 2 \\
Fator de Autocorrelação & 0,85 \\
Força Diurna Padrão & 0,25 \\
Média anual de vento $(\mathrm{m} / \mathrm{s})$ & 6,04 \\
\hline
\end{tabular}

\subsubsection{Demanda Elétrica no Vilarejo}

O limite de consumo para tarifa de baixa renda no Haiti não ultrapassa 180 kWh/mês. Como não foi feito nenhuma medição para o consumo das residências do vilarejo, então, são considerados que elas usam o limite de consumo para pessoas de baixa renda no país. Pressupõe-se que essa carga está relacionada com: iluminação, televisão, aparelho de som, geladeira, ferro de passar, máquina de lavar e chuveiro elétrico. A comunidade em estudo possui 26 casas, uma escola ( $180 \mathrm{kWh} / \mathrm{mês}$ ) e uma igreja ( $180 \mathrm{kWh} / \mathrm{mês})$ e o sistema será dimensionado para atender cada uma dessas unidades e nenhuma delas poderá consumir mensalmente mais que o limite. Considerando, o conjunto casas, escola e igreja, o consumo mensal deve ser de 5040 kWh/mês ou 168 kWh/dia.

Esse valor é obtido através da Equação 3.1 a seguir:

$$
E_{d}=\frac{\left[\left(N_{c} * E_{m}\right)+\left(E_{e}+E_{i}\right)\right]}{N_{d}}
$$

Sendo, $E_{d}$ é a energia consumida por dia pelo conjunto (casas, igreja e escola) em $\mathrm{kWh} / \mathrm{dia}, N_{c}$ representa o número de residências, $E_{m}$ representa o consumo mensal de energia (nesse caso é considerado o limite de consumo de famílias de baixa renda) em kWh/mês, $E_{i}$ é o consumo mensal da escola em $\mathrm{kWh} / \mathrm{mês},{ }_{E_{e}}$ designa o consumo mensal da igreja em $\mathrm{kWh} /$ mês e $N_{d}$ é o numero de dias considerado no mês.

Para determinar a potência do sistema, foi considerada a média mensal da menor irradiação no vilarejo, e a menor irradiação é do mês de dezembro, com um valor de $3,967 \mathrm{kWh} / \mathrm{m}^{2}$. No entanto, se o projeto for dimensionado para este mês (pior caso possível), com certeza ele funcionaria para todos os outros meses que possuem condições mais favoráveis e o sistema produziria automaticamente mais energia.

Com uma irradiação constante de $1,000 \mathrm{~kW} / \mathrm{m}^{2}$ que é a quantidade padrão de radiação utilizada para classificar a capacidade de uma matriz fotovoltaica, foi possível 
determinar o número de horas do sol $(N H S=3,967$ h) por dia utilizando a relação a seguir:

$$
N H S=\frac{I_{m}}{I_{c}}
$$

Então, a potência $(P=42,43 \mathrm{~kW})$ para esse mês foi calculada por:

$$
P=\frac{C_{m}}{N H S}
$$

NHS número de horas do sol, $I_{m}$ é a irradiação do mês considerado e $I_{c}$ ou $I_{s}$ irradiação constante (que é a quantidade padrão de radiação utilizada para classificar a capacidade da matriz fotovoltaica) e $C_{m}$ representa o consumo diária da comunidade.

Considerando os fatores de eficiência mostrado na Tabela 3 dos componentes do sistema fotovoltaico que servem para eventuais perdas, a potência total do sistema será, $P_{t}=56,45 \mathrm{~kW}$. Essa potência é dada pela Equação 3.4 .

$$
P_{t}=\frac{P}{F e}
$$

Tabela 3 - Fatores de eficiência dos componentes do sistema fotovoltaica

\begin{tabular}{cc}
\hline Componentes e Tipo de Perdas no Sistema & $\begin{array}{c}\text { Eficiência } \\
\text { (\%) }\end{array}$ \\
Tipo de módulo (no Rendimendo da Conversão) & 90 \\
Banco de Baterias (na conversão de energia elétrica em & 95 \\
eletroquímica) & 80 \\
$\begin{array}{c}\text { Tipo de Inversor (na conversão de energia CC em CA) } \\
\text { Fiação ou Condutores (na energia que está sendo } \\
\text { transformada em calor) }\end{array}$ & 98 \\
\hline
\end{tabular}

Fonte: (MESSENGER; VENTRE, 2004)

Obs.: $P_{t}$ é a potência total do sistema e $F_{e}$ representa os fatores de eficiência dos componentes. 


\section{Programa HOMER}

\subsection{Descrição Geral}

O programa HOMER (Modelo de Otimização Micropower) é uma ferramenta computacional desenvolvida pelo Laboratório Nacional de Energia Renovável (NREL) dos Estados Unidos cujo obejtivo é auxiliar na concepção de sistemas de microenergia e facilitar a comparação de tecnologias de geração de energia em uma ampla gama de aplicações. Ele modela o comportamento físico de um sistema de microenergia e seu custo de ciclo de vida (custo total de instalação e operação do sistema ao longo de sua vida útil). HOMER pode modelar sistemas de microenergia conectados ou não à rede que servem a cargas elétricas e/ou térmicas, e compreendendo qualquer combinação de módulos fotovoltaicos (PV), turbinas eólicas, energia de biomassa, geradores de motores alternativos, turbinas hidráulicas, células de combustível, baterias e armazenamento de hidrogênio. Fontes de energia renováveis aumentam a complexidade porque a sua produção de energia pode ser intermitente, sazonal e não descartável, e a disponibilidade de recursos renováveis pode ser incerta. O programa foi projetado para superar todos esses desafios. Ele realiza três tarefas principais: "Simulação, Otimização e Análise de Sensibilidade". Muitas informações citadas aqui foram extraídas do capítulo de Lambert et al., 2006.

\subsubsection{Simulação}

O processo de simulação determina como uma determinada configuração do sistema, uma combinação de componentes de tamanhos específicos e uma estratégia operacional que define como esses componentes funcionam em conjunto, se comportariam em uma determinada configuração por um longo período de tempo. O programa pode simular uma grande variedade de configurações de sistemas de microenergia, compreendendo qualquer conjunto de combinação de PV, uma ou mais turbinas eólicas, uma turbina hidráulica, até três geradores, um banco de bateria, um conversor CA-CC, um eletrolisador e um tanque de armazenamento de hidrogênio. A Figura 14 mostra arquitetura do sistema de microenergia que o programa HOMER simulou para este estudo. 


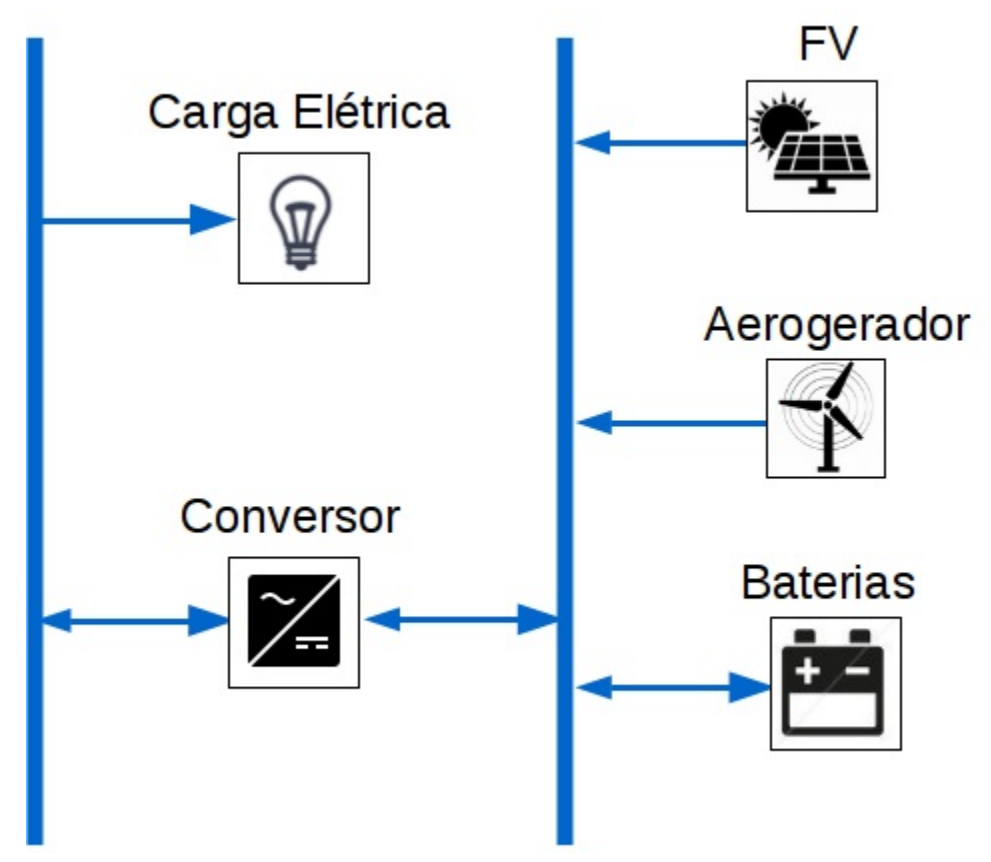

Figura 14 - Arquitetura do sistema fotovoltaico-eólica simulado

O processo de simulação tem dois propósitos. Primeiro, determinar se o sistema é viável. O sistema é viável se puder servir adequadamente as cargas elétricas e térmicas e satisfazer quaisquer outras restrições impostas pelo modelador. Em segundo lugar, estima-se o custo do ciclo de vida do sistema, que é o custo total de instalação e operação do sistema ao longo de sua vida útil. Este custo de ciclo de vida é uma métrica conveniente para comparar a economia de várias configurações do sistema.

\subsubsection{Otimização}

No processo de otimização, HOMER simula muitas configurações de sistemas diferentes em busca da que satisfaz as restrições técnicas ao menor custo do ciclo de vida. A otimização determina o valor ótimo das variáveis sobre as quais o designer do sistema tem controle, como o mix de componentes que compõem o sistema e o tamanho ou a quantidade de cada um. No HOMER, a melhor configuração de sistema possível ou ideal é aquela que satisfaz as restrições especificadas pelo usuário com o menor custo total líquido atual.

O objetivo do processo de otimização é determinar o valor ótimo de cada variável de decisão que interessa ao modelador. Uma variável de decisão é uma variável para o qual HOMER pode considerar múltiplos valores possíveis em seu processo de otimização. As variáveis de decisão no HOMER podem incluir entre outros:

a. O tamanho do conjunto PV;

b. O número de turbinas eólicas; 

c. O número de baterias;
d. O tamanho do conversor CA - CC;
e. O tamanho da eletrólise;
f. O tamanho do tanque de armazenamento de hidrogênio.

\subsubsection{Análise de Sensibilidade}

No processo de análise de sensibilidade, HOMER executa várias otimizações sob uma gama de suposições de entrada para avaliar os efeitos da incerteza ou mudanças nos inputs do modelo. A análise de sensibilidade ajuda a avaliar os efeitos da incerteza ou das variáveis sobre as quais o designer não tem controle, como a velocidade média do vento, o preço de energia da rede, o futuro preço do combustível, a taxa de juros ou a vida útil da matriz fotovoltaica. Uma análise de sensibilidade revela quão sensíveis são as saídas para as mudanças nos insumos. Se um designer de sistema não tiver certeza do valor de uma determinada variável, ele ou ela pode inserir vários valores cobrindo o intervalo provável e ver como os resultados variam nesse intervalo. Mas a análise de sensibilidade tem aplicações além de lidar com a incerteza. Um designer de sistemas pode usar a análise de sensibilidade para avaliar as compensações e responder a perguntas como: Quanto investimento de capital adicional é necessário para atingir $50 \%$ ou $100 \%$ de produção de energia renovável? Um planejador de energia pode determinar quais tecnologias, ou combinações de tecnologias, são ideais em condições diferentes.

\subsection{Formulação Energética}

Para HOMER, carga se refere a uma demanda por energia elétrica ou térmica. Servindo as cargas é a razão para a existência de sistemas de microenergia, de modo que a modelagem de tal sistema começa com a modelagem da carga ou cargas que o sistema deve servir. O programa modela três tipos de cargas: Carga Primária, Carga Deferível e Carga Térmica. A Carga Primária é a demanda elétrica que deve ser atendido de acordo com um horário específico. Carga Deferível é a demanda elétrica que pode ser servido a qualquer momento dentro de um determinado período de tempo. A Carga Térmica é a procura de calor. Para atender as cargas é preciso de recursos energéticos. O termo recurso se aplica a qualquer coisa que vem de fora do sistema e que é usado para gerar energia elétrica ou térmica. Isso inclui os quatro recursos renováveis (solar, eólica, hidráulica e biomassa), bem como qualquer combustível utilizado pelos componentes do sistema. 


\subsubsection{Recurso Solar no Programa}

O recurso solar depende fortemente da latitude e do clima de determinado local. Para modelar um sistema contendo uma matriz fotovoltaica, o designer do HOMER deve fornecer os dados do recurso solar para o local em estudo. Estes dados indicam a quantidade de radiação solar global (radiação direta do sol, mais radiação difusa proveniente de todas as partes do céu) que atinge a superfície da terra em um ano típico. Os dados podem ser de três formas: radiação solar global média horária na superfície horizontal $\left(\mathrm{kW} / \mathrm{m}^{2}\right)$, média mensal da radiação solar global na superfície horizontal $\left(\mathrm{kWh} / \mathrm{m}^{2} / \mathrm{dia}\right)$ ou clearness index (índice de clareza) médio mensal. O clearness index é a razão entre a radiação solar que atinge a superfície da terra e a radiação solar que atinge o topo da atmosfera. Um número entre zero(0) e um(1), o índice de clareza é uma medida da transmissividade da atmosfera. A Tabela 4 mostra os dados simulados do recurso solar da localidade em estudo, esses dados estão disponíveis na base de dados do METEORONORM 7.

Tabela 4 - Recurso Solar do vilarejo em estudo

\begin{tabular}{|c|c|c|c|c|c|c|c|c|c|c|c|c|}
\hline \multirow[b]{2}{*}{ Me } & \multicolumn{12}{|c|}{ Dados do Recurso Solar } \\
\hline & Jan & Fev & Mar & Abr & Mai & Jun & Jul & Ago & Sep & Out & Nov & Dez \\
\hline IC & 0,44 & 0,43 & 0,54 & 0,58 & 0,61 & 0,61 & 0,68 & 0,60 & 0,55 & 0,49 & 0,41 & 0,40 \\
\hline RD & 4,40 & 4,47 & 5,70 & 5,87 & 5,87 & 5,63 & 6,40 & 5,97 & 5,63 & 5,07 & 4,10 & 3,97 \\
\hline
\end{tabular}

Se o usuário optar por fornecer dados mensais de recursos solares, HOMER gera dados sintéticos de radiação solar global por hora usando um algoritmo desenvolvido por (GRAHAM; HOLLANDS, 1990). As entradas desse algoritmo são os valores médios mensais de radiação solar e a latitude. A saída é um conjunto de dados de 8760 horas com características estatísticas semelhantes as dos conjuntos de dados reais medidos. Uma dessas propriedades estatísticas é a autocorrelação, que é a tendência de um dia ser semelhante ao dia anterior e de uma hora ser semelhante à hora anterior.

Obs.: $\boldsymbol{M e}=$ meses, $\boldsymbol{I C}=$ Índice de clareza (clearness index) sem unidade e $\boldsymbol{R} \boldsymbol{D}=$ Radiação Diária em $\mathrm{kWh} / \mathrm{m}^{2} /$ dia .

\subsubsection{Recurso Eólico no Programa}

O recurso eólico depende dos padrões de circulação atmosférica em grande escala e das influências geográficas. Para modelar um sistema que compreende uma ou mais turbinas eólicas, o modelador deve fornecer dados de recursos eólicos indicando as velocidades de vento que as turbinas experimentariam em um ano típico. O usuário pode fornecer dados de velocidade do vento mensal, se disponível. Caso 
contrário, o HOMER pode gerar dados sintéticos por hora a partir de 12 velocidades médias mensais do vento e quatro parâmetros estatísticos adicionais: o fator de forma de Weibull, o fator de autocorrelação, a intensidade do padrão diurno e a hora da velocidade máxima do vento. Na Tabela 5 são apresentados as médias mensais da velocidade do vento e na Tabela 6 os parâmetros estatísticos adicionais para a localidade em estudo. $O$ fator de forma Weibull é uma medida da distribuição das velocidades do vento ao longo do ano. $O$ fator de autocorrelação é uma medida de quão fortemente a velocidade do vento em uma hora tende a depender da velocidade do vento na hora anterior. A intensidade diurna do padrão e a hora da velocidade máxima do vento indicam a magnitude e a fase, respectivamente, do padrão diário médio na velocidade do vento. HOMER fornece valores padrão para cada um desses parâmetros.

Tabela 5 - Recurso Eólico do vilarejo em estudo

\begin{tabular}{llllllllllllll}
\hline \multicolumn{11}{c}{ Dados do Recurso Eólico } \\
Me & Jan & Fev & Mar & Abr & Mai & Jun & Jul & Ago & Set & Out & Nov & Dez \\
VV & 6,41 & 6,56 & 7,09 & 6,62 & 6,19 & 7,10 & 7,12 & 6,79 & 7,75 & 5,38 & 5,67 & 6,59 \\
\hline
\end{tabular}

Tabela 6 - Parâmetros estatísticos simulados pelo HOMER dovilarejo em estudo

\begin{tabular}{cc}
\hline Parâmetros estatísticos & \\
Altitude $(\mathrm{m})$ & 36 \\
Altura do anemômetro $(\mathrm{m})$ & 10 \\
Weibull k & 2 \\
Fator de autocorrelação & 0,85 \\
Intensidade diurna padrão & 0,25 \\
Padrão médio da velocidade do vento (pico) & 15 \\
\hline
\end{tabular}

O usuário indica a altura do anemômetro, ou seja, a altura acima do solo, na qual os dados de velocidade do vento foram medidos ou para os quais foram estimados. Se a altura do cubo da turbina eólica for diferente da altura do anemômetro, HOMER calcula a velocidade do vento na altura do cubo da turbina usando a lei logarítmica, que pressupõe que a velocidade do vento é proporcional ao logaritmo da altura acima do solo, o que pressupõe que a velocidade do vento varia exponencialmente com a altura. Para usar a lei logarítmica, o usuário insere o comprimento de rugosidade da superfície, que é um parâmetro que caracteriza a rugosidade do terreno circundante.

Obs.: Me representa os meses e $\boldsymbol{V} \boldsymbol{V}$ é a velocidade média do vento em $(\mathrm{m} / \mathrm{s})$ 


\subsection{Tecnologias e componentes do Programa}

Para projetar sistemas de microenergia, o programa possui várias tecnologias e componentes que são embutidos, tais como, Matriz Fotovoltaica, Turbina eólica, Turbina Hidráulica, Geradores, Banco de Bateria, Grid, Caldeira, Conversor, Eletrólise e Tanque de Hidrogênio. O uso de uma ou várias tecnologias depende muito do que o modelador pretende. Aqui são discutidas apenas as tecnologias que são usadas neste estudo. As tecnologias usadas pelo programa gera, entrega, converte ou armazena modelos de energia. Entre estas tecnologias, três geram eletricidade a partir de fontes renováveis intermitentes: módulos fotovoltaicos, turbinas eólicas e turbinas hidráulicas. Os módulos fotovoltaicos convertem a radiação solar em eletricidade de CC. As turbinas eólicas convertem a energia eólica em eletricidade CA ou CC. As turbinas hidráulicas convertem a energia da água corrente em eletricidade de corrente alternada ou contínua. O programa só pode modelar instalações hidráulicas de rios, ou seja, aquelas que não compõem um reservatório de armazenamento.

Outros três tipos de tecnologias, geradores, Grid e caldeiras, são fontes de energia dispensáveis, isto é, o sistema pode controlá-los conforme o necessário. Geradores consomem combustível para produzir eletricidade CA ou CC. Um generador também pode produzir energia térmica através de recuperação de calor residual. A Grid fornece energia elétrica de corrente alternada para um sistema conectado à rede e também pode aceitar eletricidade excedente do sistema. As caldeiras consomem combustível para produzir energia térmica. Depois, encontra-se os conversores e eletrolisadores que convertem energia elétrica em outra forma. Os conversores convertem electricidade CA para CC ou vice-versa. Os eletrolisadores convertem a eletricidade em excesso em corrente alternada ou em eletricidade em hidrogênio por meio da eletrólise da água. O sistema pode armazenar o hidrogênio e usá-lo como combustível para um ou mais geradores. Finalmente, os componentes de armazenamento de energia: baterias e tanques de armazenamento de hidrogênio. As baterias armazenam eletricidade CC. Os tanques de hidrogênio armazenam hidrogênio da eletrólise para alimentar um ou mais geradores.

\subsubsection{Matriz Fotovoltaica}

HOMER modela a matriz fotovoltaica como um dispositivo que produz eletricidade de CC em proporção direta à radiação solar global incidente sobre ela, independente de sua temperatura e da voltagem a que está exposta. O programa calcula a potência de saída da matriz fotovoltaica usando a Equação 4.1 a seguir referenciada por (LAMBERT et al., 2006): 


$$
P_{P V}=\left(f_{P V} * y_{P V}\right) *\left(\frac{I_{T}}{I_{S}}\right),
$$

Onde, $f_{P V}$ é o fator de redução de energia fotovoltaica ou (desclassificação), $Y_{P V}$ a capacidade nominal da matriz fotovoltaica $(\mathrm{kW}), I_{T}$ a radiação solar global incidente na superfície da matriz fotovoltaica $\left(\mathrm{kW} / \mathrm{m}^{2}\right)$, e $I_{S}$ é $1 \mathrm{~kW} / \mathrm{m}^{2}$, que é a quantidade padrão de radiação utilizada para classificar a capacidade da matriz fotovoltaica. Para cada hora do ano, HOMER calcula a radiação solar global incidente sobre o conjunto fotovoltaico usando o modelo HDKR (Hay-Davies-Klucher-Riendl) de (DUFFIE; BECKMAN, 1991) que faz uma estimativa do feixe absolvido, a radiação solar difusa e refletida no solo pela superfície inclinada. Este modelo leva em consideração o valor atual do recurso solar (a radiação solar global incidente em uma superfície horizontal), a orientação do conjunto fotovoltaico, a localização na superfície da terra, a época do ano e a hora do dia. A orientação da matriz pode ser fixa ou pode variar de acordo com um de vários esquemas de rastreio. No HOMER, o tamanho de uma matriz fotovoltaica é sempre especificado em termos de capacidade nominal. A capacidade nominal (às vezes chamada de capacidade de pico) de um conjunto fotovoltaico é a quantidade de energia que produziria sob condições de teste padrão de $1 \mathrm{~kW} / \mathrm{m}^{2}$ de irradiância e uma temperatura de painel de $25^{\circ} \mathrm{C}$. A capacidade nominal representa tanto a área como a eficiência do módulo fotovoltaico, portanto nenhum dos dois parâmetros aparece explicitamente no programa.

O fator de redução é um fator de escala destinado a contabilizar os efeitos de poeira no painel, perdas de arame, temperatura elevada ou qualquer outra coisa que faria com que a saída do conjunto fotovoltaico desviasse do esperado em condições ideais. HOMER não explica o fato de que a potência de saída de um conjunto fotovoltaico diminui com o aumento da temperatura do painel. Na realidade, a saída de uma matriz fotovoltaica depende fortemente e não linearmente da tensão à qual está exposta. $O$ ponto de potência máxima (a tensão na qual a potência é maximizada) depende da radiação solar e da temperatura. Se a matriz fotovoltaica estiver conectada diretamente a uma carga de CC ou a um banco de baterias, ela será freqüentemente exposta a uma voltagem diferente do ponto de potência máxima e o desempenho sofrerá.

\subsubsection{Turbina Eólica}

HOMER modela uma turbina eólica como um dispositivo que converte a energia cinética do vento em eletricidade de corrente alternada ou elétrica de acordo com uma curva de potência particular, que é um gráfico da potência em relação à velocidade do vento à altura do cubo. A Figura 15 é um exemplo de curva de potência. HOMER 
assume que a curva de potência aplica-se a uma densidade de ar padrão de 1,225 $\mathrm{kg} / \mathrm{m}^{3}$, o que corresponde a condições normais de temperatura e pressão.

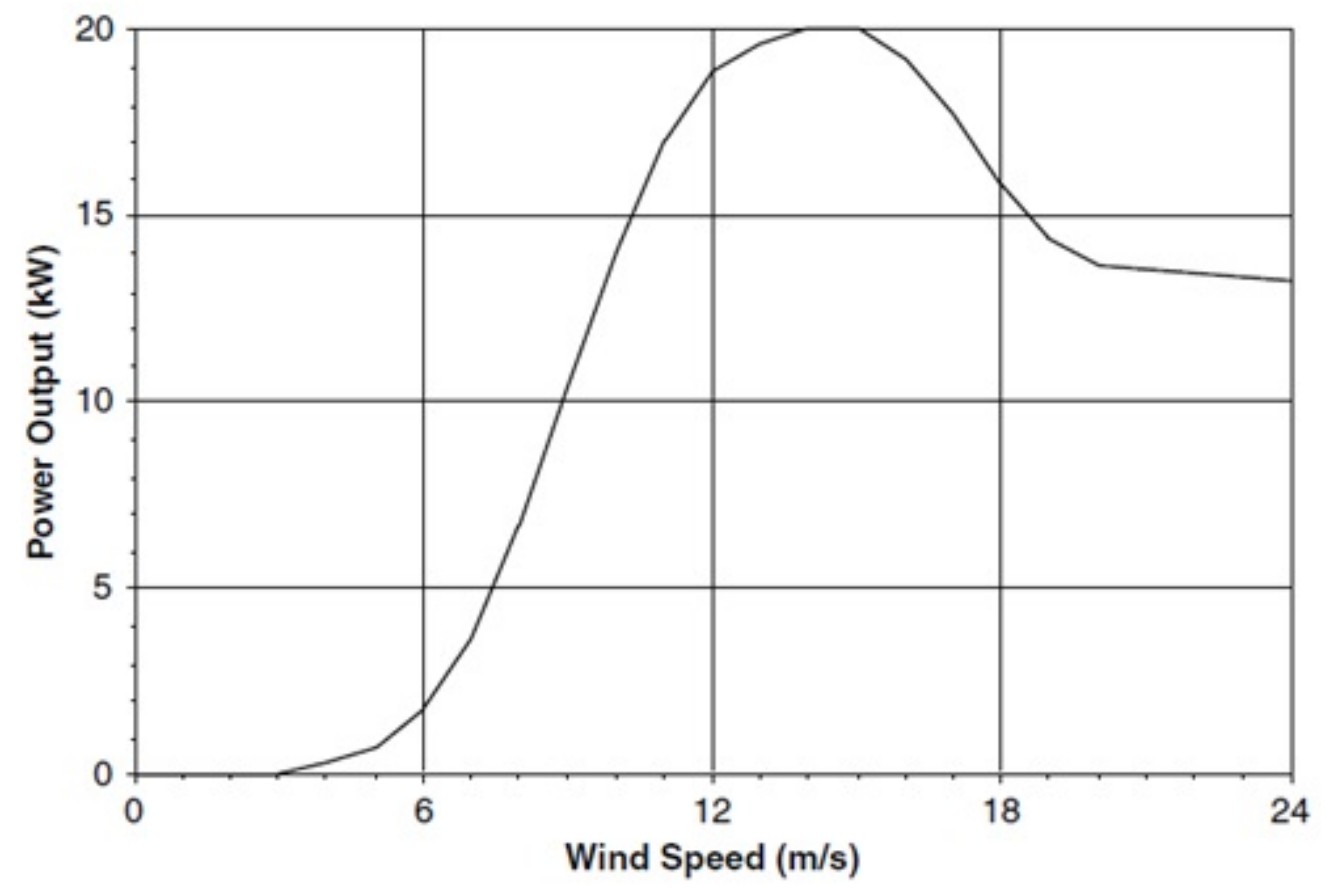

Figura 15 - Exemplo da curva de potência de uma turbina eólica.

Fonte: (LAMBERT, TOM et al., 2006)

A cada hora, HOMER calcula a potência da turbina eólica em um processo de quatro etapas. Primeiro, determina a velocidade média do vento para a hora na altura do anemômetro, referindo-se aos dados do recurso eólico. Segundo, calcula a velocidade do vento correspondente na altura do cubo da turbina usando a lei logarítmica ou a lei de potência. Terceiro, refere-se à curva de potência da turbina para calcular sua potência naquela velocidade do vento assumindo a densidade de ar padrão. E por último, ele multiplica esse valor de saída de potência pela razão de densidade do ar, que é a proporção da densidade de ar real para a densidade de ar padrão.

\subsubsection{Banco de Baterias}

O banco de baterias é uma coleção de uma ou mais baterias individuais. HOMER modela uma única bateria como um dispositivo capaz de armazenar uma certa quantidade de eletricidade de CC a uma eficiência energética fixa de ida e volta, com limites quanto à rapidez com que pode ser carregada ou descarregada, quão profundamente ela pode ser descarregada sem causar danos e a quantidade de energia pode percorrê-la antes de ser substituída. HOMER assume que as propriedades das baterias permanecem constantes durante toda a sua vida útil e não são afetadas por fatores externos como a temperatura. No HOMER, as principais propriedades físicas da 
bateria são sua tensão nominal, curva de capacidade, curva de tempo de vida, estado mínimo de carga e eficiência de ida e volta.

O programa modela o banco de bateria como um sistema de dois tanques ao invés de um e isso provoca dois efeitos. Primeiro, significa que a bateria não pode ser totalmente carregada ou descarregada de uma só vez, uma carga completa requer uma quantidade infinita de tempo a uma corrente de carga que assintoticamente se aproxima de zero. E por último, isso significa que a capacidade da bateria de carregar e descarregar depende não só do seu estado atual de carga, mas também de seu histórico recente de carga e descarga. Uma bateria carregada rapidamente a $80 \%$ do estado de carga será capaz de uma taxa de descarga mais alta do que a mesma bateria rapidamente descarregada para $80 \%$, uma vez que terá um nível mais elevado no seu tanque disponível. HOMER acompanha os níveis nos dois tanques a cada hora e modela ambos os efeitos.

A Figura 16 mostra uma curva de vida útil típica de uma bateria de chumbo-ácido de ciclo profundo. O número de ciclos até a falha (mostrado no gráfico como pontos mais claros) cai acentuadamente com o aumento da profundidade de descarga. Para cada ponto desta curva, pode-se calcular a taxa de vida útil (a quantidade de energia que circulou através da bateria antes da falha) encontrando o produto do número de ciclos, a profundidade de descarga, a tensão nominal da bateria e o limite da capacidade máxima da bateria. A curva da taxa de vida útil mostrada na Figura $16 \mathrm{com}$ os pontos pretos, mostra uma dependência muito mais fraca da profundidade do ciclo. O programa faz a suposição simplificadora de que o caudal de vida é independente da profundidade de descarga. O valor que HOMER sugere para esta taxa de vida é a média dos pontos da curva de tempo de vida acima do estado mínimo de carga, mas esse valor pode ser modificado para ser mais ou menos conservador. 


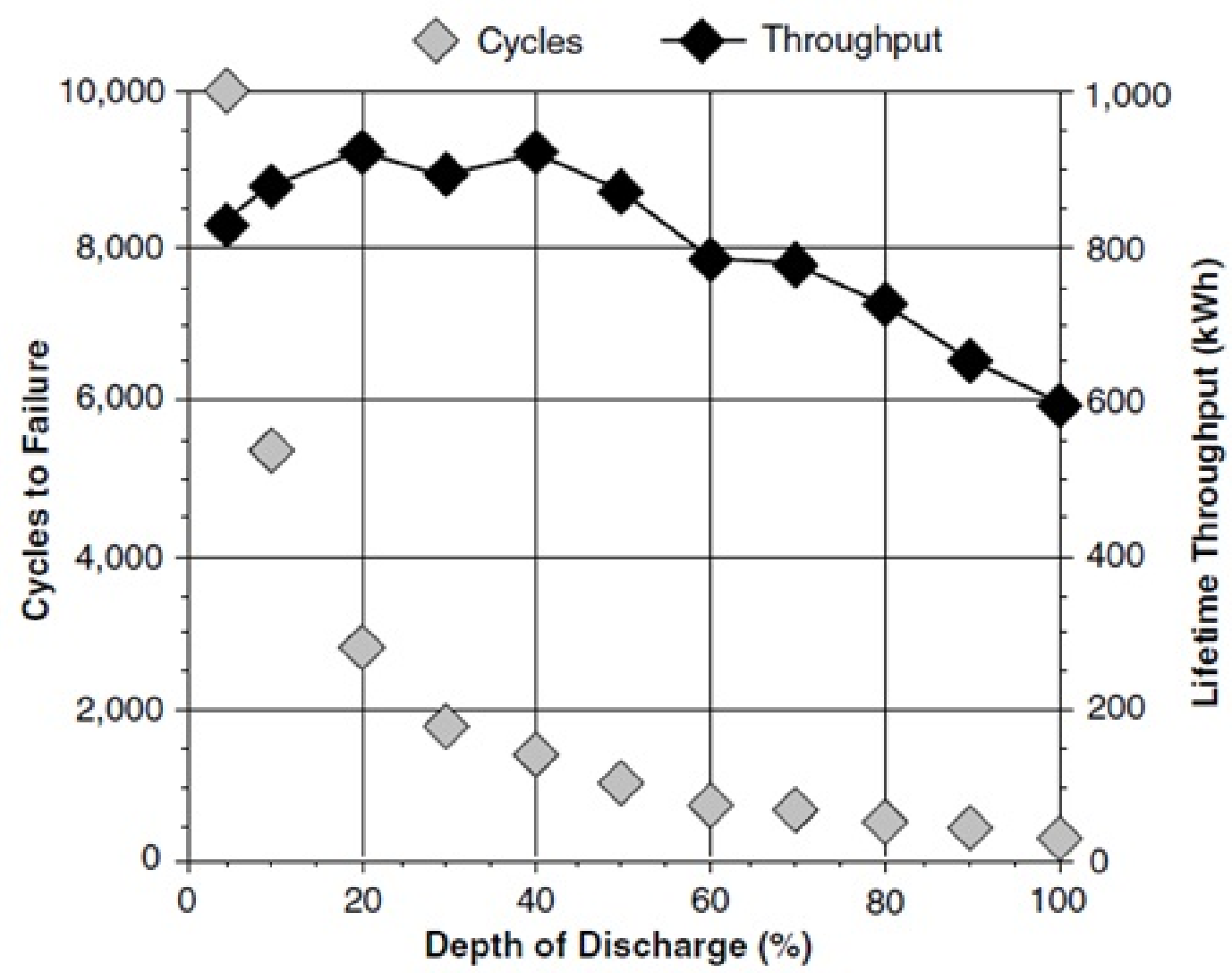

Figura 16 - Curva de vida para o modelo de bateria de ciclo profundo US-250.

Fonte: (LAMBERT, TOM et al., 2006)

A suposição de que a taxa de vida útil é independente da profundidade do ciclo significa que HOMER pode estimar a vida útil do banco de baterias simplesmente monitorando a quantidade de energia que circula através dela, sem ter que considerar a profundidade dos vários ciclos de carga-descarga. HOMER calcula a vida do banco de baterias em anos usando a Equação 4.2 a seguir:

$$
R_{\text {batt }}=\min \left[\frac{N_{\text {batt }} * Q_{\text {lifetime }}}{Q_{\text {thrpt }}}, R_{\text {batt }, f}\right]
$$

Onde $N_{b a t t}$ é o número de baterias no banco de bateria, $Q_{\text {lifetime }}$ a taxa de vida de uma única bateria, $Q_{t h r p t}$ a taxa de transferência de energia anual (o montante total de energia que percorre o banco de baterias em um ano) e $R_{b a t t, f}$ a duração do flutuador da bateria (a vida máxima, independentemente da vazão). O tempo de vida útil do banco de baterias para o vilarejo em estudo é de 4 anos.

\subsubsection{Conversor}

Um conversor é um dispositivo que converte energia elétrica de CC para CA em um processo chamado inversão, e/ou de CA para CC em um processo chamado 
retificação. HOMER pode modelar os dois tipos comuns de conversores: de estado sólido e rotativo. O tamanho do conversor, que é uma variável de decisão, referese à capacidade do inversor, ou seja, a quantidade máxima de energia CA que o dispositivo pode produzir por meio da inversão de energia CC. O usuário especifica a capacidade do retificador, que é a quantidade máxima de energia de CC que o dispositivo pode produzir por retificação de energia CA, como uma porcentagem da capacidade do inversor. A capacidade do retificador não é, portanto, uma variável de decisão separada. HOMER assume que as capacidades do inversor e do retificador não são capacidades de sobretensão que o dispositivo possa suportar apenas por curtos períodos de tempo, mas sim capacidades contínuas que o dispositivo pode suportar durante o tempo necessário. As propriedades físicas finais do conversor são suas eficiências de inversão e retificação, que HOMER assume constantes.

\subsection{Modelo Econômico}

A economia desempenha um papel integral no processo de simulação do HOMER, onde o sistema opera de modo a minimizar o custo total líquido atual em seu processo de otimização e procura a configuração do sistema com o menor custo total líquido total. HOMER usa o custo líquido total atual (NPC) para representar o custo do ciclo de vida de um sistema. O NPC total condensa todos os custos e receitas que ocorrem dentro da vida útil do projeto em um montante fixo em dólares de hoje, com fluxos de caixa futuros descontados de volta ao presente usando a taxa de desconto. $O$ NPC inclui os custos de construção inicial, substituição de componentes, manutenção, combustível, mais o custo de compra de energia da rede e custos diversos, como multas resultantes de emissões de poluentes.

HOMER usa as seguintes equações para calcular o custo líquido total atual.

$$
C_{N P C}=\frac{C_{a n n, t o t}}{C R F\left(i, R_{\text {proj }}\right)},
$$

Onde $C_{a n n, t o t}$ é o custo anualizado total, $i$ a taxa de juros real anual (taxa de desconto), $R_{p r o j}$ a vida útil do projeto e $C R F$ é o fator de recuperação de capital, dado pela Equação 4.4:

$$
C R F(i, N)=\frac{i(1+i)^{N}}{(1+i)^{N}-1}
$$

Onde $i$ é a taxa de juros real anual e $N$ é o número de anos. O programa usa a Equação 4.5 abaixo para calcular o custo normalizado de energia: 


$$
C O E=\frac{C_{a n n, t o t}}{E_{\text {prim }}+E_{\text {def }}+E_{\text {grid,sales }}},
$$

Onde $C_{a n n, t o t}$ é o custo anualizado total, $E_{p r i m}$ e $E_{\text {def }}$ são os montantes totais de carga primária e deferível, respectivamente, que o sistema abastece por ano, e $E_{\text {grid,sales }}$ é a quantidade de energia vendida à rede por ano. $O$ denominador da Equação 4.5 é uma expressão da quantidade total de energia útil que o sistema produz por ano. $O$ custo normalizado de energia é, portanto, o custo médio por quilowatthora de energia elétrica útil produzida pelo sistema.

Como destacamos nesse capítulo, existem diversas ferramentas computacionais no mercado para projeção e avaliação de sistemas de energias. Cada uma delas tem suas próprias características e isso pode definir o seu melhor uso. Para projeção de sistemas híbridos aproveitando recursos locais para atender cargas elétricas de regiões isoladas, HOMER se mostra muito eficiente. Em termos de avaliação técnica, analisando demanda elétrica, perfil de carga, excesso de eletricidade, "unmet electric load" ou carga não atendida, projetar a capacidade do sistema e outras avaliações econômicas, definindo e analisando todos os tipos de custos envolvidos no sistema, o HOMER se apresenta como uma das melhoras ferramentas. Na verdade, o HOMER é antes de tudo um modelo econômico, o usuário ou modelador pode usá-lo para fazer comparação de diferentes combinações que possuem tamanhos e quantidades de componentes e para explorar como as variações na disponibilidade de recursos e nos custos do sistema afetam o custo de instalação e operação de diferentes projetos de sistema. É uma ferramenta que também auxilia na compreensão e diminuição dos efeitos das incertezas ou mudanças nos insumos com uma análise de sensibilidade. A sua lógica de simulação é menos detalhada como a de outras ferramentas, mas em compensação é mais flexível, oferecendo maior diversidade de sistemas para simulação. Todos esses fatores são importantes para ajudar o modelador a tomar decisão sobre a melhor configuração do sistema. Por isso, na projeção do sistema híbrido do vilarejo em estudo, o emprego dessa ferramenta é de suma importância. 


\section{Resultados da Simulação}

Nesta seção, são apresentadas o sistema proposto com todos os seus componentes, os resultados simulados pelo programa sobre o sistema de energia para 0 vilarejo. Com base em dados históricos de outas comunidades próximas, foram desenvolvidos cenários para delinear possíveis caminhos de desenvolvimento, em particular para a procura de eletricidade nessa comunidade isolada. Tanto a pesquisa quanto os cenários contabilizam fontes de energia, usos de tecnologias para necessidades básicas como cozinhar, iluminação entre outros. Em particular, para examinar os usos produtivos da energia em termos tradicionais e modernos, cenários incorporam usos de energia para educação, saúde, fabricação e entretenimento.

\subsection{Sistema Proposto}

O sistema proposto e simulado para o vilarejo "Paulin/Lacorne" em estudo é formado por uma matriz fotovoltaica, uma turbina eólica, um banco de baterias, um conversor e um controlador de cargas. As duas principais tecnologias do sistema são a matriz fotovoltaica e a turbina eólica responsáveis para converter a radiação solar e a força do vento em energia elétrica. $O$ banco de baterias é um componente do sistema que armazena energia produzida pela matriz fotovoltaica e entregá-la a carga quando não há geração. A sua principal função é garantir a autonomia do sistema nos períodos noturnos e dias chuvosos e/ou nublados quando a matriz fovoltaica não consegue fornecer quantidade de energia suficiente. O inversor converte a corrente CC em CA. A sua função é de ajustar seu sinal de saída com a frequência. E o controlador protege as baterias contra cargas e descargas excessivas. A Figura 17 mostra o sistema desenhado para o vilarejo.

Obs.: De maneira geral, todos os sistemas elétricos devem ser aterrados de acordo com os padrões locais e nacionais e não é diferente para o sistema deste estudo. $\mathrm{O}$ aterramento oferece proteção contra descargas atmosféricas, choques elétricos, picos de tensão e eletricidade estática. 


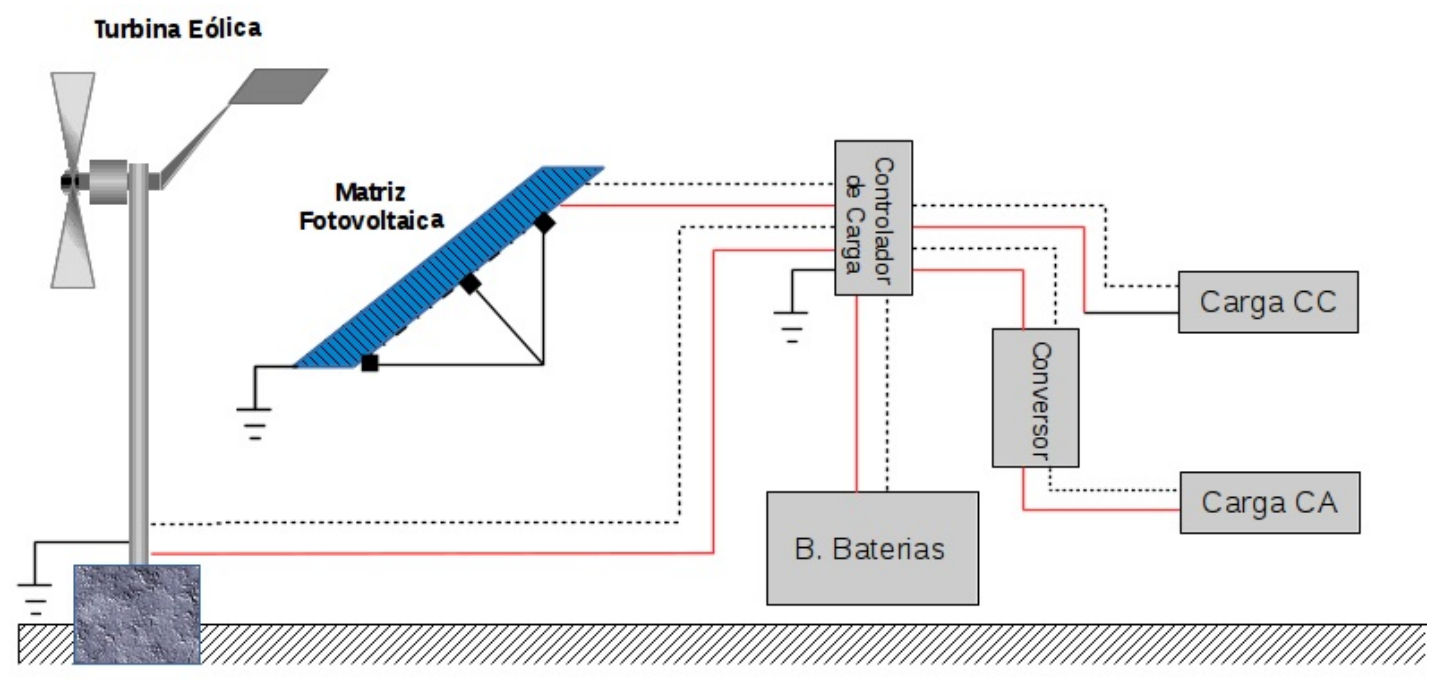

Figura 17 - Sistema proposto para o vilarejo

\subsubsection{Especificações do Sistema Fotovoltaico}

Cada painel do modelo escolhido tem uma potência de $140 \mathrm{Wp}$. Para facilitar um melhor arranjo e com maior facilidade de distribuição, a quantidade de painéis inicialmente dimensionada deve ser encontrada usando a relação abaixo.

$$
Q_{t p}=\frac{P_{p 1} * P_{t}}{P_{u n}}
$$

$Q_{t p}$ representa a quantidade de painéis necessários; $P_{p 1}$ é considerado como uma unidade de painel; $P_{t}$ é a potência total do sistema (W ou kW) e $P_{u n}$ é a potência de uma unidade de painel (Wp). A tabela 7 e as Figuras 18 e 19 apresentam respectivamente as especificações técnicas, o desenho e o modelo do painel escolhido para o projeto.

Tabela 7 - Especificações Técnicas do painel

\begin{tabular}{cc}
\hline Dimensão $(\mathrm{cm})$ & $1470 \times 680 \times 25$ \\
Tipo de célula & Policristalino \\
Potência máxima $(\mathrm{Wp})$ & 140 \\
Voltagem de máxima potência $(\mathrm{V})$ & 18 \\
\hline
\end{tabular}




\begin{tabular}{cc}
\hline Dimensão $(\mathrm{cm})$ & $1470 \times 680 \times 25$ \\
Corrente de máxima potência $(\mathrm{A})$ & 7,77 \\
Eficiência do painel $(\%)$ & 14 \\
Temperatura de operação de célula & $(\stackrel{0}{ } \mathrm{C})$ \\
Número de célula de cada painel & $46 \pm 2$ \\
Vidro, tipo e espessura $(\mathrm{mm})$ & 36 \\
Fabricante & Alta transmissividade, baixo ferro, \\
Vida útil (anos) & temperado, 3,2 \\
& Yingli Solar \\
\end{tabular}

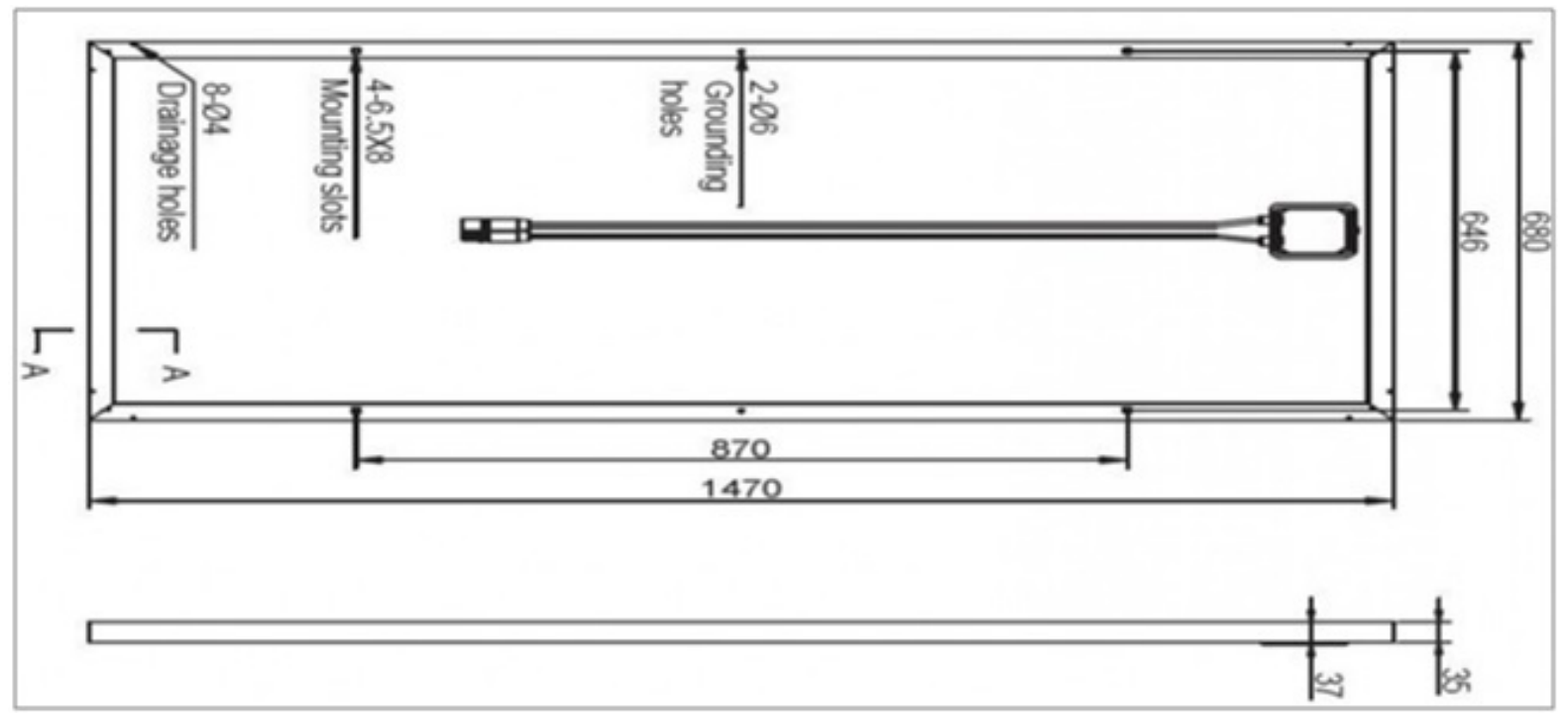

Figura 18 - Desenho do painel solar

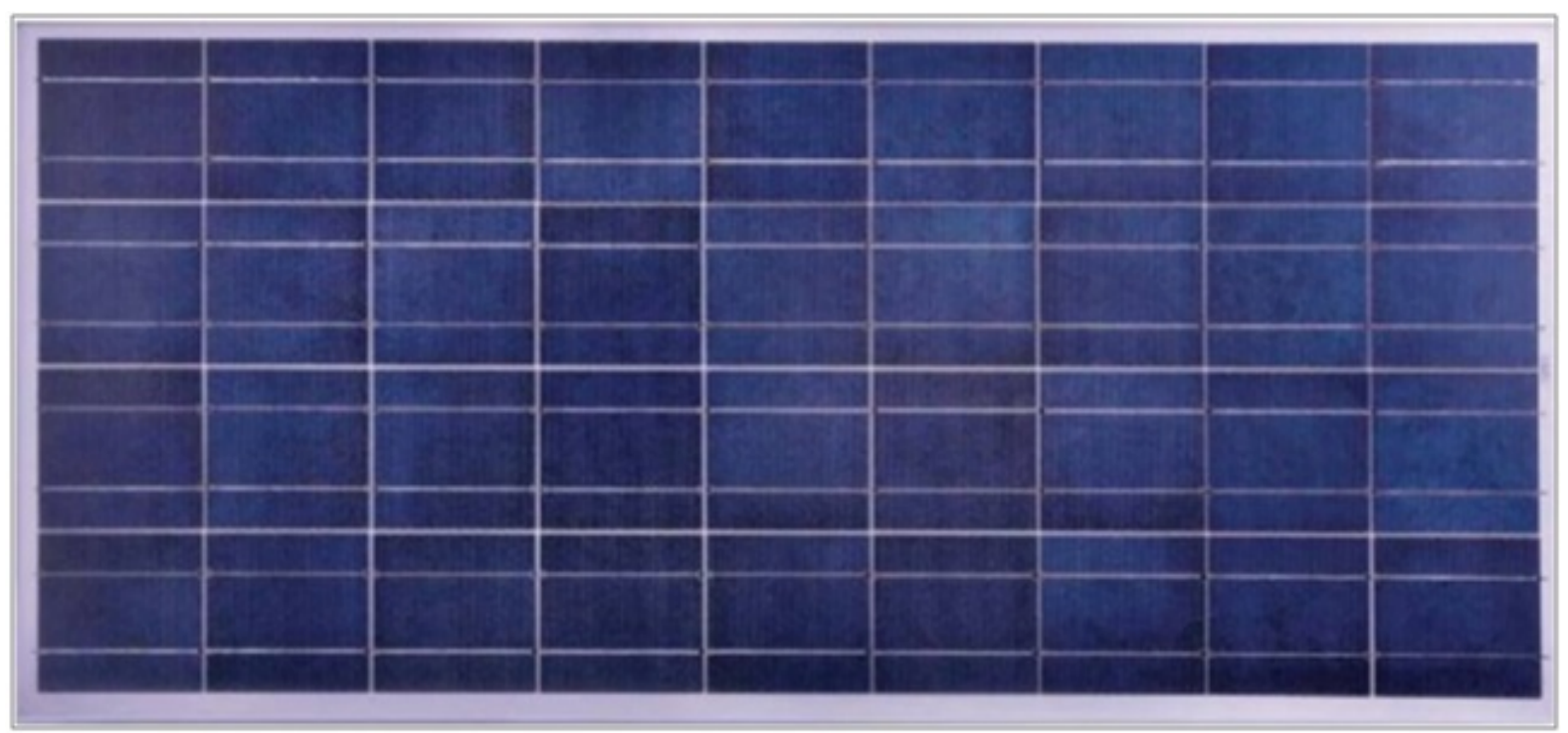

Figura 19 - Modelo de painel usado no projeto 


\subsubsection{Especificações do Sistema Eólico}

A turbina é importante no sistema, ela serve para manter o sistema equilibrado contribuindo nas horas de pico fazendo com que o sistema consiga atender a demanda de carda requerida. Ela pode contribuir para fornecer energia nas horas de pouca radiação como a noite, nos dias nublados e/ou chovosos e assim contribuindo para evitar grandes custos com o banco de bateria. São descritas na Tabela 8 e na Figura 20 as caracteristicas e o modelo da turbina.

O modelo da turbina é Skystream 3.7, é um modelo de turbina projetado para funcionar em locais com velocidades médias de vento menores que 8,5 m/s, condições de vento Classe II da "IEC" (Comissão Eletrotécnica Internacional). A sua instalação em locais com médias de vento superiores acelera o desgaste dos componentes e exige vistoria mais frequentes. A média de velocidade do local em estudo é de $6,04 \mathrm{~m} / \mathrm{s}$ e a maior velocidade como observado na Figura 29 do mês de setembro é de 7,747, ou seja, isso nos permite deduzir que esta é uma turbina adequada para esse projeto em estudo.

Na Figura 21a, é mostrada para cada velocidade média anual do ano como seria a produção energética da turbina. De acordo com a nossa observação, as velocidades mais baixas têm produção menores, já quando a velocidade é mais alta, a turbina teria uma produção mais alta o que nos indica que ventos com velocidade média anual mais altos teriam impactos positivos na produção do sistema. E o desempenho da turbina depende de uma faixa de velocidade que varia entre $5 \mathrm{~m} / \mathrm{s}$ a $25 \mathrm{~m} / \mathrm{s}$, velocidades que não se encontram nessa faixa diminuiriam o desempenho da turbina em termo de potência como pode ser observado na Figura 21b.

Tabela 8 - Especificações da Turbina

\begin{tabular}{cc}
\hline Potência $(\mathrm{kW})$ & 2,4 \\
Modelo & Skytream 3.7 \\
Diâmetro do rotor $(\mathrm{m})$ & 3,72 \\
Área varrida $\left(\mathrm{m}^{2}\right)$ & 10,87 \\
Velocidade nominal $(\mathrm{rpm})$ & $50-325$ \\
Vento nominal $(\mathrm{m} / \mathrm{s})$ & 9,4 \\
Garantia (anos) & 5 \\
\hline
\end{tabular}




\begin{tabular}{cc} 
Potência $(\mathrm{kW})$ & 2,4 \\
Vida útil (anos) & +20 \\
Empuxo do eixo $(\mathrm{N})$ & 2802 \\
Momento fletor $(\mathrm{N} . \mathrm{m})$ & 1532 \\
1 torre de $(\mathrm{cm})$ & $46 \times 30 \times 213$ \\
Cargas calculadas a $(\mathrm{mph}-\mathrm{m} / \mathrm{s})$ & $145-65$ \\
Fabricante & Southwest Windpower \\
\hline
\end{tabular}

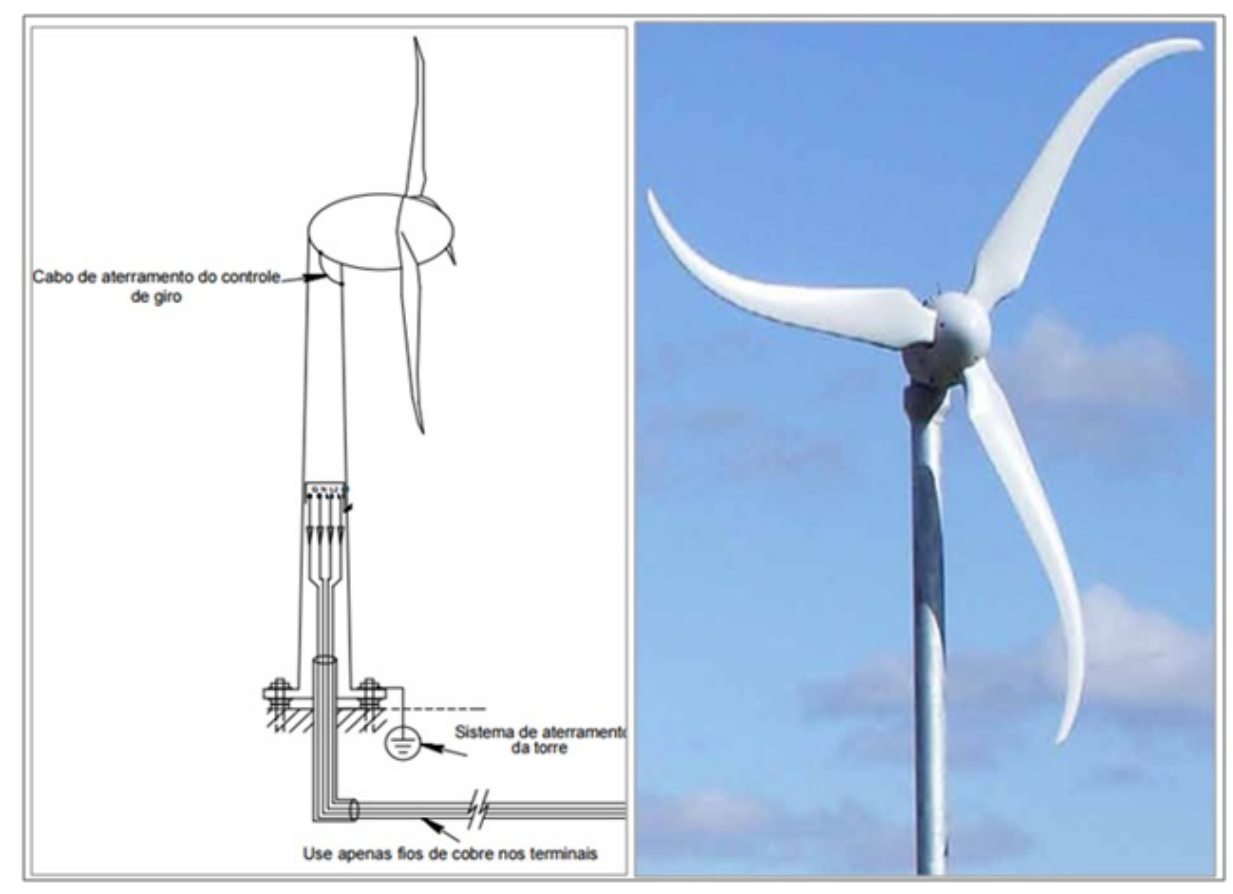

Figura 20 - Desenho do modelo de turbina simulado no sistema
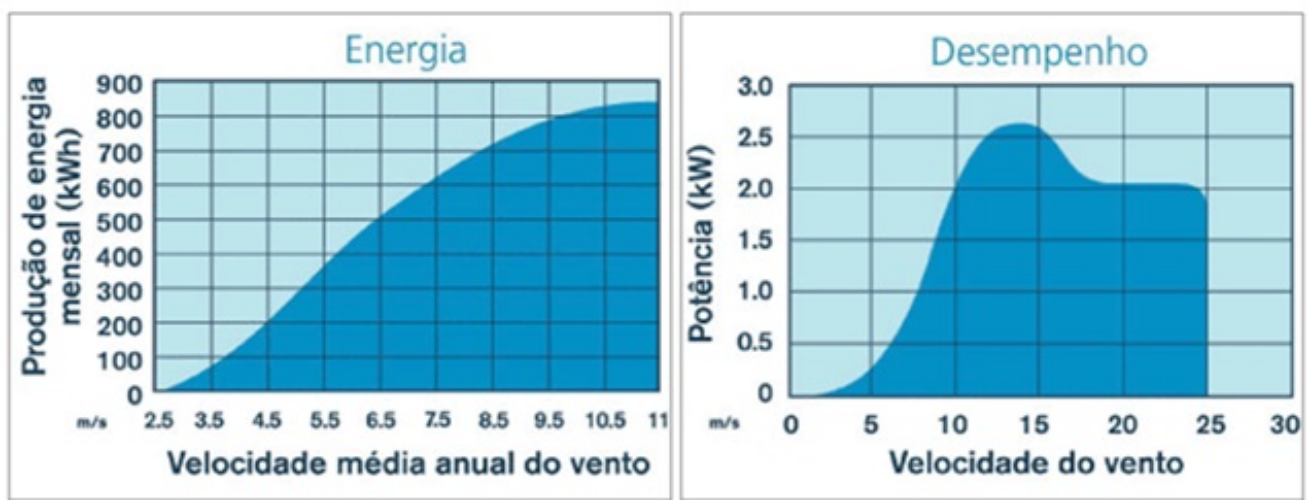

Figura 21 - a) Energia da Turbina no sistema. b) desempenho da turbina no sistema. Fonte: Southwest Windpower

Obs.: Como vimos na Tabela 7, a vida útil desta turbina é 20 anos, de acordo com o fabricante, depois desse período as hélices devem ser substituídas. É um equipamento que não exige manutenção de rotina ou periodica, porém, para prever possíveis 
danos é necessário desligar anualmente as hélices para inspeção identificando possíveis rachaduras e lascas nas bordas das hélices.

\subsubsection{Especificações do Banco de baterias}

Para determinar a quantidade de bateria $\left(Q_{b}\right)$ foi necessária a utilização das equações abaixo:

$$
Q_{b}=\frac{I_{T}}{C_{b}}
$$

$I_{t}$ é a corrente do sistema e $C_{b}$ capacidade da bateria. A equação 5.2 representa a quantidade de bateria para uma tensão de $12 \mathrm{~V}$ (bateria considerada). Para uma tensão de $48 \mathrm{~V}$ (tensão do sistema em estudo), a quantidade de bateria total do sistema ou a partir da equação 5.2, encontramos a equação 5.3.

$$
Q_{t b}=Q_{b} *\left[\frac{T_{s}}{V_{b}}\right]
$$

$Q_{t b}$ representa a quantidade de bateria total do sistema, $T_{s}$ é a tensão do sistema e $V_{b}$ é a voltagem da bateria. As especificações são definidas na tabela 8 e o modelo da bateria é apresentado na Figura 24. Nas Figuras 22 e 23 são apresentadas respectivamente a profundidade de descarga $x$ ciclos e a temperatura de trabalho $x$ vida útil da bateria. Na Figura 22, observamos que quanto menos a bateria descarrega melhor ciclos ela apresenta e quanto mais ela descarrega menor é o ciclo. Já a Figura 23 mostra que a vda útil da bateria depende da temperatura de trabalho. Para temperaturas de cerca de $10^{\circ}$ até $35^{\circ} \mathrm{C}$ mais ou menos, a bateria mantém a sua vida útil em $100 \%$ e quando ela trabalha no ambiente que apresenta temperaturas maiores que $35^{\circ} \mathrm{C}$ a sua vida útil começa a diminuir e para temperatuas entre $70^{\circ} \mathrm{C}$ ou mais, a sua vida útil diminui consideravelmente. $O$ que nos indica que o banco de baterias deve ser instalado num ambiente onde a maior temperatura não deve ultrapassar 35․ A Tabela 9 mostra as especificações das baterias. 


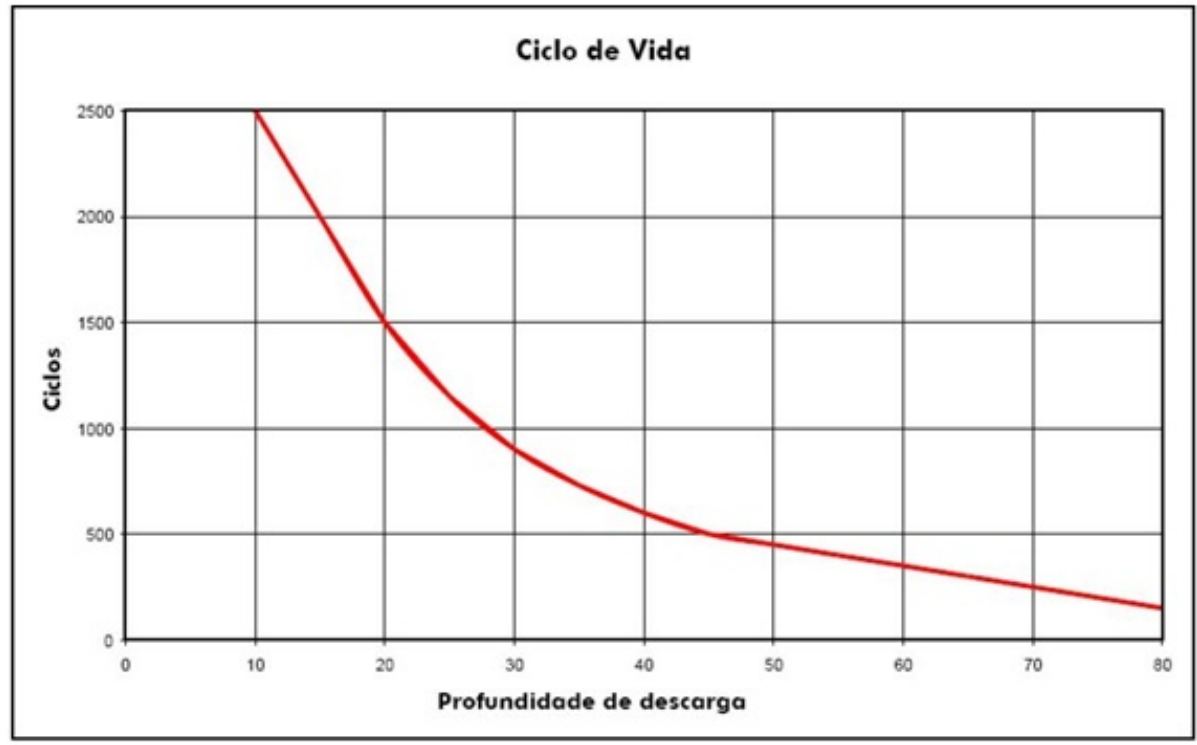

Figura 22 - Profundidade de descarga x ciclos da bateria

Fonte: Neosolar

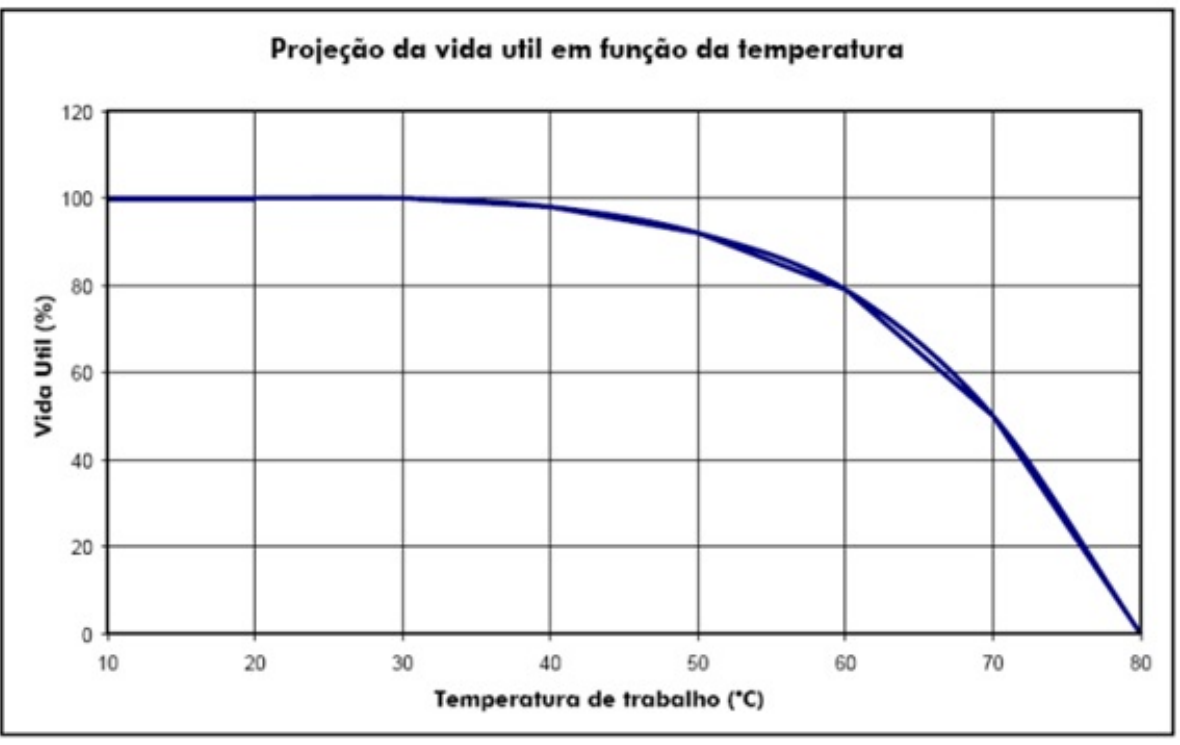

Figura 23 - Temperatura de trabalho $\mathrm{x}$ vida útil da bateria

Fonte: Neosolar 


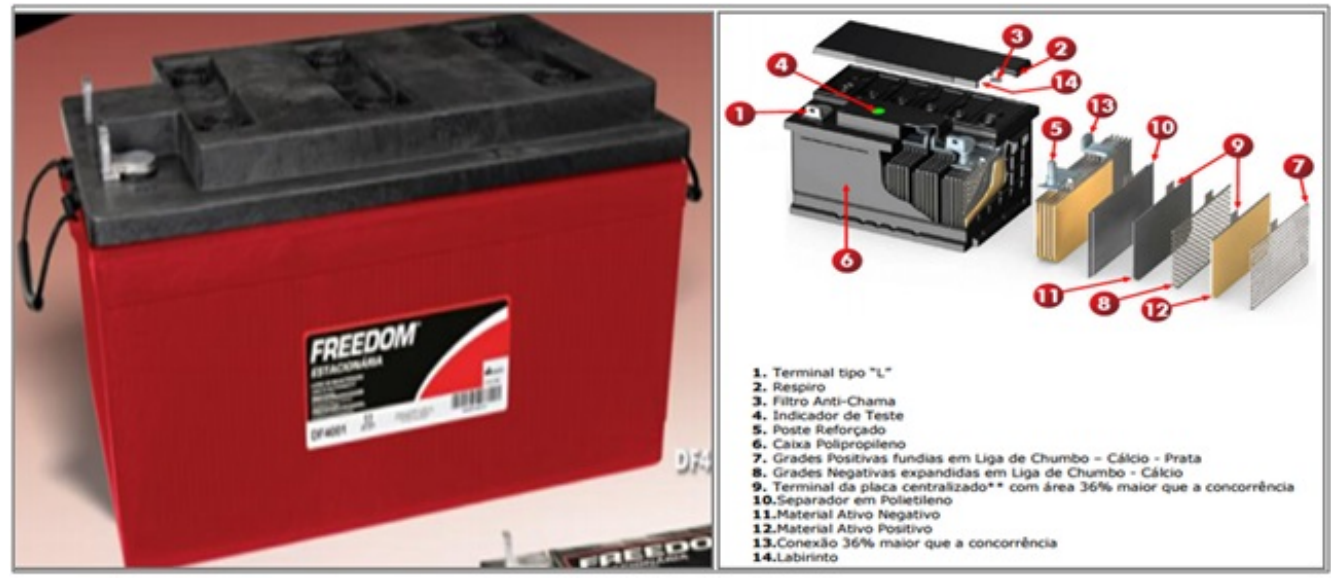

Figura 24 - Modelo de Bateria para o sistema em estudo

Fonte: Neosolar

Tabela 9 - Especificações das Baterias

\begin{tabular}{|c|c|}
\hline Modelo & FREEDOM DF4001 (240Ah/220Ah) \\
\hline Capacidade nominal (Ah) & 240 (em 100h), 220 (em 20h), 200 (em 10h) \\
\hline Tamanho (mm) & $525 \times 275 \times 250$ \\
\hline Peso (Kg) & 60,30 \\
\hline Vida útil (anos) & 4 \\
\hline Garantia (anos) & 2 (nenhuma manutenção nem reposição de água) \\
\hline Fabricante & Johnson Controls \\
\hline
\end{tabular}

\subsubsection{Especificações do Conversor}

A Tabela 10 e a Figura 25 mostram as especificações técnicas e a imagem do conversor definido para este projeto. Os inversores PROSines oferecem saída com onda senoidal pura e de boa qualidade. A onda sinoidal pura é idêntica a corrente alternada fornecida pela rede elétrica e ela é ideal para lidar com cargas sensíveis e melhora o desempenho dos equipamentos $\mathrm{CA}$, incluindo televisores, sistemas de áudio, ferramentas de velocidade variável e muito mais. Os inversores possuem um visor de LCD com iluminação, o monitor removível de LCD pode ser montado remotamente para controle e monitoramento. Possuem terminais CC que oferecem conexões de 180 graus para facilitar a instalação em locais apertados. 
Tabela 10 - Especificações do Conversor

\begin{tabular}{cc}
\hline Quantidade & 2 (cada um de 12 V) \\
Máxima potência de saída contínua (W) & 1800 \\
Máxima potência de surto (W) & 2900 \\
Corrente de saída (pico) & $45 \mathrm{~A}$ \\
Voltagem de saída & 125 Vac $\pm 3 \%$ \\
Frequência de saída $(\mathrm{Hz})$ & $60 \pm 0,05$ \\
Faixa de temperatura de operação $\left({ }^{\circ} \mathrm{C}\right)$ & $0-60$ ou $\left(32-140{ }^{\circ} \mathrm{F}\right)$ \\
Dimensões (mm) & $115 \times 280 \times 390$ \\
Peso líquido $(\mathrm{kg})$ & 7,5 \\
Fabricante & Xantrex \\
Modelo & PROsine 1000 \\
Garantia (anos) & 2 \\
\hline
\end{tabular}

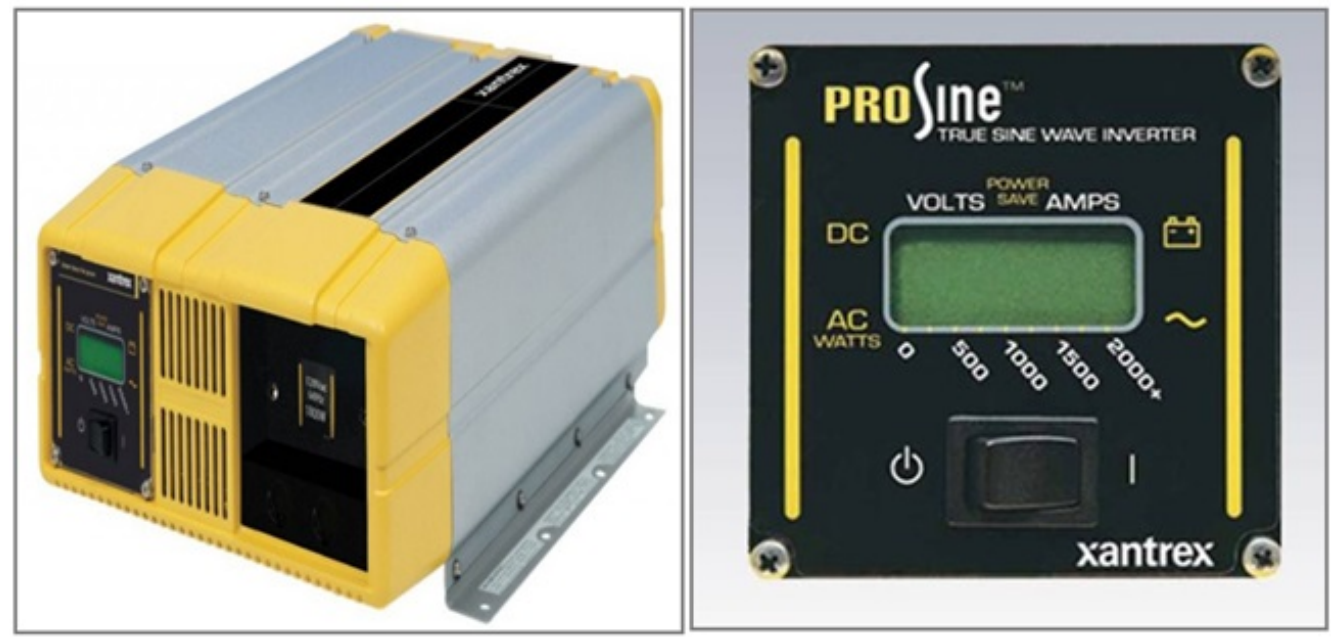

Figura 25 - Modelo de conversor para o sistema

Fonte: Neosolar

\subsubsection{Especificações do Controlador de carga}

Um dos componentes mais importantes de um sistema envolvendo painéis solares é o regulador de carga ou como é chamado tecnicamente "Controlador de Carga". Ele é o principal responsável pela vida útil das baterias. A sua principal função é garantir que toda energia que entra no banco de baterias é armazenada com maior eficiência possível, e assim, protegê-las baterias contra sobrecargas e evitar descargas profundas, isto é, garantir a qualidade da potência. Os carregadores possuem uma série de dispositivos que diretamente passam informações alertando sobre o estado de carga do sistema e assim aumentar a vida útil do banco de baterias. O regulador 
de carga é definido pela corrente e pela tensão do sistema e a sua capacidade deve superar essa corrente.

A corrente do sistema foi calculada pela seguinte relação:

$$
I_{1}=\frac{C_{t c}}{T_{s}}
$$

Sendo, $C_{t c}$ é o consumo total para todas as casas e $T_{s}$ é a tensão do sistema.

$I_{2}$ é o valor do $I_{1}$ corrigido considerando os fatores de eficiência da Tabela 3 do capítulo 3 , usados para considerar eventuais perdas no sistema. $l_{2}$ é calculado pela equação a seguir:

$$
I_{2}=\frac{I_{1}}{F_{e}}
$$

$F_{e}=$ Fatores de eficiência (para eventuais perdas no sistema).

E enfim, é calculada a corrente total $\left(I_{T}\right)$ do sistema pela equação abaixo:

$$
I_{T}=\frac{I_{2}}{A_{s}}
$$

$A_{s}$ é considerada como autonomia do sistema.

Obs.: essa corrente e a voltagem do banco de bateria serão usadas para dimensionar o controlador de carga.

NOTA: "Em geral no Haiti, existe dois períodos chuvosos, um que vai de abril a junho e outro que vai de outubro a novembro. A região do norte, que é a região onde o projeto deverá ser implementada é a mais seca do país com respectivamente 524 e 910 mm/ano, já o sul apresenta uma variação de 2000 a 2660 mm/ano de chuva. Informações : http://www.haiticulture.ch/Haiti.html. Considerando essas informações, o sistema pode ser projetado com uma autonomia de três dias, considerando dias chuvosos e/ou nublados. Pesquisas revelam que a profundidade de descarga máxima de uma bateria de chumbo-ácido considerando o sistema fotovoltaico é de $80 \%$, isto é, o quanto em termo de percentagem a bateria foi utilizada sem deixar terminar a carga inteira o que melhora consideravelmente a sua eficiência e duração."

Entre os tipos de controladores que existem no mercado, encontra-se controladores de: PWM e MPPT. Os controladores PWM geralmente têm um custo menor. 
Mas quando se precisa decidir qual tipo de controlador escolher, deve se levar em conta dois fatores essenciais e que podem ser crucial na escolha. Primeiramente, é necessário saber o número de células que compõe o painel solar e em segundo lugar, deve identificar a tensão do banco de baterias que pretende carregar. Ter ciência dessas duas informações, logo pode usar a Tabela 11 a seguir para escolher o tipo de controlador para o sistema.

Tabela 11 - Tecnologia de controladores $X$ painéis e baterias

\begin{tabular}{cc} 
Painéis e baterias & Controlador \\
Painéis a 36 células e baterias $12 \mathrm{~V}$ & MPPT \\
Painéis a 48 células e baterias $12 \mathrm{~V} / 24 \mathrm{~V}$ & MPPT \\
Painéis a 54 células e baterias $12 \mathrm{~V} / 24 \mathrm{~V}$ & MPPT \\
Painéis a 72 células e baterias $12 \mathrm{~V} / 24 \mathrm{~V}$ & MPPT \\
Painéis a 144 células e baterias $48 \mathrm{~V}$ & MPPT \\
Painéis a 30 células e baterias $12 \mathrm{~V}$ & PWM \\
Painéis a 60 células e baterias $24 \mathrm{~V}$ & PWM \\
Painéis a 120 células e baterias $48 \mathrm{~V}$ & PWM \\
\hline
\end{tabular}

Fonte: osol.com.br

Para o sistema em estudo, cada painel possui 36 células e a tensão do banco de baterias é de $48 \mathrm{~V}$. Logo, o controlador mais adequado para o sistema é MPPT. As especificações do controlador de carga são mostradas na Tabela 12 e o desenho e a imagem são apresentados nas Figuras 26 e 27 abaixo.

Tabela 12 - Especificações do controlador de carga

\begin{tabular}{cc}
\hline Faixa de tensão de operação & $0 \mathrm{Vdc} \sim 80 \mathrm{Vdc}$ \\
Máxima tensão de operação PV & $150 \mathrm{~V}$ \\
Máxima de corrente de carga & $60 \mathrm{~A}$ \\
Máximo de mínimo diâmetro para condutor & $10 \mathrm{a} 2,5 \mathrm{~mm}^{2}$ \\
Máxima potencia de saída & $3500 \mathrm{~W}$ \\
Consumo de energia (Tempo noturno) & $2,5 \mathrm{~W}$ \\
Saída auxiliar & $5 \sim 13 \mathrm{~V}$, até $200 \mathrm{~mA}$ \\
\hline
\end{tabular}




\begin{tabular}{cc}
\hline Faixa de tensão de operação & oVdc $\sim 80 \mathrm{Vdc}$ \\
Garantia & 5 \\
Peso & $8 \mathrm{~kg}$ \\
Dimensões & $36,8 \times 14,6 \times 13,8 \mathrm{~cm}$ \\
Temperatura de operação & $-20^{\circ} \mathrm{C} \sim 45^{\circ} \mathrm{C}$ \\
Fabricante & Schneider Electric \\
\hline
\end{tabular}

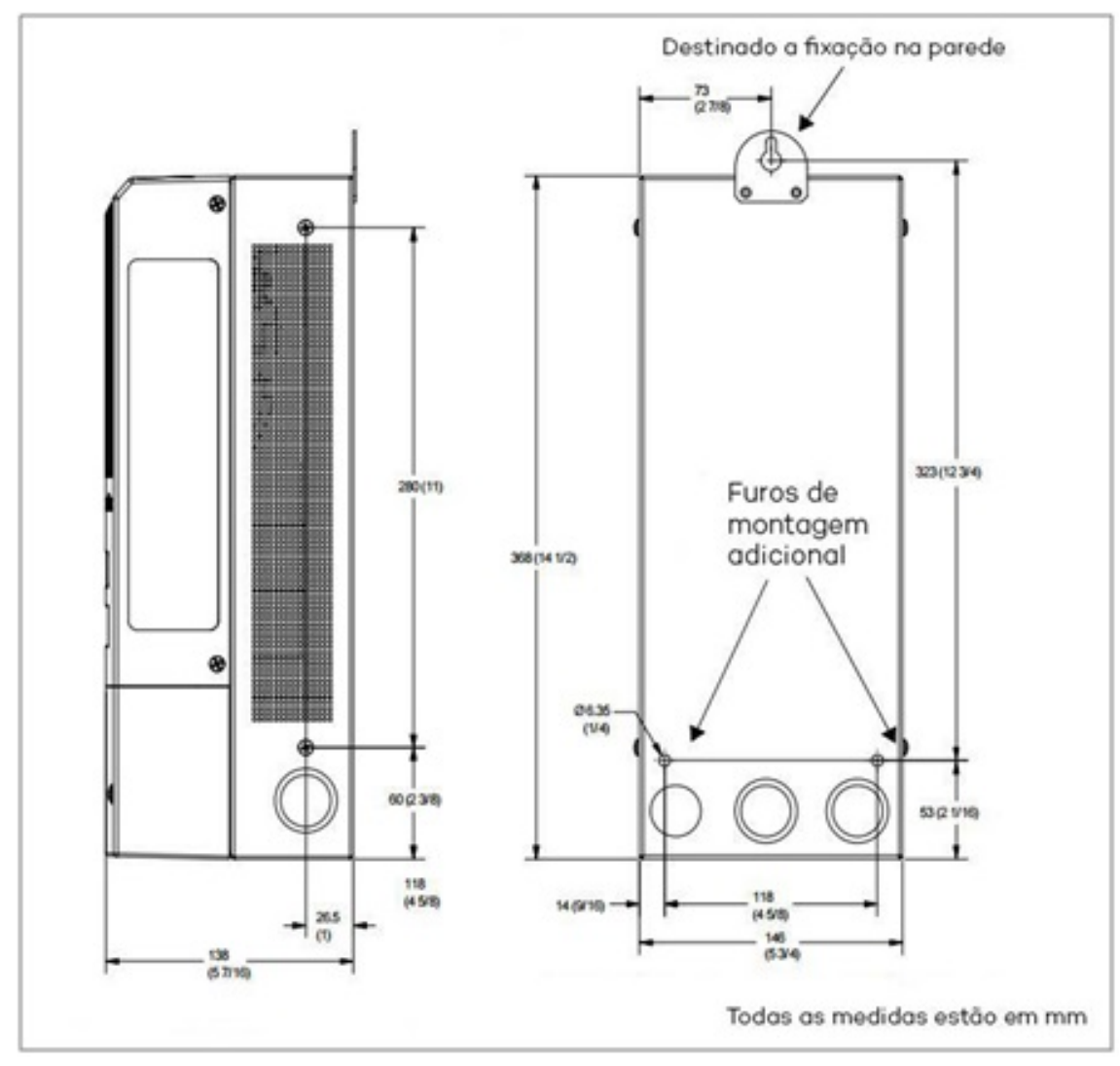

Figura 26 - Desenho do controlador de carga

Fonte: neosolar.com.br 


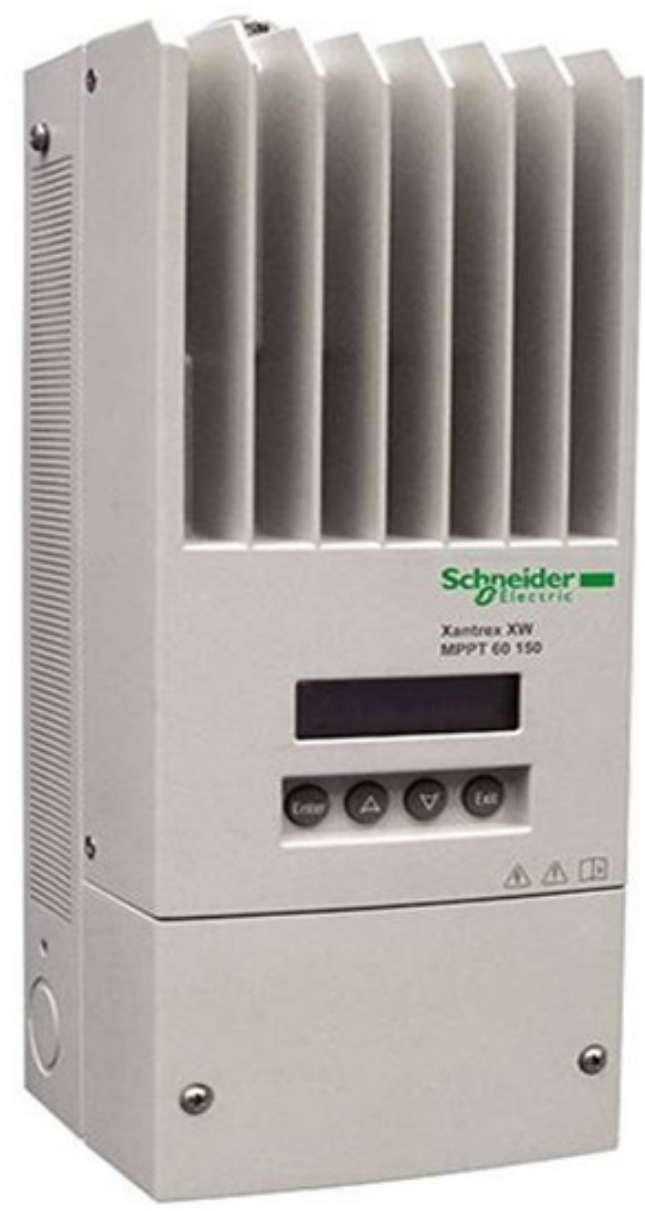

Figura 27 - Modelo de controlador de carga MPPT escolhido para o sistema

Fonte: neosolar.com.br

\subsubsection{Dados do recurso solar do vilarejo}

Os dados de radiação foram disponibilizados pelo programa METEONORM 7. Fornecedendo a latitude (1956 '16“N), a longitude (7249'55”E) e a altitude (36m), o programa automaticamente disponibiliza a média mensal de radiação solar do vilarejo. A Figura 28 mostra a média mensal de radiação solar no vilarejo. Nota-se que dezembro é o mês com a menor radiação, seguido por novembro. Já nos outros meses a radiação é forte e praticamente se estabiliza, só o mês de julho apresenta um pico maior. 


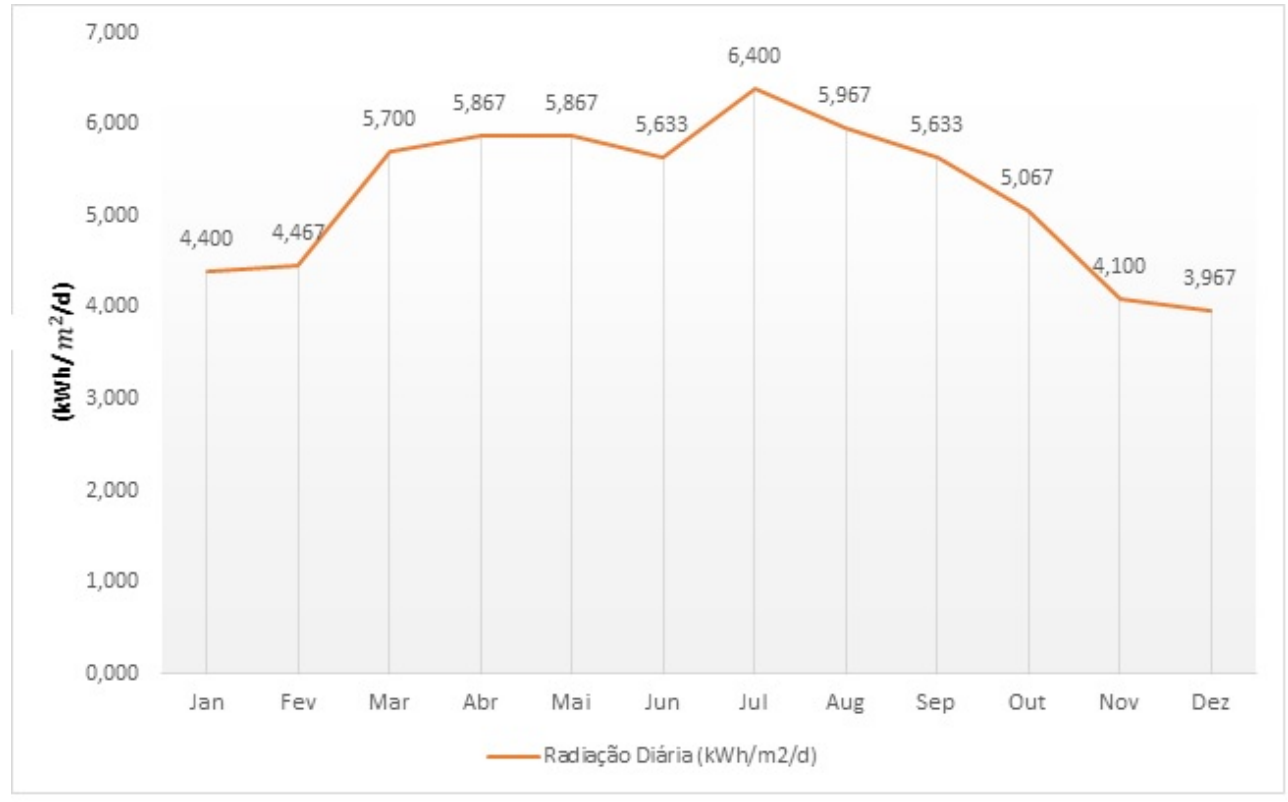

Figura 28 - Média de irradiação solar do vilarejo $\left(\mathrm{kW} / \mathrm{m}^{2} / \mathrm{dia}\right)$

\subsubsection{Dados do recurso eólico do vilarejo}

É mostrada na Figura 29 a variação da média mensal do recurso eólico no vilarejo. Os meses com maior e menor média mensal de vento são setembro e outubro. Durante o resto do ano, a média mensal de recurso eólico é praticamente a mesma. A média mensal geral da velocidade do vento é de $6,04 \mathrm{~m} / \mathrm{s}$, isto é, o vilarejo possui boas condições de gerar eletricidade por meio de tecnologia que converte a energia cinética do vento em energia mecânica e em seguida em energia elétrica. Os dados da velocidade do vento estão disponíveis numa estação meteorológica prómixa a região.

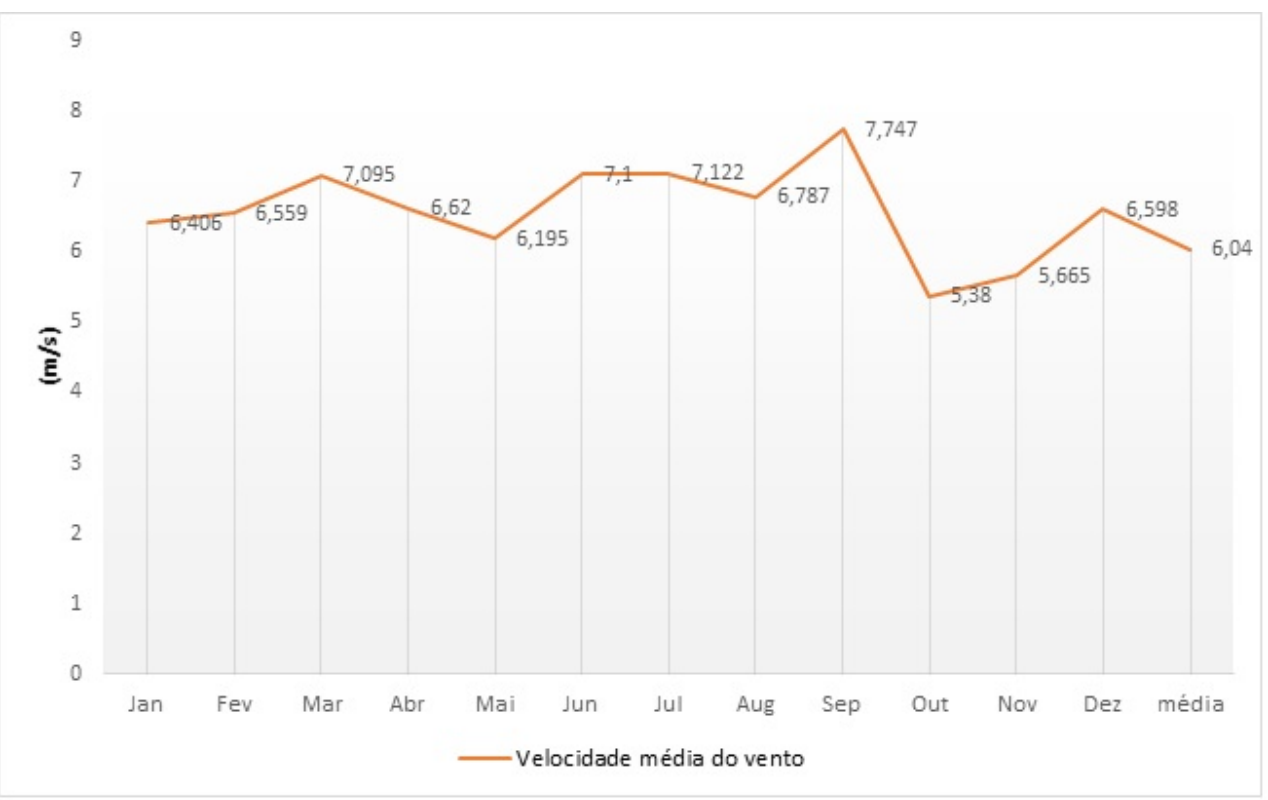

Figura 29 - Média mensal da velocidade do vento $(\mathrm{m} / \mathrm{s})$ 


\subsubsection{Perfil de carga do vilarejo}

Uma das características mais importante na demanda elétrica do vilarejo é a determinação do perfil de carga. Na simulação realizada pela ferramenta HOMER, foi estimado o perfil de carga durante um dia para toda a comunidade conforme observada na Figura 30. O maior consumo durante o dia acontece a partir das 18:00 e se estabiliza até às 20:00, é nesse horário que as residências irão usar mais energia devido ao número maior de pessoas em casa que conseqüentemente irão aumentar o uso de equipamentos elétricos como lâmpadas, televisores, chuveiros, etc. No período de 00:00 até 05:00 da manhã o consumo é baixo já que haveria menos uso de equipamentos elétricos, a partir das 05:00 o consumo começar a crescer, pois é nesse horário que os usuários saem de casa para ir a campo para realizar atividades agrícolas e/ou de pesca. Mas a partir das 06:00 até às 16:00 e pouco, ele passa de $4 \mathrm{~kW}$ até $11 \mathrm{~kW}$ que é o período de consumo moderado. Essa curva se estende para os períodos de chuva, calor, frio e prováveis sazonalidades no consumo. A Tabela 13 nos fornece os valores dos parâmetros da demanda média diária de $168 \mathrm{kWh} /$ dia, com uma média de $7 \mathrm{~kW}, 22,7 \mathrm{~kW}$ de pico e o fator de carga do sistema será de $30,8 \%$ que geralmente é o valor típico de pequenas comunidades rurais.

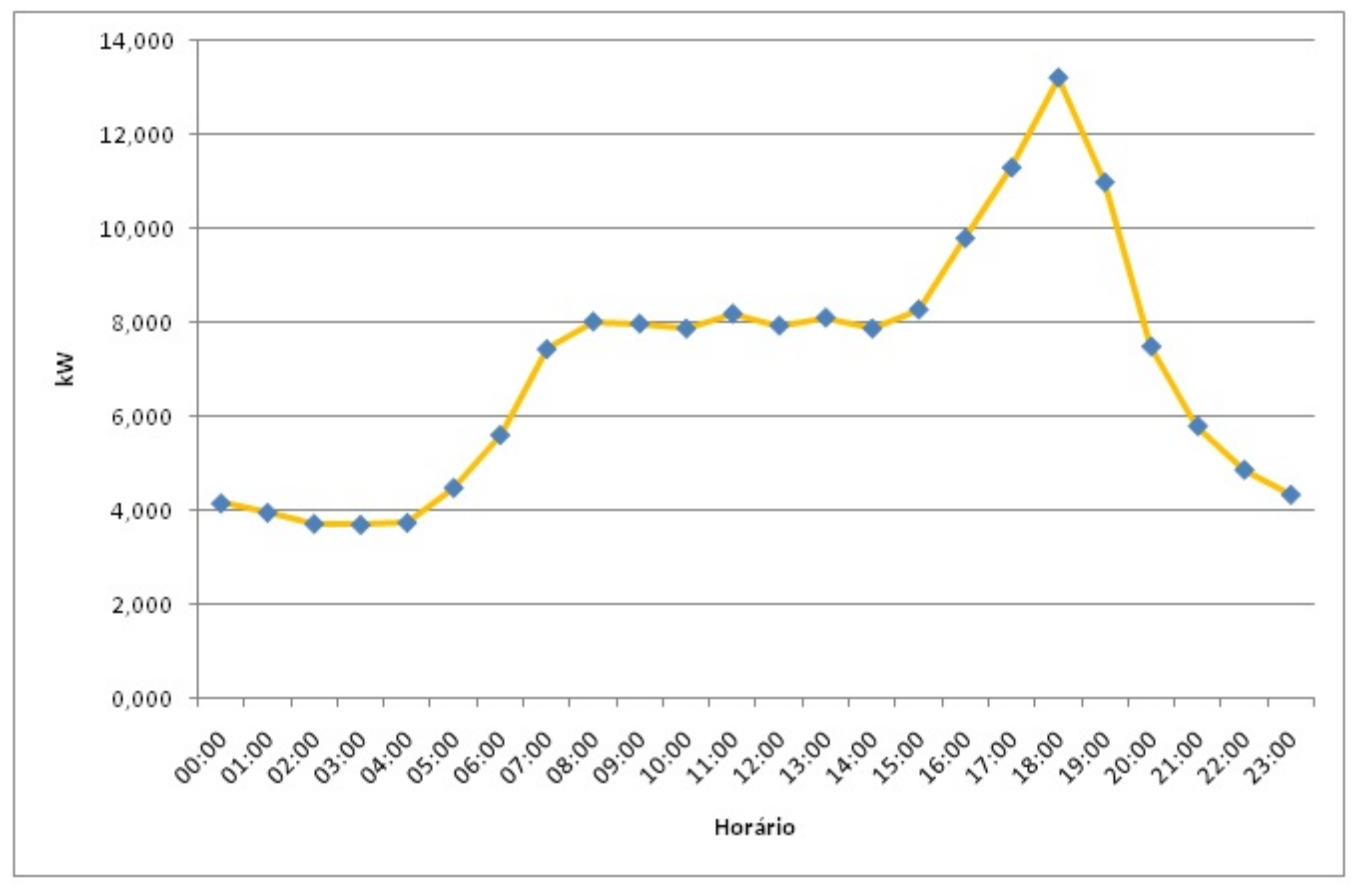

Figura 30 - Perfil diária do consumo de eletricidade do vilarejo 
Tabela 13 - Parâmetros da demanda diária da comunidade

\begin{tabular}{cc}
\hline Média $(\mathrm{kWh} / \mathrm{d})$ & 168 \\
Média $(\mathrm{kW})$ & 7,0 \\
Pico $(\mathrm{kW})$ & 22,7 \\
Fator de Capacidade & 0,308 \\
\hline
\end{tabular}

\subsection{Resultados}

O programa simulou o sistema híbrido completo para diferentes condições de operação das fontes de energia como pode ser obersavado na Figura 31 abaixo (as diferentes configurações do sistema). Cada linha na tabela representa uma configuração de sistema e as quatro primeiras colunas contêm ícones que indicam a presença dos diferentes componentes, as quatro colunas seguintes indicam o número ou o tamanho de cada componente e as cinco colunas seguintes contêm alguns dos principais resultados de simulação: o custo total de capital do sistema, custo de operação, o custo líquido total atual, o custo de energia (custo por quilowatt-hora) e a vida útil da bateria. Cada configuração possui uma matriz fotovoltaica, uma turbina, um banco de bateria e um conversor, seus respectivos custos e a vida útil de cada componente. O programa por sua vez seleciona a configuração considerada mais viável.

Para análise de viábilidade técnica e econômica foi considerada outras configuções chamadas de "configurações intensivas" para comparação com a configuração escolhida pelo sistema. As configurações intensivas são mostradas na Tabela 14. Chamada de C1, a configuração inicial escolhida pelo sistema como a melhor, C2 é a configuração intensiva de turbinas, C3 representa a configuração intensiva do banco de baterias e C4 é a configuração intensiva da matriz fotovoltaica e de turbinas. 


\begin{tabular}{|c|c|c|c|c|c|c|c|c|c|c|c|}
\hline \multicolumn{12}{|c|}{ Double click on a system below for simulation results. } \\
\hline TAब⿴囗口 & $\mathrm{PV}$ & AlR & DF4001 & Conv. & $\begin{array}{l}\text { Intial } \\
\text { Coptal }\end{array}$ & $\begin{array}{l}\text { Operating } \\
\text { Cost (s.y })\end{array}$ & $\begin{array}{l}\text { Total } \\
\text { NPC }\end{array}$ & $\left|\begin{array}{c}C O E \\
(s / k W h)\end{array}\right|$ & $\begin{array}{l}\text { Ren. } \\
\text { Frac. }\end{array}$ & $\begin{array}{l}\text { Capacity } \\
\text { Shortago }\end{array}$ & $\begin{array}{l}\text { Batt. } 1 \text {. } \\
(y+1)\end{array}$ \\
\hline JळI & 53.2 & 1 & 48 & 12 & 5141.592 & 5.5229 & $\$ 2212.277$ & 0.283 & 1.00 & 0.07 & 4.0 \\
\hline$\sigma \square$ & 57.0 & 1 & 48 & 12 & $\$ 142,307$ & 5,529 & $\$ 212,992$ & 0.280 & 1.00 & 0.05 & 4.0 \\
\hline$\sigma$ & 53.2 & 1 & 48 & 24 & s 182.149 & 6.607 & s 266.607 & 0.349 & 1.00 & 0.04 & 4.0 \\
\hline$\square$ & 57.0 & 1 & 48 & 24 & S 182.864 & 6.607 & $\$ 267.322$ & 0.345 & 1.00 & 0.02 & 4.0 \\
\hline 四 & 53.2 & i & 96 & 12 & s 158,969 & 9.192 & \& 276,471 & 0.363 & 1.00 & 0.05 & 4.0 \\
\hline 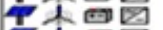 & 57.0 & 1 & 96 & 12 & s 159.684 & 9.192 & \& 277.186 & 0.362 & 1.00 & 0.04 & 4.0 \\
\hline 밈 & 53.2 & 1 & 96 & 24 & S 199.526 & 10.269 & S 330,801 & 0.426 & 1.00 & 0.01 & 4.0 \\
\hline$\sigma$ & 57.0 & 1 & 96 & 24 & S 200.241 & 10.269 & s 331.516 & 0.423 & 1.00 & 0.00 & 4.0 \\
\hline 밈 & 53.2 & 3 & 48 & 12 & s 288.892 & 7.109 & s 379.765 & 0.504 & 1.00 & 0.07 & 4.0 \\
\hline 凹四 & 57.0 & 3 & 48 & 12 & S 289.607 & 7.109 & s 380,480 & 0.499 & 1.00 & 0.05 & 4.0 \\
\hline बه & 53.2 & 3 & 48 & 24 & s 329.449 & 8.186 & s 434.095 & 0.566 & 1.00 & 0.03 & 4.0 \\
\hline ब园 & 57.0 & 3 & 48 & 24 & s 330.164 & 8.186 & s 434.810 & 0.560 & 1.00 & 0.01 & 4.0 \\
\hline 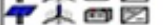 & 53.2 & 3 & 96 & 12 & s 306.269 & 10.771 & s 443.960 & 0.581 & 1.00 & 0.04 & 4.0 \\
\hline 밈 & 57.0 & 3 & 96 & 12 & s 306.984 & 10.771 & s 444.674 & 0.580 & 1.00 & 0.04 & 4.0 \\
\hline ब四 & 53.2 & 3 & 96 & 24 & s 346.826 & 11.848 & s 498.290 & 0.640 & 1.00 & 0.01 & 4.0 \\
\hline 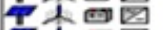 & 57.0 & 3 & 96 & 24 & s 347.541 & 11,848 & s 499.005 & 0.637 & 1.00 & $0 . \infty$ & 4.0 \\
\hline 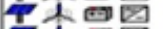 & 53.2 & 5 & 48 & 12 & S 436.192 & 8.688 & s 547.253 & 0.725 & 1.00 & 0.06 & 4.0 \\
\hline ब四 & 57.0 & 5 & 48 & 12 & s 436.907 & 8.688 & s 547.968 & 0.718 & 1.00 & 0.05 & 4.0 \\
\hline 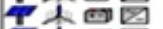 & 53.2 & 5 & 48 & 24 & s 476.749 & 9.765 & \& 601,583 & 0.783 & 1.00 & 0.03 & 4.0 \\
\hline 밈 & 57.0 & 5 & 48 & 24 & s 477.464 & 9.765 & s 602.298 & 0.774 & 1.00 & 0.01 & 4.0 \\
\hline$\sigma \square$ & 53.2 & 5 & 96 & 12 & \& 453.569 & 12,350 & $\$ 611,448$ & 0.799 & 1.00 & 0.04 & 4.0 \\
\hline 凹 & 57.0 & 5 & 96 & 12 & s 454.284 & 12,350 & \& 612,163 & 0.798 & 1.00 & 0.04 & 4.0 \\
\hline 밈 & 53.2 & 5 & 96 & 24 & s 494,126 & 13.428 & s 665.778 & 0.854 & 1.00 & 0.01 & 4.0 \\
\hline 凹四 & 57.0 & 5 & 96 & 24 & \$ 494,841 & 13,428 & \$ 666,493 & 0.850 & 1.00 & 0.00 & 4.0 \\
\hline *1 & 53.2 & 1 & 48 & 12 & S 141.592 & 5.529 & \$ 212.277 & 0.283 & 1.00 & 0.07 & 4.0 \\
\hline & 53.2 & 1 & 48 & 24 & \$ 182.149 & 6.607 & $\$ 266.607$ & 0.349 & 1.00 & 0.04 & 4.0 \\
\hline & 53.2 & 1 & 96 & 12 & \$ 158.969 & 9.192 & $\$ 276,471$ & 0.363 & 1.00 & 0.05 & 4.0 \\
\hline & 53.2 & 1 & 120 & 12 & \$ 167.658 & 11.023 & \$ 308.569 & 0.403 & 1.00 & 0.04 & 4.0 \\
\hline 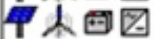 & 53.2 & 1 & 48 & 35 & $\$ 219.326$ & 7.594 & \$ 316.409 & 0.415 & 1.00 & 0.04 & 4.0 \\
\hline & 53.2 & 1 & 96 & 24 & \$ 199,526 & 10.269 & \$ 330,801 & 0.426 & 1.00 & 0.02 & 4.0 \\
\hline & 53.2 & 1 & 140 & 12 & \$ 174,899 & 12.549 & $\$ 335,316$ & 0.437 & 1.00 & 0.04 & 4.0 \\
\hline & 53.2 & 1 & 120 & 24 & $\$ 208.215$ & 12.100 & $\$ 362.899$ & 0.465 & 1.00 & 0.01 & 4.0 \\
\hline 지 & 53.2 & 1 & 96 & 35 & $\$ 236,704$ & 11.257 & \$ 380,604 & 0.490 & 1.00 & 0.02 & 4.0 \\
\hline$\sqrt{2}$ & 53.2 & 1 & 140 & 24 & $\$ 215,456$ & 13.626 & $\$ 389,647$ & 0.497 & 1.00 & 0.00 & 4.0 \\
\hline (4) & 53.2 & 1 & 120 & 35 & $\$ 245,392$ & 13.088 & $\$ 412,701$ & 0.529 & 1.00 & 0.01 & 4.0 \\
\hline (2) & 53.2 & 1 & 140 & 35 & $\$ 252,633$ & 14,614 & $\$ 439,449$ & 0.561 & 1.00 & 0.00 & 4.0 \\
\hline
\end{tabular}

Figura 31 - Diferentes configurações do sistema para o vilarejo.

As quatro configurações intensivas em estudo são diferentes uma das outras na quantidade e/ou no tamanho dos componentes. C1, C2 e C3 possuem uma matriz fotovoltaica de 53,2 kW de potência, a potência da FV da configuração intensiva C4 é de 57,2 kW. C1 e C3 têm uma turbina, C2 tem três turbinas e C4 possui 5 turbinas. $O$ tamanho do banco de bateria e do conversor das configurações C1, C2 e C4 é o mesmo, já C3 possui banco de baterias e conversor maior que as outras. E por último, todas as configurações se diferenciam nos custos, cada uma tem os seus custos diferentes das outras. A Tabela 14 mostra todas as diferenças entre as quatro configurações.

Tabela 14 - Tabela das configurações em estudo.

\begin{tabular}{|c|c|c|c|c|c|c|c|c|c|}
\hline $\begin{array}{l}\text { Cená- } \\
\text { rios }\end{array}$ & $\begin{array}{c}\text { FV } \\
(k W)\end{array}$ & Turb. & Bat. & $\begin{array}{l}\text { Conv. } \\
\text { (kW) }\end{array}$ & $\begin{array}{l}\text { Cap. } \\
\text { Inic. }\end{array}$ & $\begin{array}{l}\text { Custo } \\
\text { Oper. } \\
\text { (\$/ano) }\end{array}$ & $\begin{array}{l}\text { NPC } \\
\text { Total }\end{array}$ & $\begin{array}{c}\text { O\&M } \\
(\$ / k W h)\end{array}$ & $\begin{array}{l}\text { Dur. } \\
\text { Bat. }\end{array}$ \\
\hline
\end{tabular}




\begin{tabular}{cccccccccc}
\hline $\begin{array}{c}\text { Cená- } \\
\text { rios }\end{array}$ & $\begin{array}{c}\text { FV } \\
\mathbf{( k W )}\end{array}$ & Turb. & Bat. & $\begin{array}{l}\text { Conv. } \\
\mathbf{( k W )}\end{array}$ & $\begin{array}{l}\text { Cap. } \\
\text { Inic. }\end{array}$ & $\begin{array}{l}\text { Custo } \\
\text { Oper. } \\
\mathbf{( \$ / a n o )}\end{array}$ & $\begin{array}{l}\text { NPC } \\
\text { Total }\end{array}$ & $\begin{array}{l}\text { O\&M } \\
\mathbf{( \$ / k W h )}\end{array}$ & $\begin{array}{l}\text { Dur. } \\
\text { Bat. }\end{array}$ \\
$\mathbf{C 1}$ & 53,2 & 1 & 48 & 12 & 141.592 & 5.929 & 212.277 & 0,283 & 4,0 \\
C2 & 53,2 & 3 & 48 & 12 & 288.892 & 7.109 & 379.765 & 0,505 & 4,0 \\
C3 & 53,2 & 1 & 140 & 24 & 215.456 & 13.626 & 389.647 & 0,497 & 4,0 \\
C4 & 57,0 & 5 & 48 & 12 & 436.907 & 8.688 & 547.968 & 0,718 & 4,0 \\
\hline
\end{tabular}

\subsubsection{Rendimento Energético}

Na Tabela 15 é apresentada para cada configuração alguns parâmetros como o consumo de carga em kWh/ano, o excesso de eletricidade no sistema em kWh/ano, a carga elétrica não atendia por ano expresso em kWh/ano e a participação da matriz fotovoltaica e da turbina na produção total elétrica do sistema. As médias mensais de energia de cada tecnologia (PV e Turbina) para cada configuração para atender a demanda mensal do vilarejo em estudo são mostradas nas Figuras 32, 33, 34 e 35.

Tabela 15 - Parâmetros relacionados a produção elétrica para cada configuração.

\begin{tabular}{ccccc}
\hline Parâmetros & $\mathbf{C 1}$ & $\mathbf{C 2}$ & $\mathbf{C 3}$ & $\mathbf{C 4}$ \\
FV (kWh/ano) & 81.685 & 81.685 & 81.685 & 87.519 \\
Representação (\%) & 99 & 98 & 99 & 98 \\
Turbina (kWh/ano) & 439 & 1.318 & 439 & 2.196 \\
Representação (\%) & 1 & 2 & 1 & 2 \\
Produção Total (kWh/ano) & 82.124 & 83.002 & 82.124 & 89.715 \\
Excesso de eletricidade & 9.719 & 10.498 & 7.888 & 16.280 \\
$\quad$ (kWh/ano) & 11,8 & 12,6 & 9,60 & 18,1 \\
Representação (\%) & 2.643 & 2.479 & 0,002 & 1.648 \\
Carga não atendida (kWh/ano) & 4,3 & 4,0 & 0,0 & 2,7 \\
Representação (\%) & & & & \\
\hline
\end{tabular}




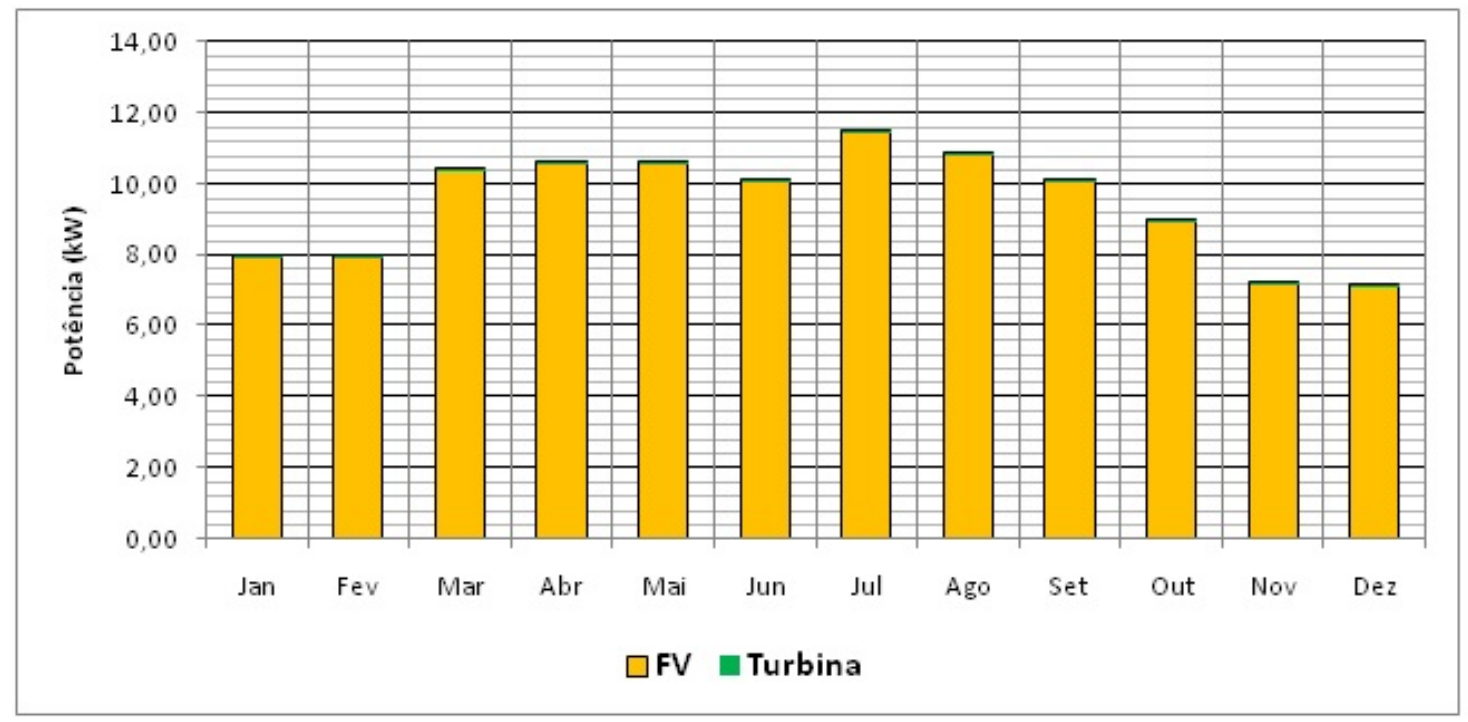

Figura 32 - Média mensal da produção elétrica do sistema (C1).

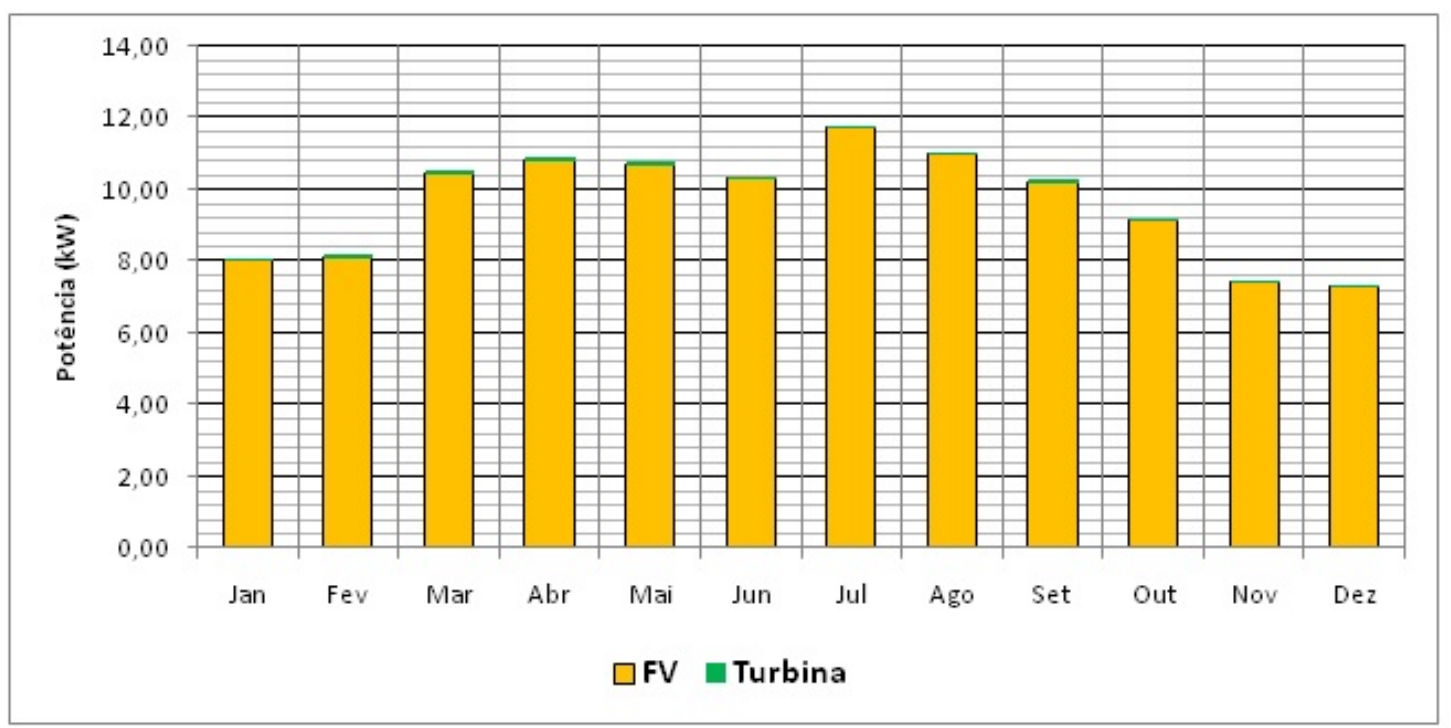

Figura 33 - Média mensal de produção elétrica do sistema (C2). 


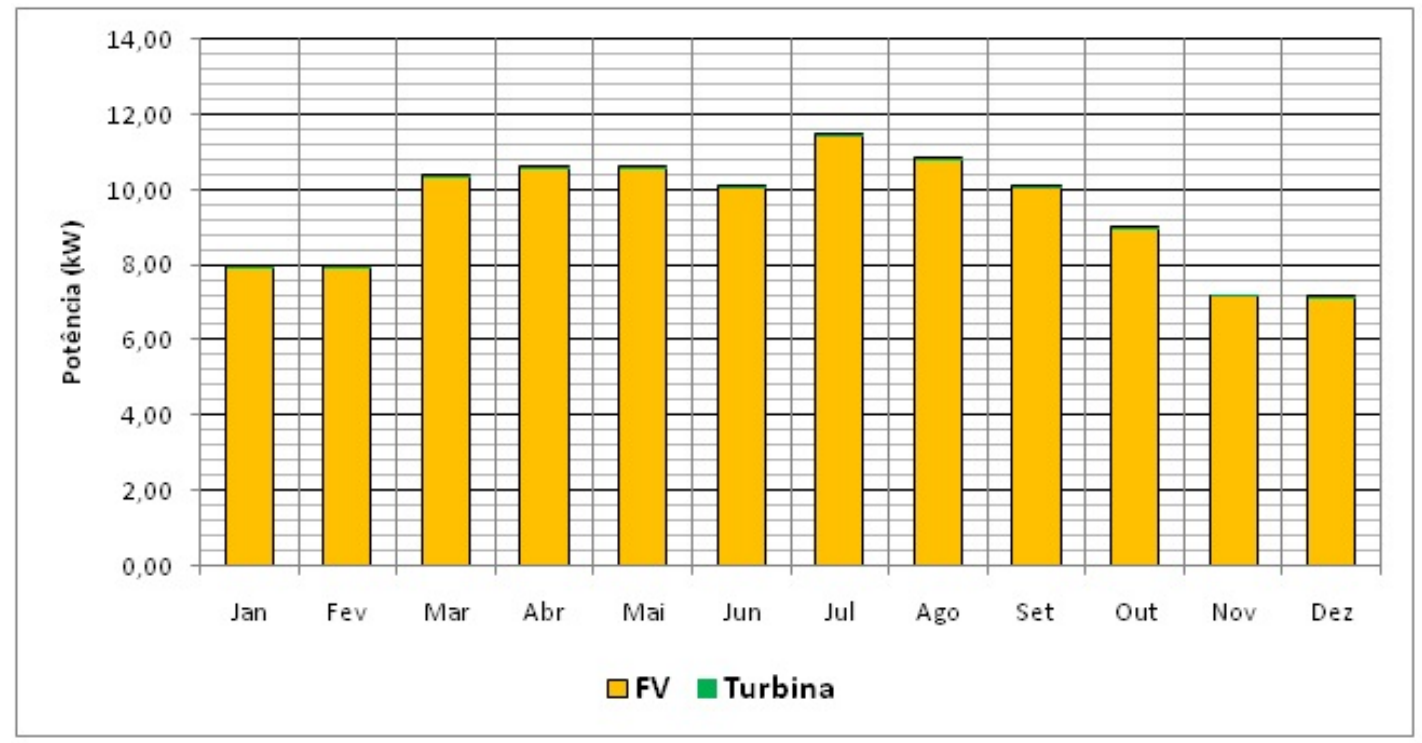

Figura 34 - Média mensal de produção elétrica do sistema (C3).

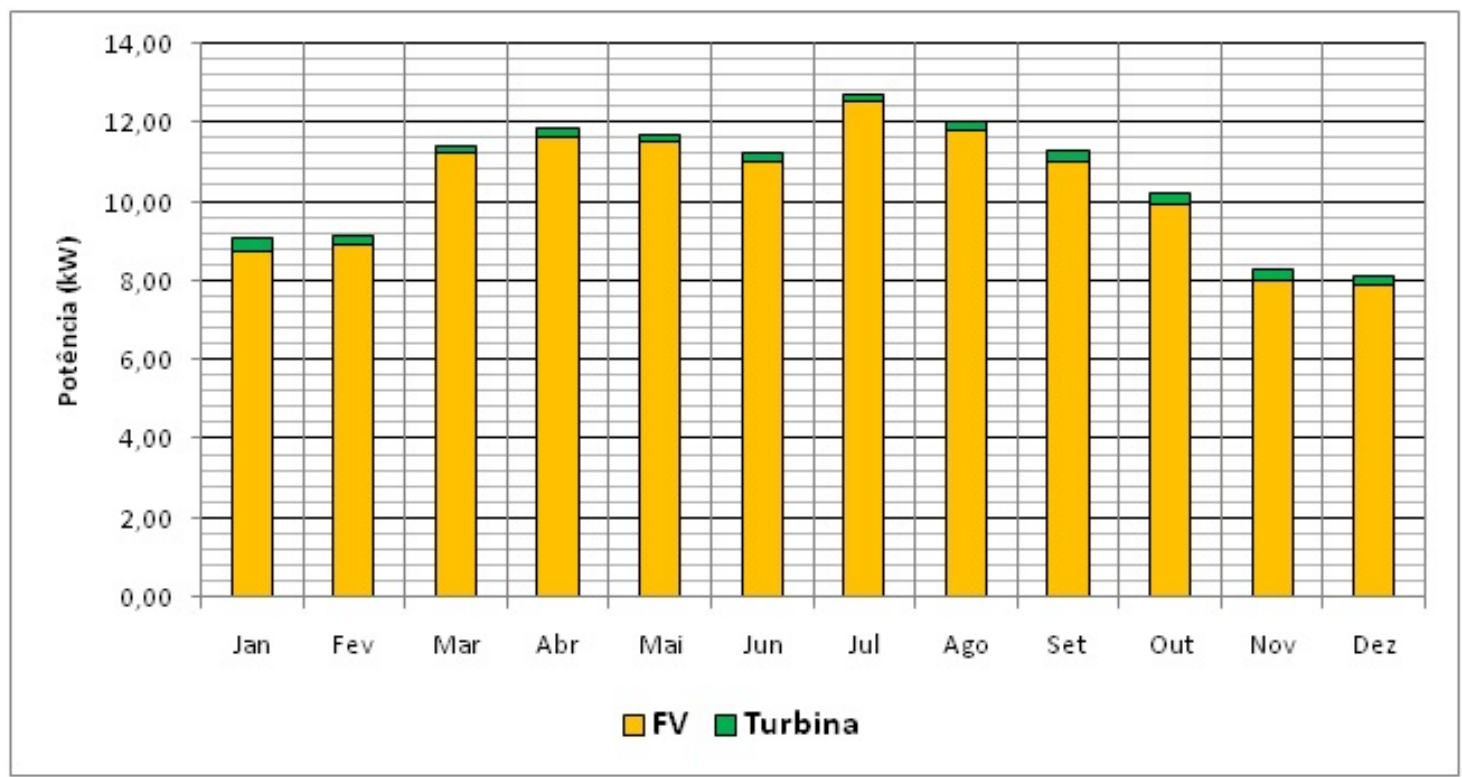

Figura 35 - Média mensal de produção elétrica do sistema (C4).

A Figura 36 apresenta uma comparação da produção elétrica mensal para as quatro configurações. O gráfico da Figura 37 por sua vez mostra uma comparação do rendimento energético da configuração do sistema e as configurações intensivas. Já a Figura 38 mostra a variação do excesso de carga e da demanda não atendida para cada uma das configurações em estudo. 


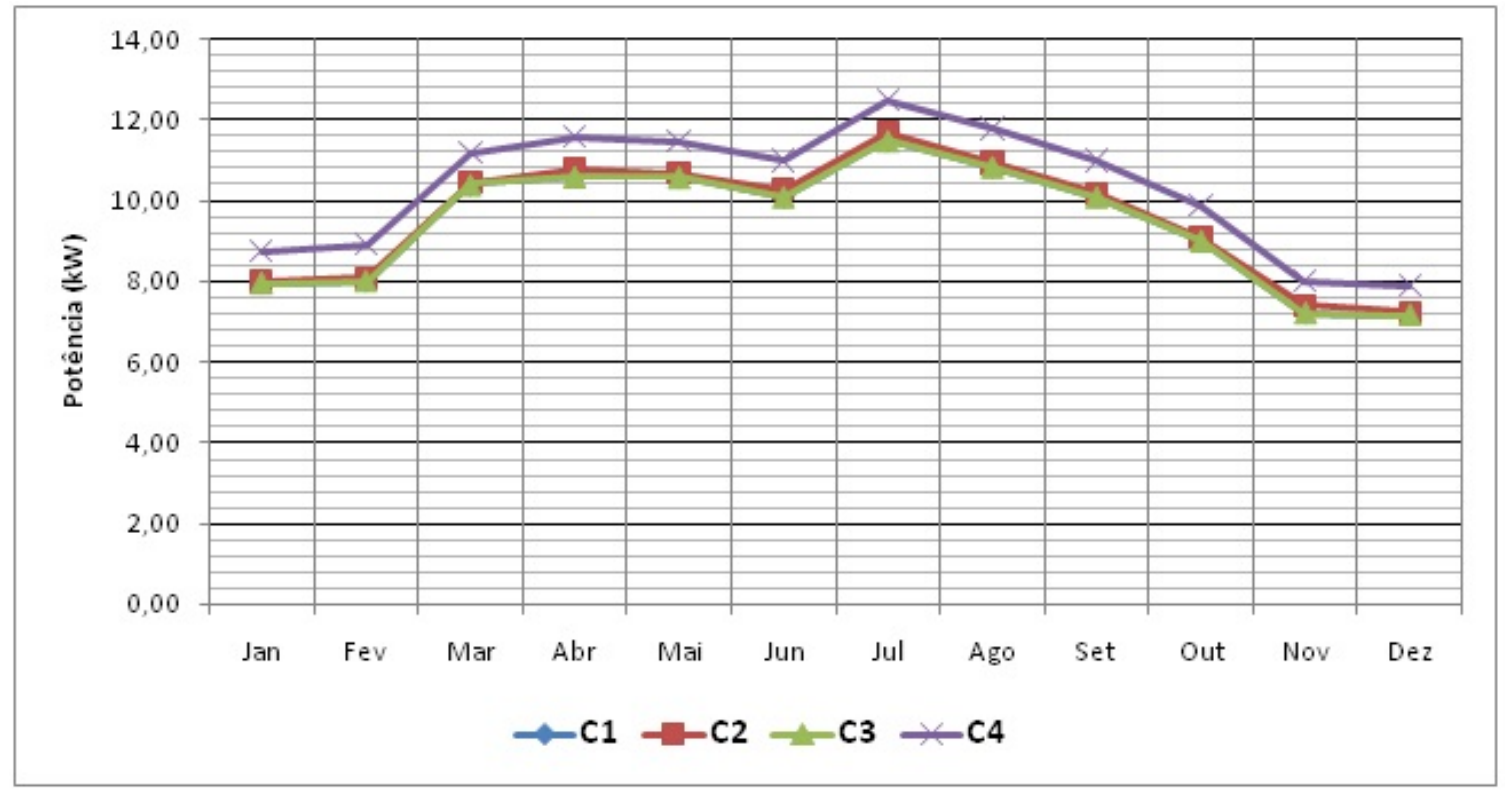

Figura 36 - Comparação da produção elétrica mensal das quatro configurações.

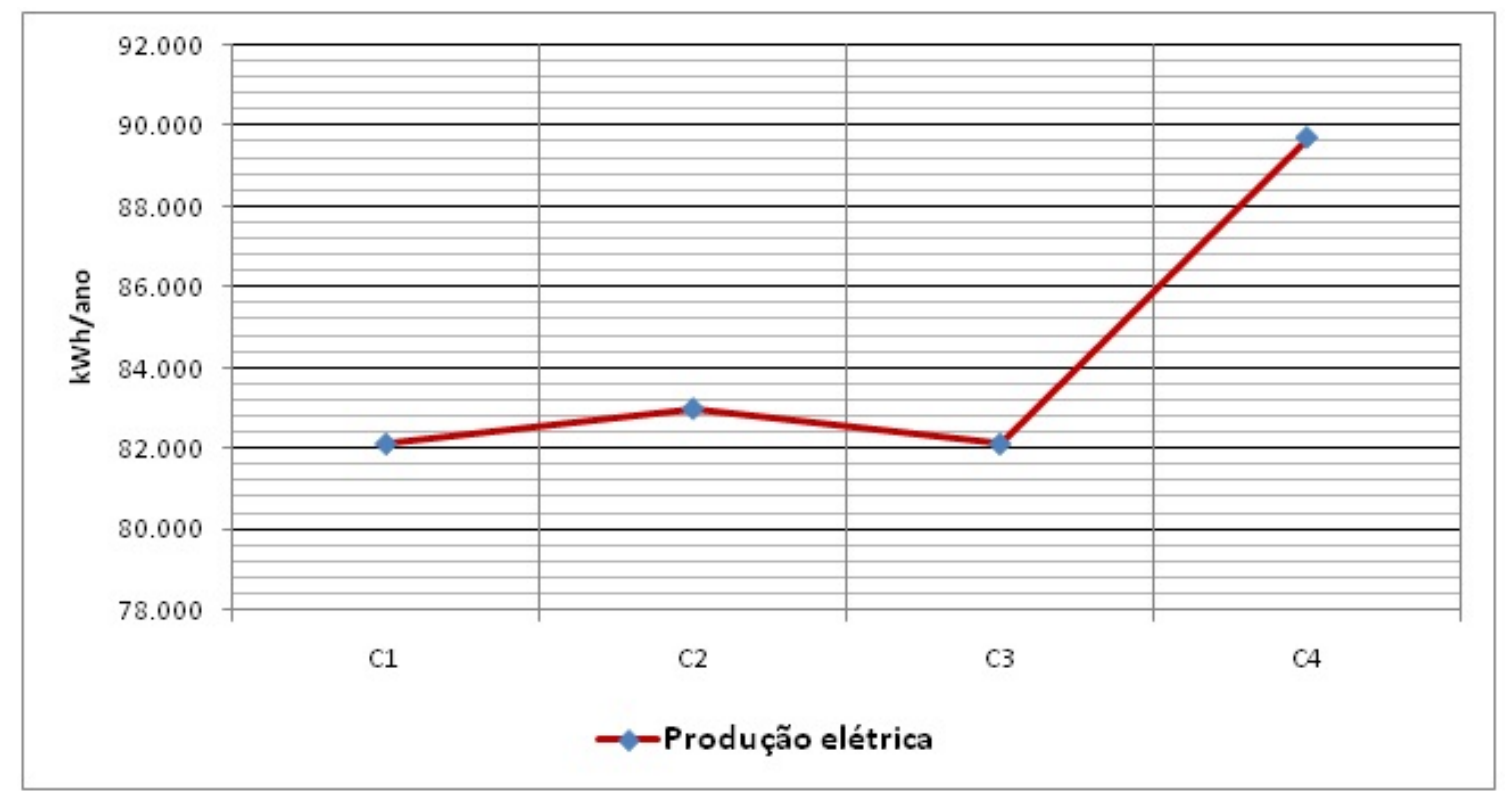

Figura 37 - Comparação dos rendimentos totais de energia considerando as configurações intensivas. 


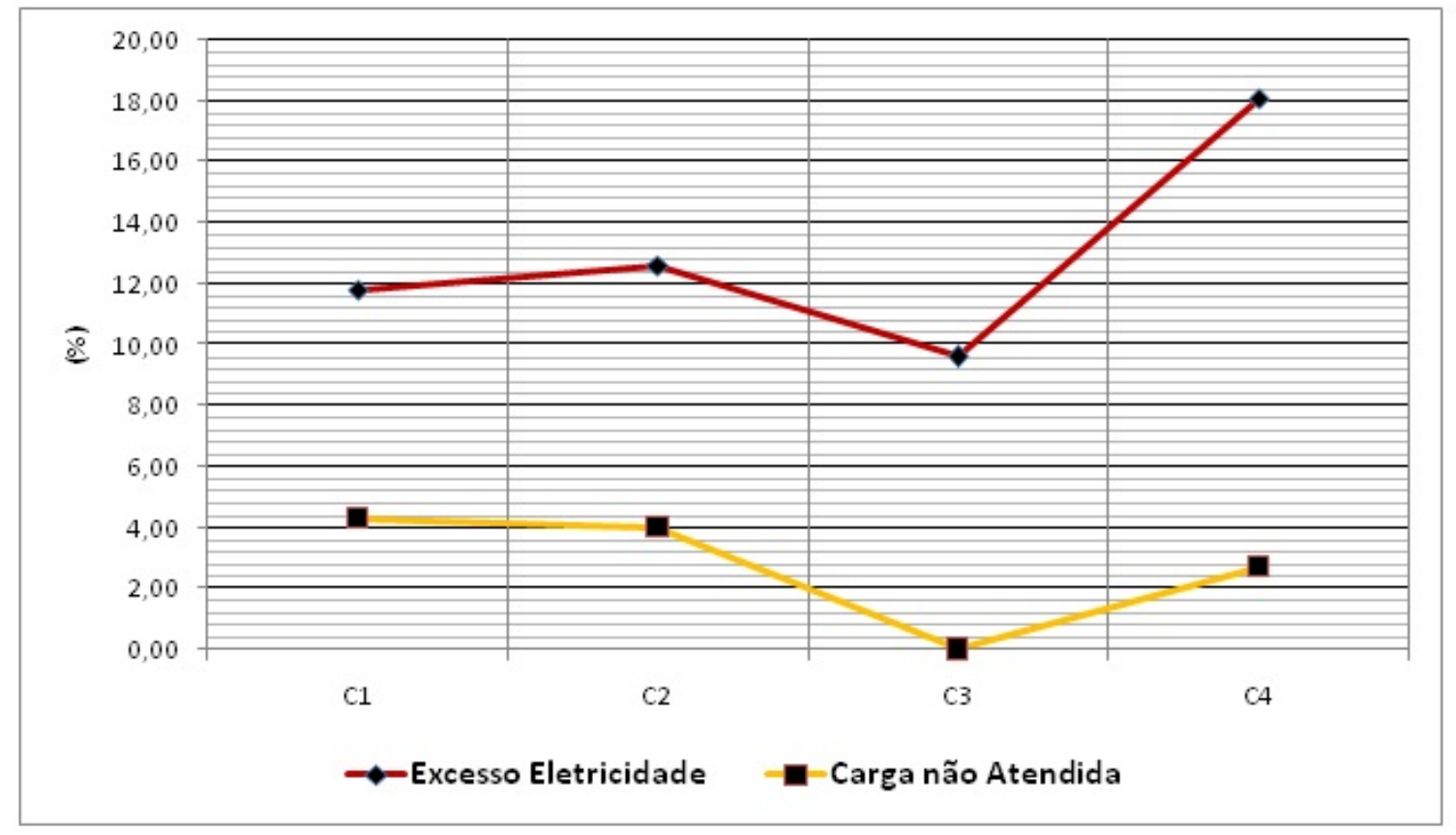

Figura 38 - Variação na demanda de carga não atendida e excesso de eletricidade anual.

\subsubsection{Produção da matriz fotovoltaica}

Na Tabela 16 a seguir é possível visualizar os valores referente às saídas da matriz fotovoltaica para cada configuração em análise. Esses valores representam a capacidade nominal, a saída média por dia, o fator de capacidade, a produção total anual, a quantidade de horas de operação e o custo nivelado de energia que é calculado contabilizando todos os custos esperados ao longo da vida do sistema (custo de construção, financiamento, combustível, manutenção, impostos, seguros, inflação) e o seu valor total é divido pela potência (kWh) do sistema durante a sua vida útil. A vida útil da matriz fotovoltaica é de 25 anos. A saída ou a quantidade de energia gerada pelos painéis para cada hora do dia durante os doze meses do ano no vilarejo é a mesma para as configurações C1, C2 e C3 (Figura 39). Devido ao aumento na capacidade da FV, então C4 apresenta uma saída com geração de energia um pouco maior que as configurações como mostra a Figura 40.

Tabela 16 - Valores da saída da matriz fotovoltaica para todas as configurações.

\begin{tabular}{ccccc}
\hline Parâmetros & C1 & C2 & C3 & C4 \\
Produção Total (kWh/ano) & 81.685 & 81.685 & 81.685 & 87.519 \\
\hline
\end{tabular}




\begin{tabular}{ccccc}
\hline Parâmetros & C1 & C2 & C3 & C4 \\
Fator de Capacidade (\%) & 17,5 & 17,5 & 17,5 & 17,5 \\
Saída média (kWh/d) & 224 & 224 & 224 & 240 \\
Capacidade Nominal (kW) & 53,2 & 53,2 & 53,2 & 57,0 \\
Horas de Operação (h/ano) & 4.380 & 4.380 & 4.380 & 4.380 \\
Custo Nivelado (\$/kWh) & 0,00958 & 0,00958 & 0,00958 & 0,00958 \\
\hline
\end{tabular}

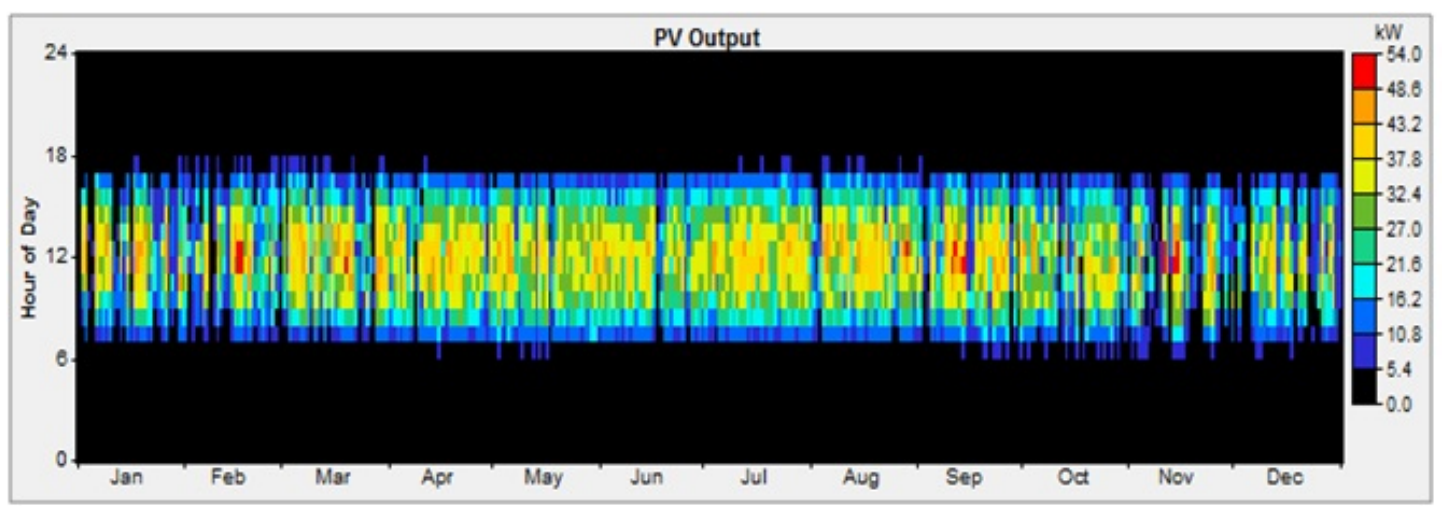

Figura 39 - Produção dos painéis solares para cada hora do dia/mês (C1, C2 e C3).

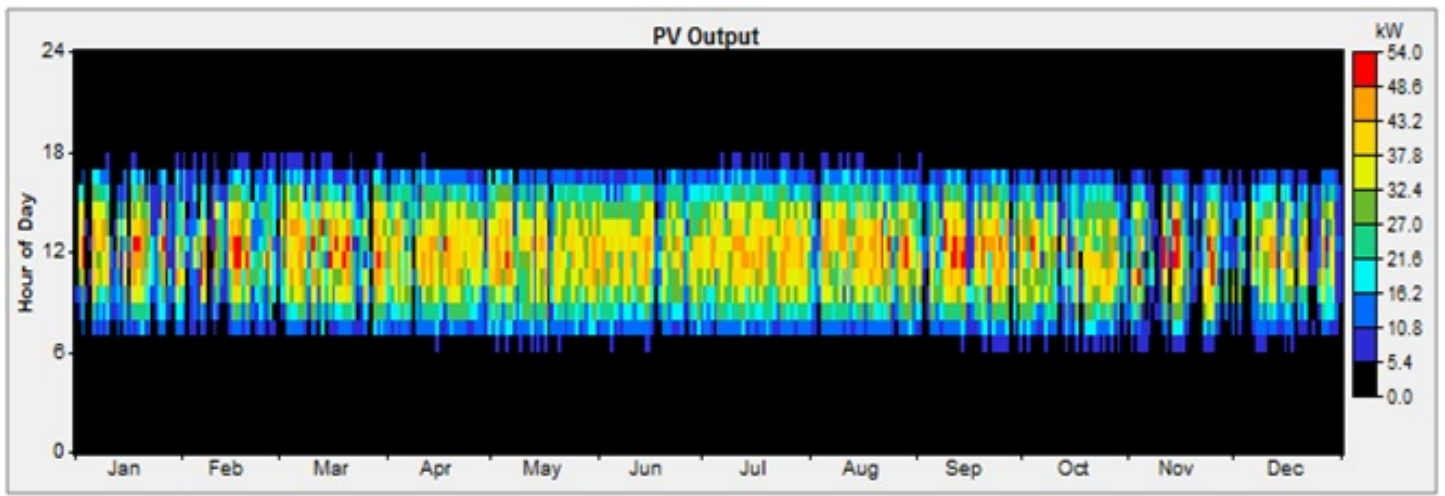

Figura 40 - Produção dos painéis solares para cada hora do dia/mês (C4).

A Figura 41 a seguir mostra a diferença no rendimento de produção de energia com as configurações intensivas para a matriz fotovoltaica. 


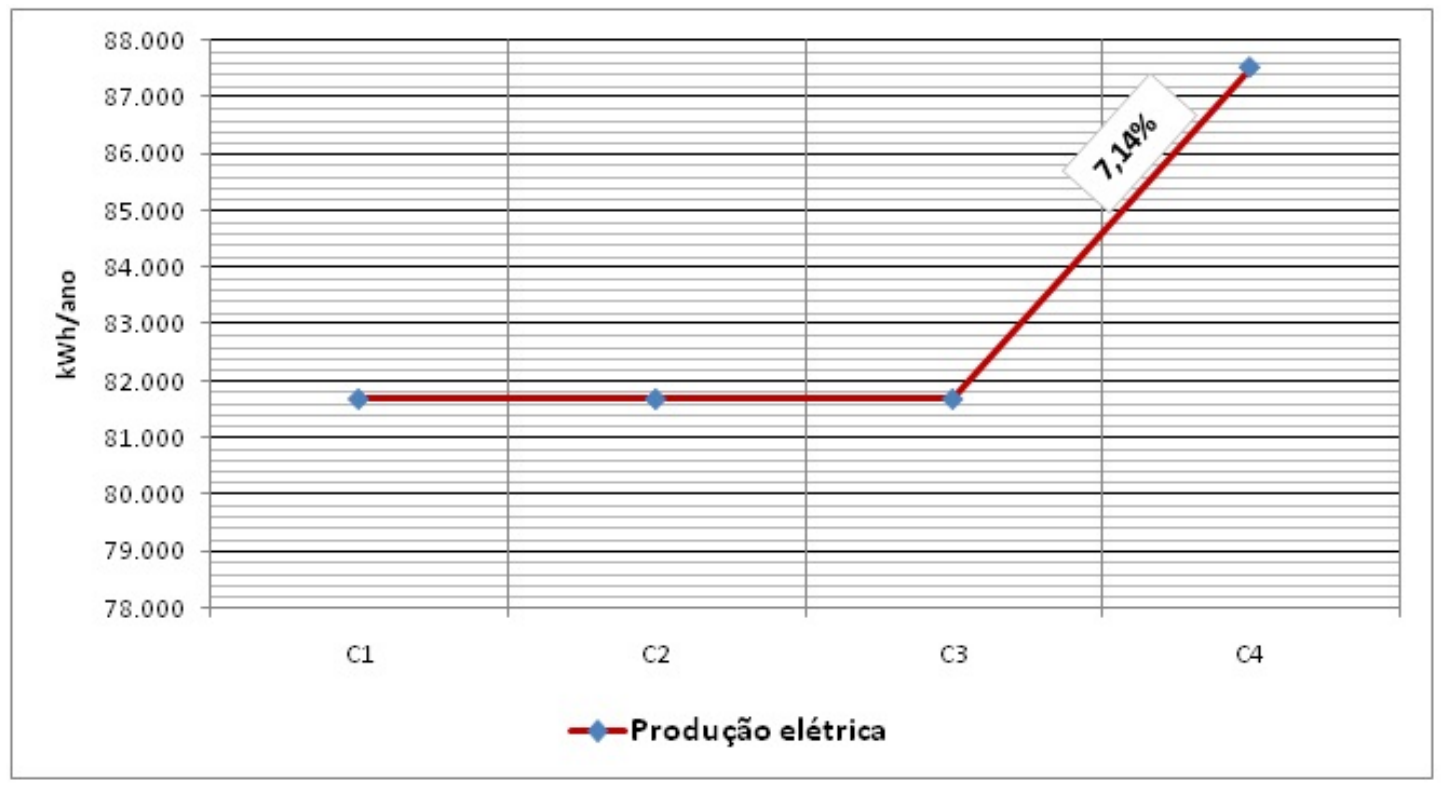

Figura 41 - Comparação no rendimento elétrico da FV para todas as configurações.

\subsubsection{Produção da Turbina}

É possível visualizar os valores referente às saídas da turbina na Tabela 17 para todas as configurações. Esses valores representam a capacidade nominal, a saída média por dia, o fator de capacidade que representa a proporção entre a produção efetiva da turbina durante um período e a capacidade total máxima neste mesmo periodo, produção total anual, quantidade de horas de operação. As configurações C1 e C3 possuem somente uma turbina, portanto, as suas saídas de energia são iguais e mostradas na Figura 42. Nas Figuras 43 e 44 são mostradas para as configurações C2 e C4 a saída ou a quantidade de energia gerada pela(s) turbina(s) para cada hora do dia durante os doze meses do ano no vilarejo.

Tabela 17 - Valores da saída da(s) turbina(s)

\begin{tabular}{ccccc}
\hline Parâmetros & C1 & C2 & C3 & C4 \\
Produção Total (kWh/ano) & 439 & 1.318 & 439 & 2.196 \\
Fator de Capacidade (\%) & 2,09 & 2,09 & 2,09 & 2,09 \\
Capacidade Nominal (kW) & 2,40 & 7,20 & 2,40 & 12,0 \\
Horas de Operação (h/ano) & 7.049 & 7.049 & 7.049 & 7.049 \\
\hline
\end{tabular}




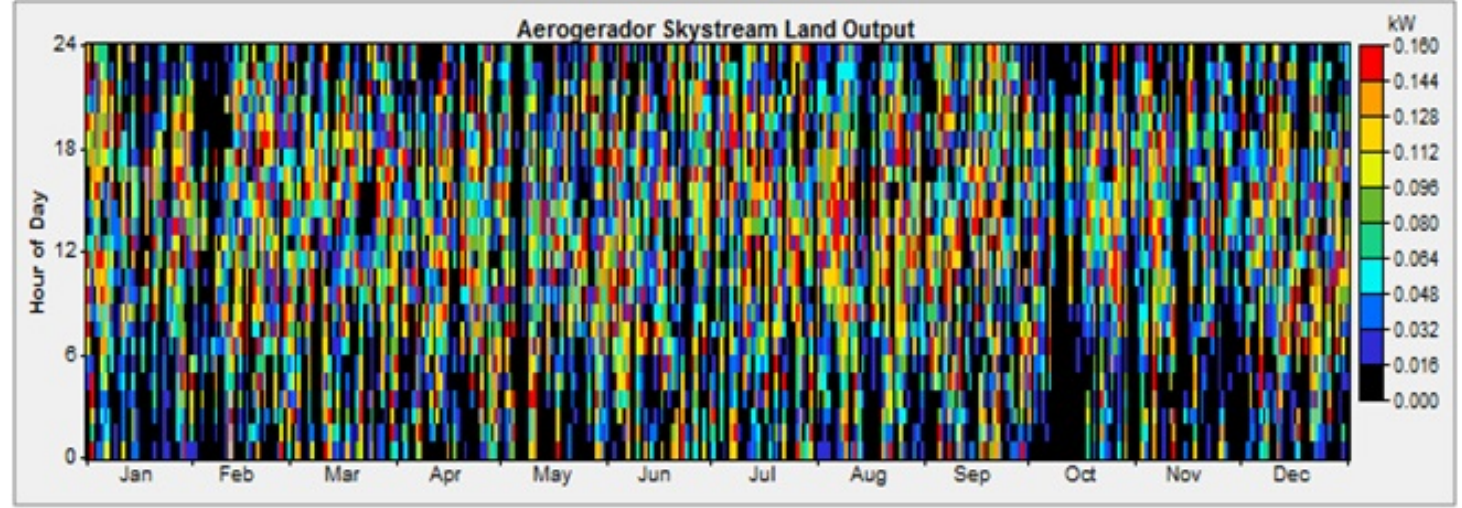

Figura 42 - Produção da turbina para cada hora do dia/mês (C1 e C3).

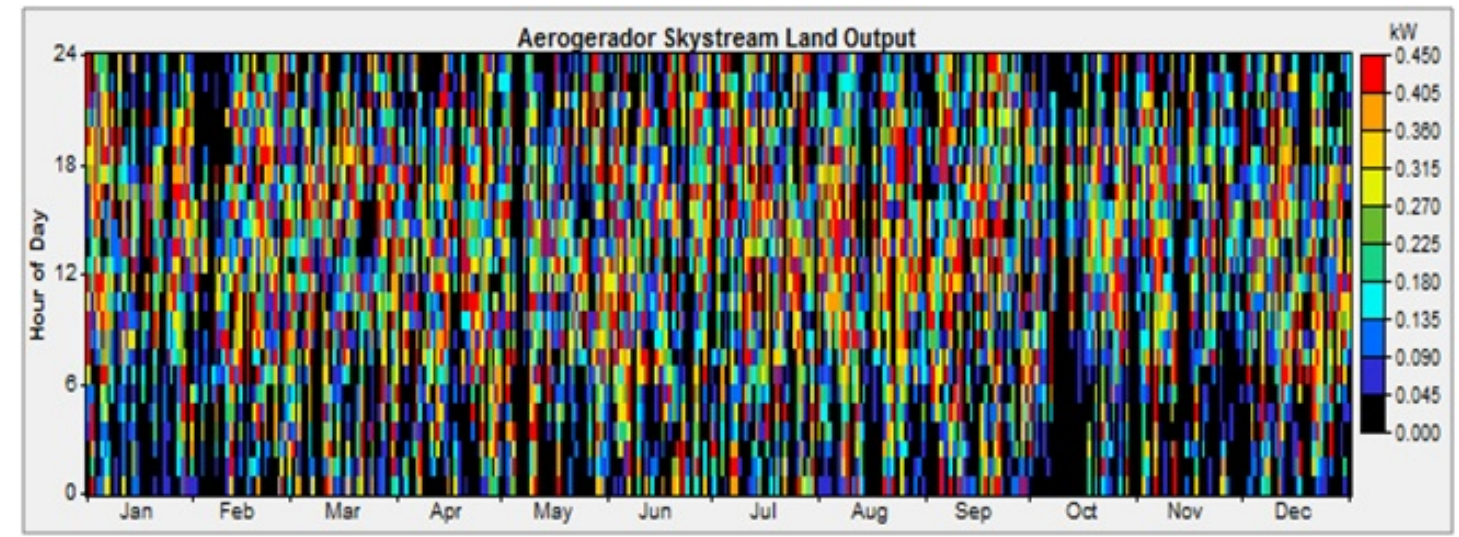

Figura 43 - Produção da turbina para cada hora do dia/mês (C2)

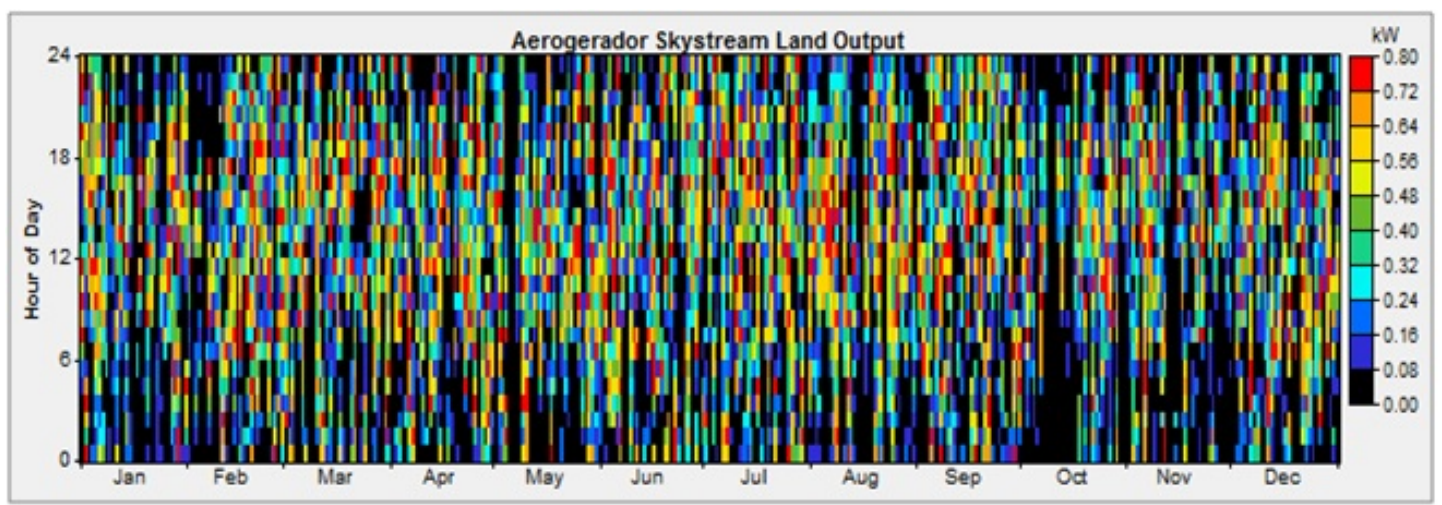

Figura 44 - Produção da turbina para cada hora do dia/mês (C4).

A Figura 45 a seguir mostra a diferença do rendimento de produção de energia com as configurações intensivas para as turbinas. 


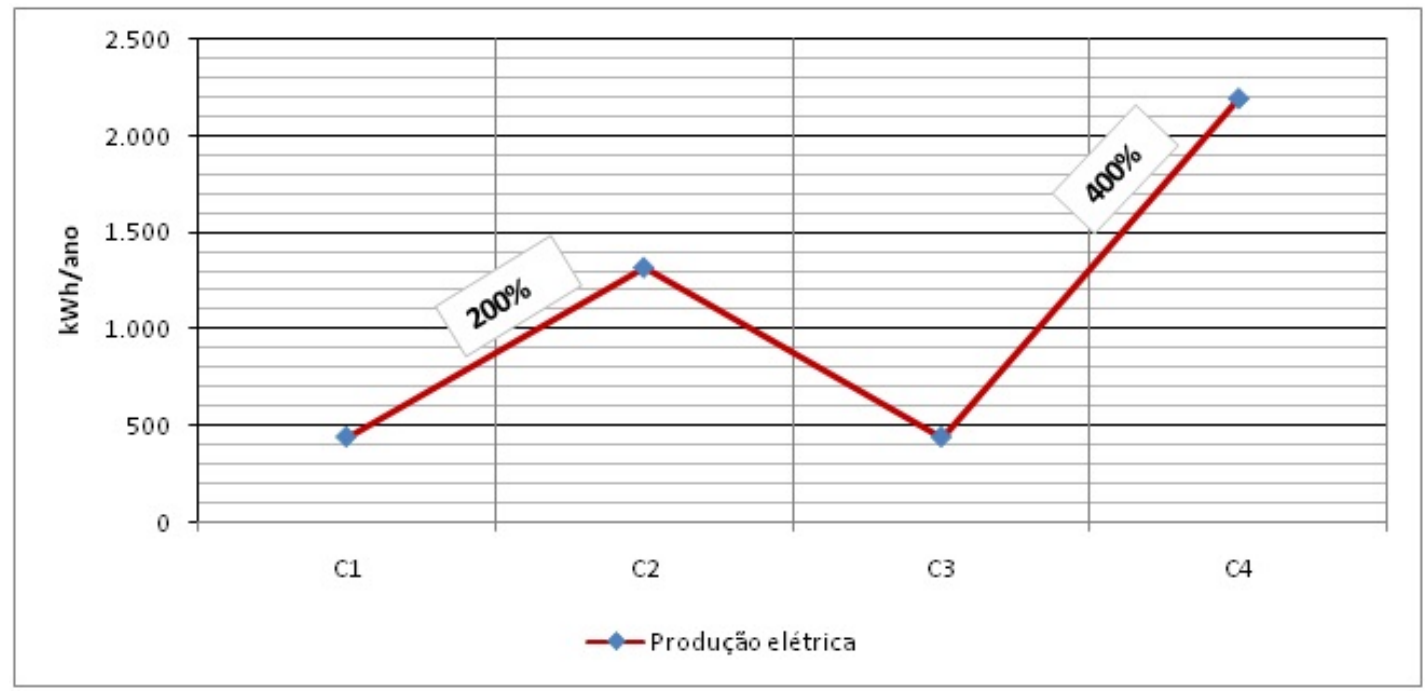

Figura 45 - Comparação do rendimento elétrico das turbinas para as quatro configurações.

\subsubsection{Saída de Energia do Banco de Baterias}

A Tabela 18 mostra os valores da capacidade nominal, a autonomia, as perdas, as entradas e saídas de energia e o custo de desgaste em $\$ / \mathrm{kWh}$, o tempo limite esperado da vida útil do banco de baterias considerando as quatro configurações. As configurações $\mathrm{C} 1$, C2 e C4 têm os seus bancos de baterias com capacidade nominais iguais e a Figura 46 mostra a variação da taxa de carga e descarga durante cada hora do dia e para cada mês do ano. Já a Figura 47 mostra a variação da taxa de carga e descarga durante cada hora do dia e para cada mês do ano para a configuração C3. Nas Figuras 48, 49 e 50 são mostradas respectivamente as diferenças em termo de autonomia, perdas e entradas e saídas de energia do banco de baterias para as quatro configurações em estudo.

Tabela 18 - Indicadores do banco de baterias para todas as quatro configurações.

\begin{tabular}{ccccc}
\hline Parâmetros & C1 & C2 & C3 & C4 \\
Capacidade Nominal (kWh) & 138 & 138 & 403 & 138 \\
Autonomia (horas) & 15,8 & 15,8 & 46,1 & 15,8 \\
Custo de Desgaste (\$/kWh) & 0,012 & 0,012 & 0,012 & 0,012 \\
Tempo Limite de vida útil & 4,0 & 4,0 & 4,0 & 4,0 \\
Perdas (kwh/ano) & 7.097 & 7.015 & 5.785 & 7.023 \\
\hline
\end{tabular}




\begin{tabular}{ccccc}
\hline Parâmetros & C1 & C2 & C3 & C4 \\
Entrada de Energia (kWh/ano) & 39.936 & 39.528 & 41.710 & 39.567 \\
Saída de Energia (kWh/ano) & 32.729 & 32.402 & 35.607 & 32.433 \\
\hline
\end{tabular}

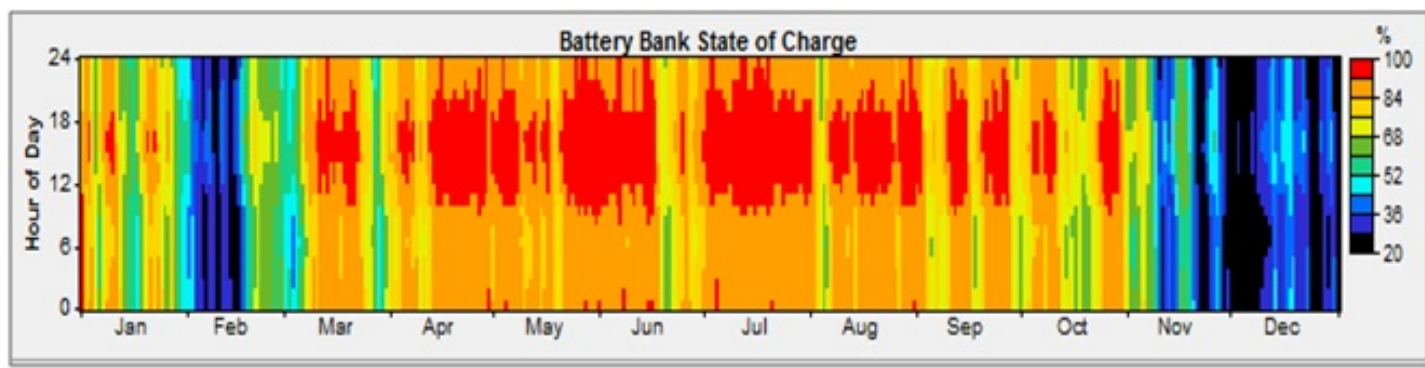

Figura 46 - Variação da taxa de descarga das baterias para cada hora/mês (C1, C2 e C4).

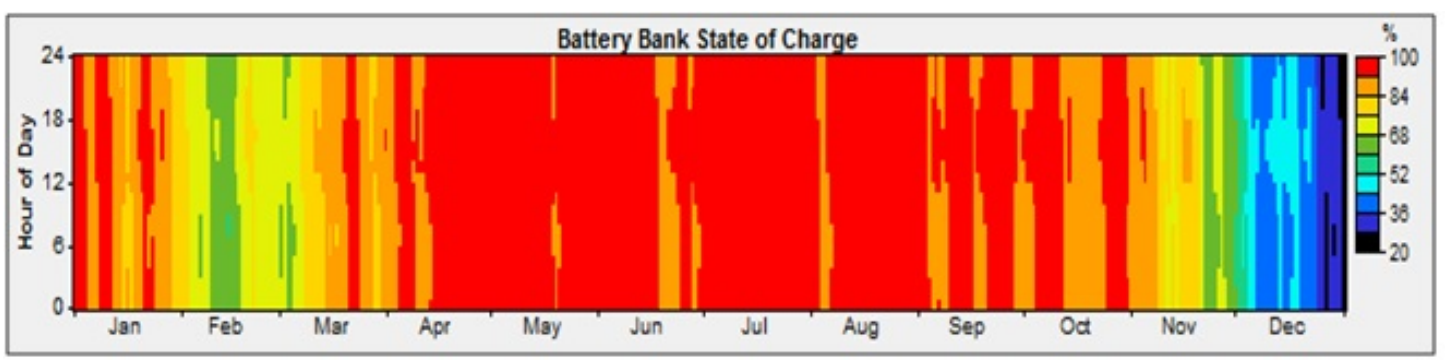

Figura 47 - Variação da taxa de descarga das baterias para cada hora/mês (C3).

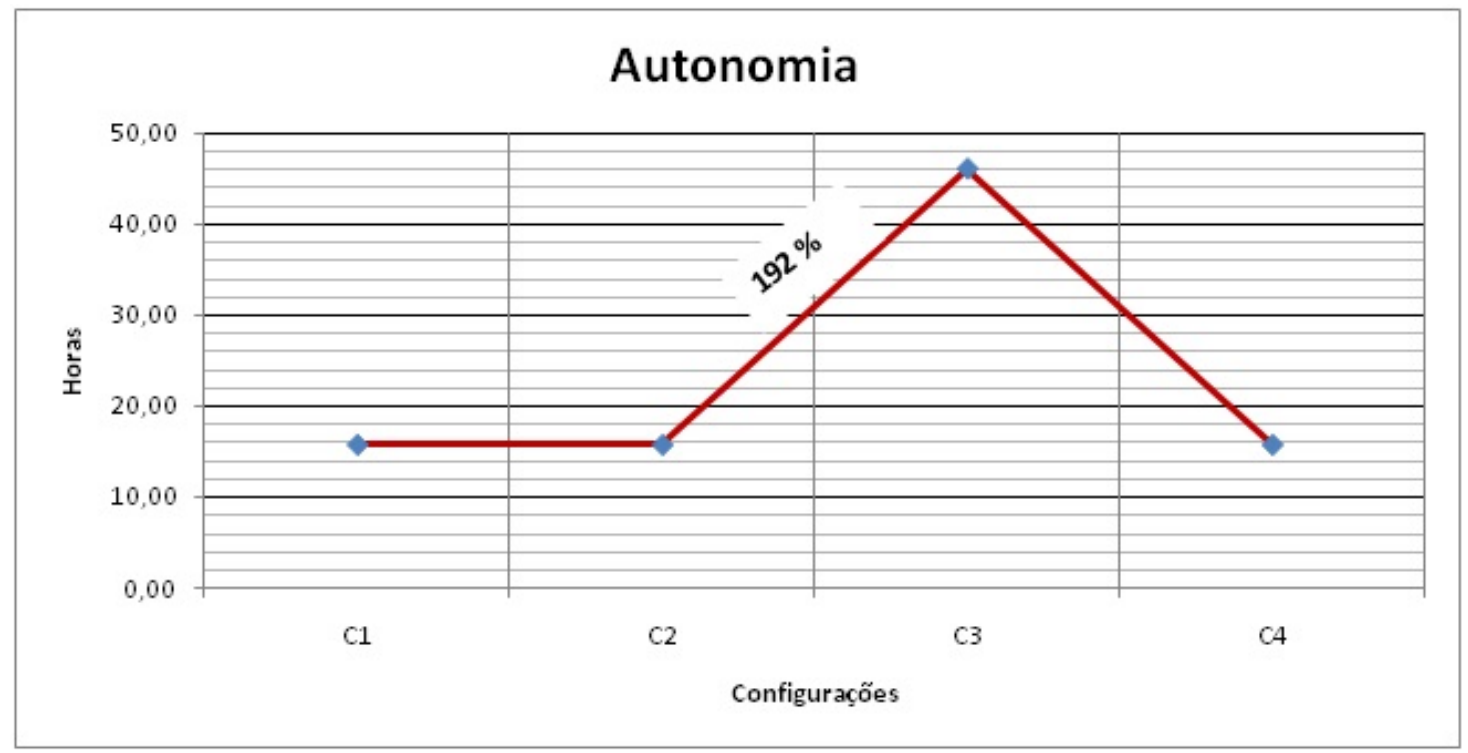

Figura 48 - Autonomia do sistema de baterias das diversas configurações. 


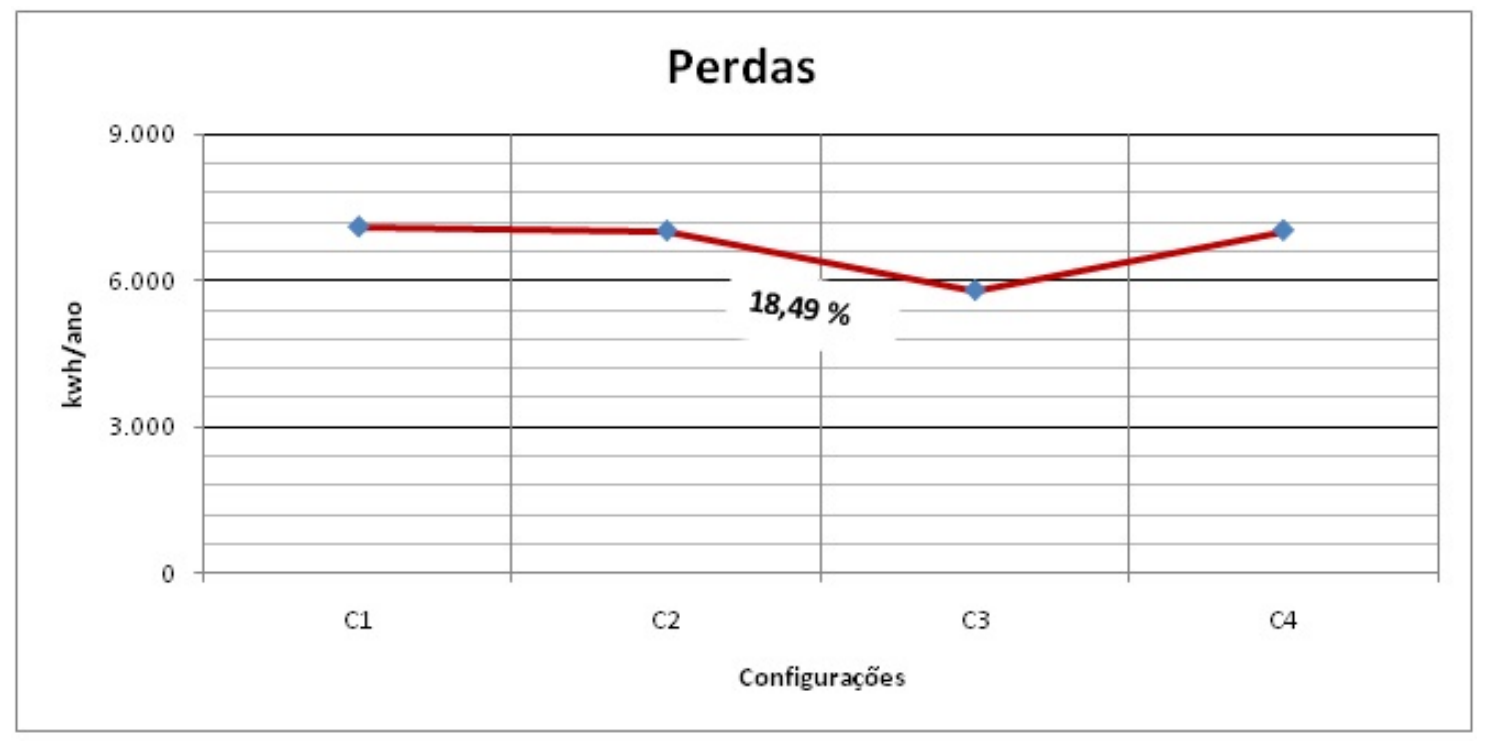

Figura 49 - Perdas no sistema de baterias das diversas configurações.

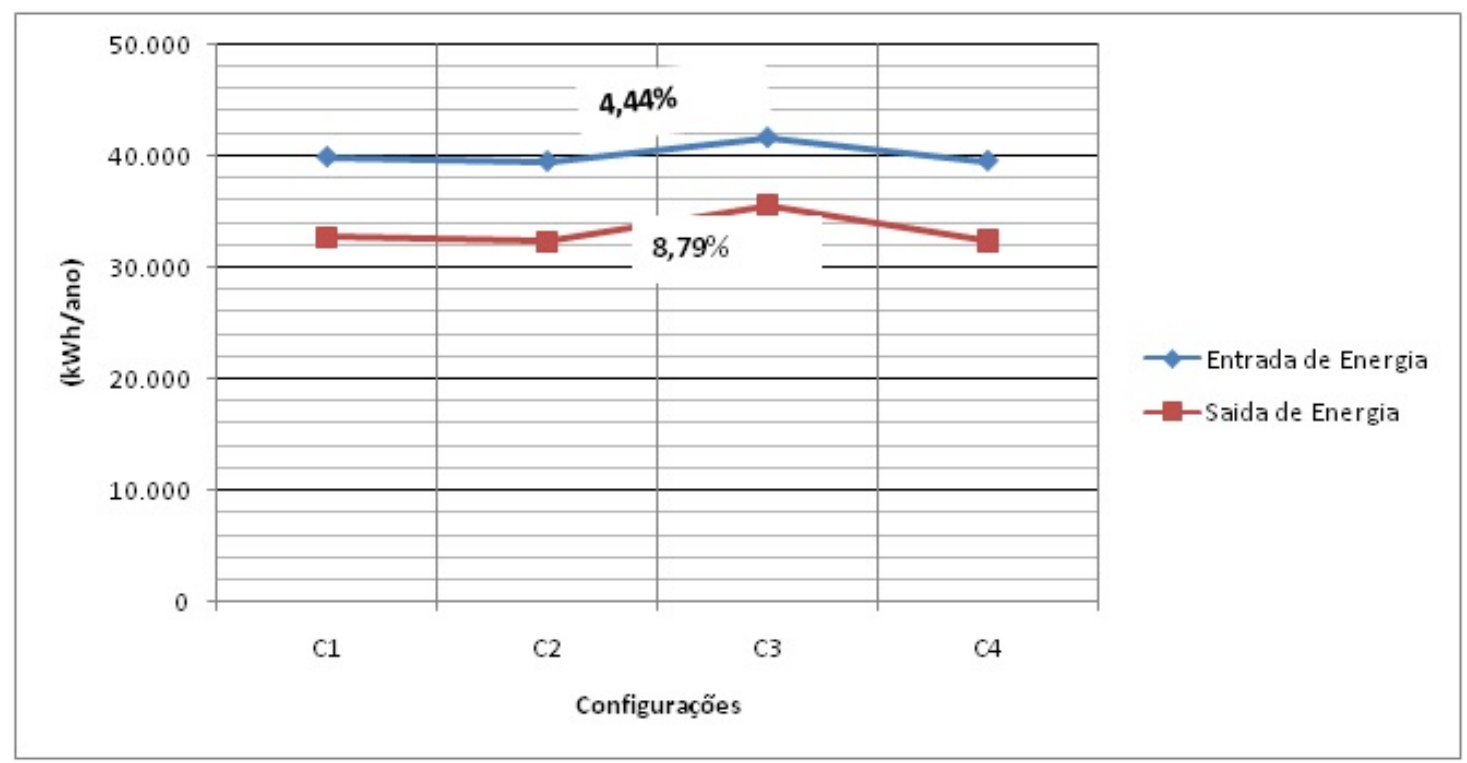

Figura 50 - Entrada e Saída de Energia no banco de baterias das diversas configurações.

\subsubsection{Custos do Sistema}

\subsubsection{Fluxo de caixa do sistema}

Nas Tabelas 19 e 20 são apresentadas os custos de cada componente e os diversos tipos de custos do sistema para as quatro configurações. Nessas tabelas ainda são descritas os custos presente líquido (NPC) para cada componente do sistema. O NPC representa o custo do ciclo de vida do sistema em estudo e ele condensa todos os custos e receitas que ocorrem dentro da vida útil do projeto em um montante 
fixo em custos do presente (\$), com fluxos de caixa futuros descontados de volta ao presente usando a taxa de desconto (especificado pelo modelador). Para todas as quatro configurações, é mostrada na Figura 51 os resumos dos custos de capital inicial referente a cada componente do sistema.

Tabela 19 - Custos de cada componentes para todas as configurações.

\begin{tabular}{lccccc}
\hline & $\mathbf{F V}(\$)$ & Turbina $(\$)$ & Baterias $(\$)$ & Conversor $\mathbf{( \$ )}$ & NPC (\$) \\
C1 & 10.008 & 83.744 & 64.195 & 54.330 & 212.277 \\
C2 & 10.008 & 251.232 & 64.195 & 54.330 & 379.765 \\
C3 & 10.008 & 83.744 & 187.234 & 108.660 & 389.647 \\
C4 & 10.723 & 418.721 & 64.195 & 54.330 & 547.968 \\
\hline
\end{tabular}

O NPC inclui os custos de construção inicial, substituição de componentes, manutenção, combustível, mais o custo de compra de energia da rede e custos diversos, como podem ser observados na Tabela 20 para cada configuração em análise. As receitas são provenientes da venda de energia à rede, mais qualquer valor residual que ocorra no final da vida útil do projeto.

Tabela 20 - Custos por tipo de custo para todas as configurações.

\begin{tabular}{lccccc}
\hline & Capital (\$) & Substituição (\$) & O\&M (\$) & Salvamento (\$) & NPC (\$) \\
C1 & 141.592 & 89.741 & 0 & -19.057 & 212.277 \\
C2 & 288.892 & 135.670 & 0 & -44.797 & 379.765 \\
C3 & 215.456 & 202.218 & 0 & -28.027 & 389.647 \\
C4 & 436.907 & 181.599 & 0 & -70.538 & 547.968 \\
\hline
\end{tabular}

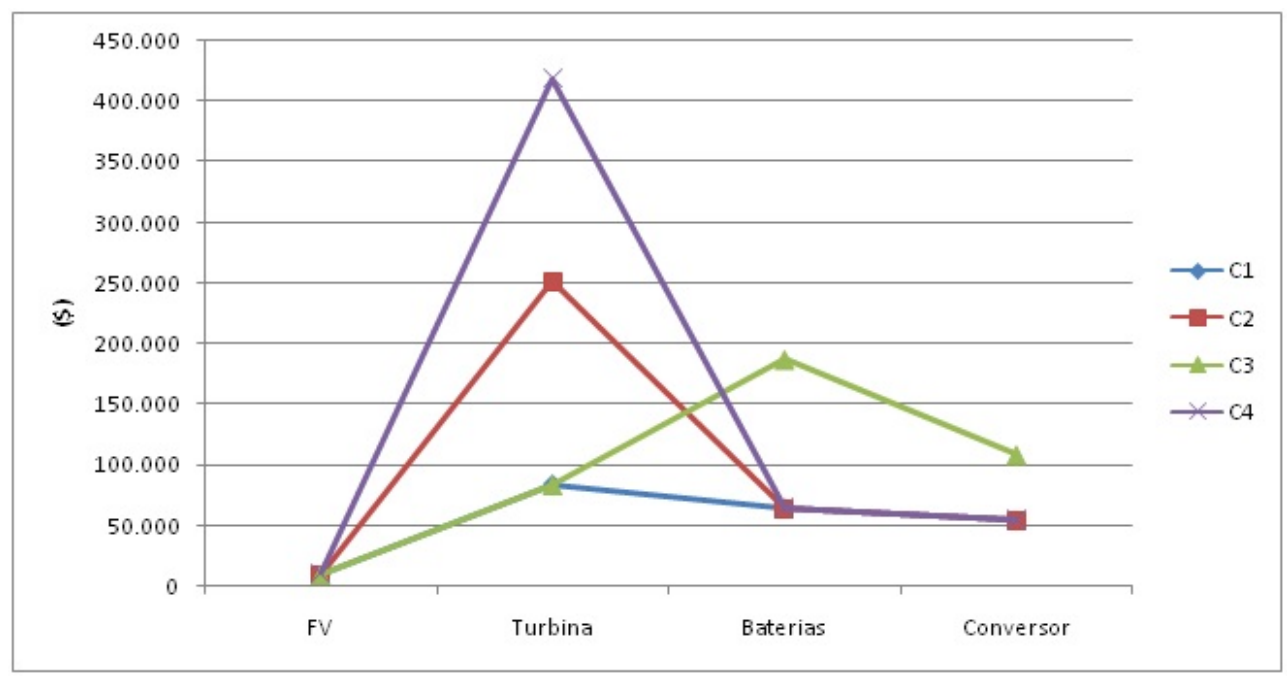

Figura 51 - Custos dos componentes para todas as configurações. 


\subsubsection{Custos Anuais}

Nas Tabelas 21 e 22 para cada configuração são apreesntadas os custos anuais por tipo de custos e para cada componente. O custo anual de cada componente é encontrado com a combinação dos custos de capital, substituição, manutenção e combustível, juntamente com o valor de salvamento e quaisquer outros custos ou receitas. Esse é o custo anual hipotético que, se ocorrer a cada ano da vida útil do projeto, renderia um custo líquido presente equivalente ao de todos os custos e receitas individuais associados a esse componente ao longo da vida útil do projeto. E por último, para encontrar o custo total anual do sistema o programa soma os custos anual de cada componente, juntamente com quaisquer custos diversos, tais como penalidades para emissões de poluentes. Na Figura 52, é mostrada os custos anuais para cada tipo de componente de todas as configurações em estudo. Como informado nos tópicos anteriores esse valor é utilizado pelo programa para determinar o custo líquido total atual e o custo nivelado de energia que são os dados econômicos mais importante no projeto.

Tabela 21 - Custos de capitais anuais por tipo de custo das quatro configurações.

\begin{tabular}{lccccc}
\hline & Capital (\$) & Substituição (\$) & O\&M (\$) & Salvamento (\$) & Total (\$) \\
C1 & 11.076 & 7.020 & 0 & -1.491 & 16.606 \\
C2 & 22.599 & 10.613 & 0 & -3.504 & 29.708 \\
C3 & 16.854 & 15.819 & 0 & -2.192 & 30.481 \\
C4 & 34.178 & 14.206 & 0 & -5.518 & 42.866 \\
\hline
\end{tabular}

Tabela 22 - Custos de capitais anuais dos diversoscomponentes do sistema.

\begin{tabular}{lccccc}
\hline & FV (\$) & Turbina (\$) & Bateria (\$) & Conversor (\$) & Total (\$) \\
C1 & 783 & 6.551 & 5.022 & 4.250 & 16.606 \\
C2 & 783 & 19.653 & 5.022 & 4.250 & 29.708 \\
C3 & 783 & 6.551 & 14.647 & 8.500 & 30.481 \\
C4 & 839 & 32.755 & 5.022 & 4.250 & 42.866 \\
\hline
\end{tabular}




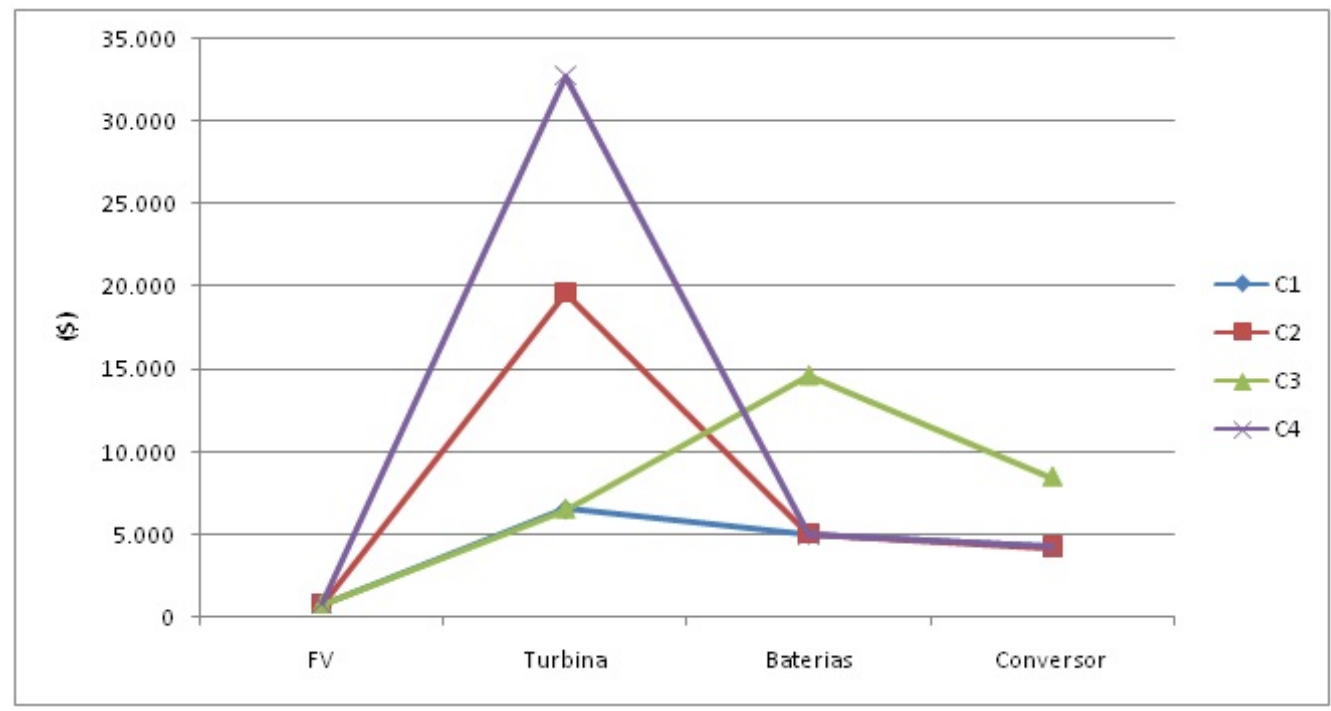

Figura 52 - Custos anuais dos componentes para todas as configurações.

A Figura 53 mostra as diferenças em termo de custos NPC da configuração escolhida pelo sistema e as três configurações intensivas de aumento de turbinas, banco de baterias e matriz fotovoltaica.

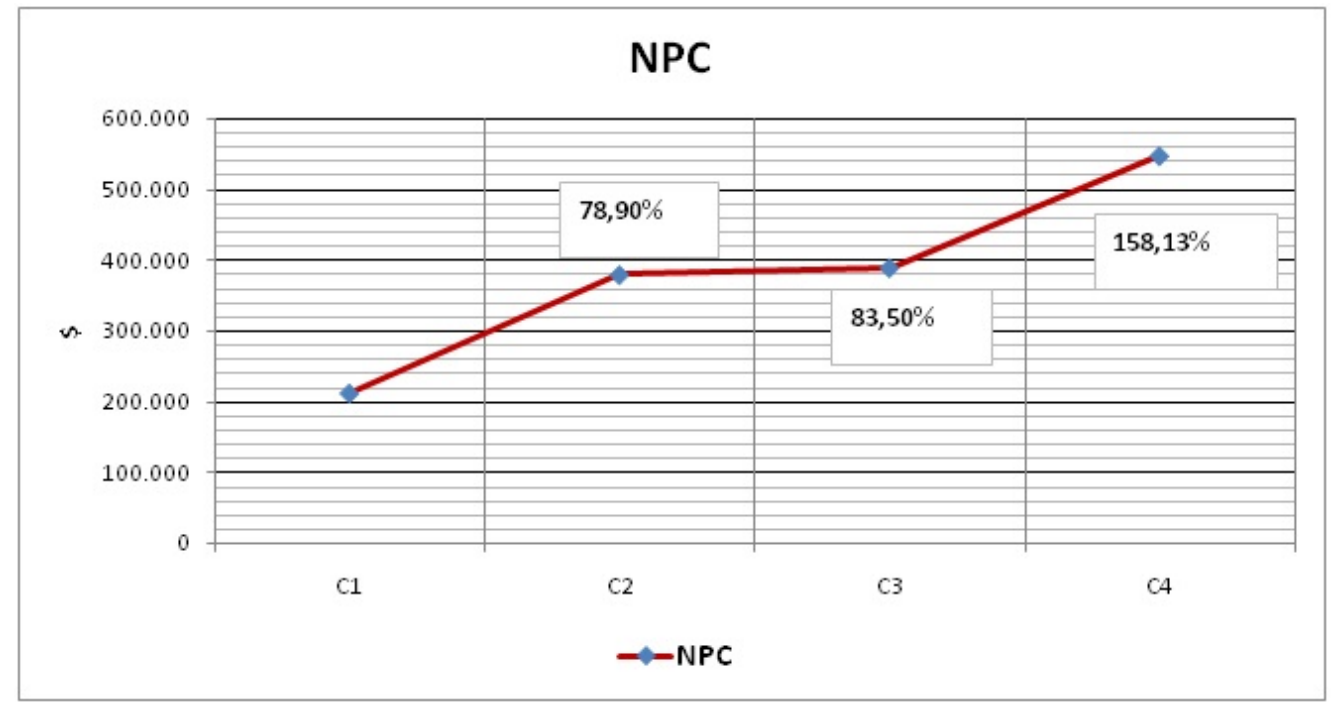

Figura 53 - Comparação dos custos NPC das quatro configurações.

Os resultados são bem consistentes, eles vão permitir fazer uma análise com abordagens econômica e técnica do projeto e consequentemente tomar decisões pertinentes a respeito das configurações simuladas pelo programa. Eles mostram várias situações ou configurações que poderiam ser úteis na implementação do sistema real. Cabe ao modelador analisar esses resultados e determinar qual configuração que melhor atende o vilarejo. 


\subsection{Análise e Discussão}

O estudo avalia os desempenhos técnico e financeiro usando um conjunto de critérios. Para avaliação técnica, os fatores considerados foram: seleção do tamanho do sistema, demanda elétrica atendida, qualidade de reparo da instalação, operação/manutenção e contribuição e reciclagem do banco de baterias. Para a avaliação financeira, o desempenho foi avaliado com base na sustentabilidade financeira.

\subsubsection{Análise técnica}

O sistema híbrido simulado consiste em uma combinação de painéis/módulos PV suplementado com aerogerador(es), um banco de baterias e um conversor. $O$ estudo explora uma mistura adequada de parâmetros inter-dependentes/parâmetros chave/ variáveis tais como potência da matriz fotovoltaico ( $\mathrm{kWp}$ ), armazenamento de bateria e capacidade da(s) turbina(s) à carga pré-definida.

O programa simulou várias configurações como as mostradas na Figura 31. A primeira linha é a configuração ideal considerada pelo sistema, significando aquela com o custo presente líquido total (NPC) mais baixo. Neste caso, a configuração ideal contém uma matriz fotovoltaica de $53,2 \mathrm{~kW}$, uma turbina de $2,4 \mathrm{~kW}$, um banco de bateria com capacidade nominal de $138 \mathrm{kWh}$ e um conversor de $12 \mathrm{~kW}$.

Esta primeira linha da Figura 31 é considerado como configuração 1 ou C1 para fim de análise. No processo de otimização o programa classifica as configurações de acordo com o custo NPC e escolhe a mais viável considerando a menor rede de custo como a configuração ideal do sistema. No entanto, visando melhor otimização do sistema, comparando detalhes técnicos, outras configurações que apresentam NPC ligeiramente maior não podem ser descartadas, ou seja, a configuração ideal considerada pelo programa pode não ser a melhor apesar de apresentar o menor NPC. Foram escolhidas outras configurações denominadas configurações intensivas (C2, C3 e C4) para comparação com a configuração escolhida pelo sistema como mostram na Tabela 14. Estas configurações intensivas apresentam custos maiores que a configuração inicial, porém, os seus resultados técnicos são bem melhores como veremos a diante, são parâmetros importantes que devem influenciar na tomada de decisão.

C2 ou configuração intensiva da turbina é constituída por uma matriz fotovoltaica de 53,2 kW, três turbinas de 2,4 kW cada, um banco de bateria com tamanho de 138 kWh e um conversor de $24 \mathrm{~kW}$. C3 que é a configuração intensiva do banco de baterias possui uma matriz $\mathrm{FV}$ de $53,2 \mathrm{~kW}$, uma turbina, um banco de baterias de capacidade nominal 403 kWh e um conversor de tamanho de 24 kW. Já C3 que representa a configuração intensiva da FV e da turbina é composta por uma FV de 57,0 kW, 5 
turbinas de 2,4 kW cada, um banco de baterias de $138 \mathrm{kWh}$ e um conversor de $12 \mathrm{~kW}$.

De acordo com a Tabela 14, a configuração C4 tem maior capacidade de geração de energia pois, tem mais turbinas e o tamanho da matriz fotovoltaica é maior do que todas as outras configurações e conseqüentemente apresenta maiores custos de capital inicial e NPC. C3 por sua vez, possui maior capacidade de armazenamento de energia já que seu banco de baterias é muito maior que as outras configurações, ela apresenta um aumento de 191,66\% em relação às outras configurações e mesmo assim essa configuração não apresenta maior custo de NPC, é uma das configurações com menor custo de capital inicial. C2 possui três turbinas, um total de 7,2 kW de potência, um banco de baterias igual o banco de bateria das configurações $\mathrm{C} 1$ e C4, porém apresenta um custo inicial maior que C3 e C1, ela só não é maior que C4 em termo de custo de capital inicial. E C1 que é a configuração escolhida pelo HOMER como a melhor, apresenta custos de capital inicial e NPC menores que todas as outras configurações, porém com capacidade de produção e armazenamento menor que as configurações intensivas. Observando essa tabela acima citada, nas configurações $\mathrm{C} 1$ e C3 que possuem só uma turbina, a matriz fotovoltaica é responsável por fornecer 99\% da produção elétrica do sistema e a turbina só 1\%. Já na C2 e C4 que possuem respectivamente 3 e 5 turbinas, a FV fornece $98 \%$ da produção de energia e as turbinas são responsáveis por $2 \%$.

Na Tabela 15, para todas as configurações são apresentadas a produção total de energia por ano. São também apresentados o excesso de eletricidade e a carga anual não atendia por ano para cada configuração. Nas configurações C1 e C3, a produção anual total de energia elétrica é de $82.124 \mathrm{kWh} / \mathrm{ano}$, na configuração C2 a quantidade de energia anual é de $83.002 \mathrm{kWh} /$ ano um aumento de 1,07\% em relação às configurações C1 e C3 e a configuração C4 que apresenta um cenário melhor em termo de produção de eletricidade já que tem maior capacidade de produção, consegue produzir $89.715 \mathrm{kWh} /$ ano, isto é, um aumento de $9,24 \%$ a mais comparando com C1 e C3.

Nas Figuras 32, 33, 34 e 35, são mostradas a média mensal de produção de energia elétrica para todas as configurações. Como informado nos parágrafos anteriores, a C4 em termos de instalação possui uma capacidade maior que as outras configurações com 57,0 kW de FV e 5 turbinas para uma potência de 12,0 kW, então é óbvio que ela consegue produzir um pouco mais de energia. A sua média mensal de produção energética é conseqüentemente maior, ela tem uma média de cerca de 10,34 kW como mostra a Figura 35. A C2 possui 3 turbinas para uma média de 7,2 kW e uma FV de 53,2 kW e uma média de produção mensal de 9,58 kW (Figura 33). C1 e C3 possuem uma turbina de 2,4 kW e FV de 53,2 kW de potência, elas têm uma média mensal de produção elétrica de aproximadamente 9,45 kW (Figuras 32 e 34). A 
diferença na média de produção elétrica mensal de C1 e C3 para C2 que possui uma maior capacidade para gerar emergia é de 1,37\%, ou seja, em termos de capacidade isso é praticamente insignificante, observando o gráfico da Figura 36, a produção dessas três configurações é praticamente a mesma durante todos os meses do ano. Já de C1 e C3 para C4, o aumento na geração é de 9,42\%, como observado na Figura 37 (comparação dos rendimentos totais de energia considerando as configurações intensivas). Neste caso poderia levar em consideração essa configuração C4 como melhor, mas ainda é muito cedo para estabelecer qualquer conclusão já que possui outros detalhes técnicos e econômicos que podem influenciar de maneira significativa na tomada de decisão.

De maneira geral em todas as configurações como mostram as Figuras 32, 33, 34 e 35, nos meses de novembro, dezembro e fevereiro, a geração de energia é menor. O sistema como vimos na Tabela 15 é fortemente dependente da FV que por sua vez depende da radiação solar, nesses meses, a radiação é menor devido às chuvas, neblinas e outros fatores de tempo na localidade em estudo que conseqüentemente impacta na produção do sistema. Então neste período, ter um banco de baterias eficiente e/ou turbinas eólicas é importante para manter o sistema em funcionamento. Nos outros meses a geração é forte com destaque para o mês de julho que apresenta um pico maior.

A Figura 38 mostra a diferença de excesso de eletricidade e de carga anual não atendida pela localidade. No gráfico de excesso de eletricidade anual desta figura, C4 apresenta maior excesso de eletricidade do que $\mathrm{C} 1, \mathrm{C} 2$ e $\mathrm{C} 3$. Em termos de reserva operacional a configuração C4 representa 18,1\%, 12,6\% (C2), 11,8\% (C1) e 9,6\% (C3) que é a configuração com menor porcentagem de excesso de eletricidade anual. Já no gráfico de carga anual não atendida dessa mesma figura, a porcentagem de carga não atendida de C1 é maior, com uma representação de 4,3\%, seguida por C2 $(4,0 \%)$, C4 $(2,7 \%)$ e C3 (0\%) de carga anual não atendida. Esse detalhe técnico é super importante no sistema, o objetivo do sistema é fornecer anualmente $100 \%$ de energia elétrica para toda a comunidade. Como destacamos as configurações C1, C2 e C4 apresentam certas porcentagens importantes de carga anual não atendida, isto é, durante certo período de tempo haveria certa interrupção no fornecimento de carga elétrica para a comunidade. Essa interrupção deve estar relacionado com a diminuição na produção da matriz fotovoltaica nos meses de novembro, dezembro e fevereiro (Figura 32, 33, 34 e 35) devido a redução na radiação solar e que automaticamente impactaria na autonomia do sistema de bateria causando esgostamento (sistema não consegue fornecer toda a carga durante esse periodo) e descargas prolongadas.

Na configuração intensiva de bateria (C3), o valor de carga não atendida é $0 \%$, ou seja, o sistema em termos técnicos teria total condição de atender a demanda de 
carga anual do vilarejo em estudo mesmo com a redução de geração da FV nos meses de menor radiação. C3 faria um trabalho de evitar descargas profundas e prolongadas do banco de bateria, o que poderia reduzir drasticamente a vida útil das baterias no sistema real. Esse detalhe provavelmente fará muita diferença na tomada de decisão para saber qual das configurações que melhor atende o vilarejo em termo de viabilidade técnica.

Nos resultados da Tabela 16, a capacidade nominal de C1, C2 e C3 é de 53,2 kW e a produção anual do gerador fotovoltaico é de $81.685 \mathrm{kWh} /$ ano e C4 tem uma capacidade nominal de $57,0 \mathrm{~kW}$ e a FV produz $87.519 \mathrm{kWh} /$ ano. Essa matriz fotovoltaica está diretamente conectada a um banco de bateria e isso faz com que ela se exposta a uma voltagem diferente do ponto de potência máxima (a tensão na qual a potência é maximizada e que depende da radiação solar e da temperatura) que com isso irá diminuir o seu desempenho. $O$ custo nivelado de energia para todas as configurações é igual e tem um valor de $0,00958 \$ / \mathrm{kWh}$ e todas as configurações possuem o mesmo fator de capacidade que é 17,5\% e a FV irá trabalhar 4.380 horas/ano.

A geração diária dos painéis para cada hora do dia durante os doze meses do ano no vilarejo é mostrada nas Figuras 39 e 40 que representa C1, C2, C3 e C4. No período de março a outubro como mostra os resultados das figuras, a produção será bem alta, já que são os meses com maior radiação solar, sendo o mês de julho é destacado pela maior geração elétrica da FV. Nos períodos de 00:00 até 06:00 e de 18:00 até 00:00, a produção é zero, já entre 06:00 até as 18:00 ela gera quantidade importante de energia dependendo da hora do dia e do mês. 12:00 é a hora com maior radiação e automaticamente a geração é maior, dependendo do dia e do mês a geração pode chegar até mais de $46 \mathrm{~kW}$, caso de algumas horas dos meses de fevereiro, julho, setembro e novembro. O mês com menor geração é dezembro, dependendo do dia, a energia gerada pode ficar abaixo de 10,8 kW.

$\mathrm{Na} \mathrm{C} 1, \mathrm{C} 2$ e C3 a geração anual é a mesma já que possuem a mesma capacidade nominal de FV. Já C4 apresenta uma maior geração anual, pois possui maior capacidade nominal. Como mostra a Figura 41, ela apresenta uma diferença de 7,14\% em relação às outras configurações.

Apesar da pouca produção da(s) turbina(s), ela(s) desenvolve um papel importante no sistema. Além de ajudar na oferta nos dias mais ensolarados, nos dias de sol fraco, nublados, chuvosos e nos períodos que não têm sol como de noite ela(s) desempenha um papel fundamental fazendo com que seja mantido o equilíbrio entre oferta e demanda de energia. Como mostra a Tabela 17, na C1 e C3 que possuem só uma turbina, a produção é de $439 \mathrm{kWh} / \mathrm{ano}, \mathrm{C} 2$ com três turbinas gera $1.318 \mathrm{kWh} /$ ano e por último C4 com 5 turbinas geraria $2.196 \mathrm{kWh} /$ ano. Elas trabalhariam 7.049 horas/ano. Observando as Figuras 42, 43 e 44 percebemos que para todas as configurações a 
geração de energia da(s) turbina(s) varia muito de acordo com a hora e o dia do mês. Existem horas que elas conseguem gera até $0,160 \mathrm{~kW}$ exemplo de julho e agosto entre 06:00 até às 18:00 e tem hora que ela praticamente não gera energia caso do mês de outubro entre 00:00 até 06:00. Na pesquisa de Himri et al. (2007), "estudo técnico-econômico de uma instalação híbrida para uma aldeia remota na Argélia", resultados semelhantes foram encontrados para variação de energia gerada por turbinas durante certo período de tempo apesar da velocidade média de vento é diferente para a comunidade em estudo.

A Figura 45 mostra para as quatro configurações a diferença de geração de energia elétrica da(s) turbina(s). De C1 para C2, haveria um aumento de $200 \%$, de C1 para C3 a produção não altera e de C1 para C4 o aumento seria de $400 \%$. Mesmo com estes aumentos, a participação das turbinas continua baixa no sistema de geração total. Para um aumento de $200 \%$ de produção das turbinas, isto é, passando de uma turbina para 3, a saída total do sistema passou de $82.124 \mathrm{~kW} /$ ano para $83.002 \mathrm{~kW} / \mathrm{ano}$ que representa um pequeno acréscimo de 1,07\%. Quando passamos de uma turbina para cinco, isso deu um acréscimo de 2,14\% na geração inicial. Enfim, mesmo com adição de mais turbinas no sistema, a participação delas no sistema continua baixa, ou seja, será que vale a pena insistir em adicionar mais turbinas no sistema já que possuem elevados custos como veremos adiante? Mesmo com aumento das turbinas o aproveitamento da energia eólica não parece satisfatório, então para compensar, um investimento num banco de baterias talvez seria viável como mostra a configuração C3 e Saheb-Koussa, Haddadi e Belhamel (2009) mostraram no seu estudo resultados parecidos.

Na Tabela 18 para o 1, o banco de baterias teria uma saída de energia de $32.729 \mathrm{kWh} / \mathrm{ano}$, perdas na ordem de $7.097 \mathrm{kWh} / \mathrm{ano}$, uma autonomia de 15,8 horas e sua capacidade nominal de $138 \mathrm{kWh}$. Na C2, o banco de baterias teria uma saída de energia de $32.402 \mathrm{kWh} / \mathrm{ano}$, perdas na ordem de $7.015 \mathrm{kWh} / \mathrm{ano}$, uma autonomia de 15,8 horas e sua capacidade nominal de $138 \mathrm{kWh}$. Para a C3, o banco de baterias teria uma saída de energia de $35.607 \mathrm{kWh} / \mathrm{ano}$, perdas na ordem de $7.785 \mathrm{kWh} / \mathrm{ano}$, uma autonomia de 46,1 horas e sua capacidade nominal de $403 \mathrm{kWh}$. E por último, na C4 o banco de baterias teria uma saída de energia de $32.433 \mathrm{kWh} / \mathrm{ano}$, perdas na ordem de $7.023 \mathrm{kWh} / \mathrm{ano}$, uma autonomia de 15.8 horas e sua capacidade nominal de $138 \mathrm{kWh}$.

As Figuras 46 e 47 mostram a variação da taxa de descarga das baterias para cada hora do dia durante os doze meses do ano para C1, C2, C3 e C4. A bateria é um dispositivo que armazena certa quantidade de eletricidade CC a uma eficiência energética fixa. No sistema, o banco de baterias absorve energia quando a saída de energia fotovoltaica excede a carga e descarrega energia quando a carga excede a saída de energia fotovoltaica. O limite de profundidade de descarga do 
banco de bateria é um fator importante para manter a eficiência e as propriedades das baterias. Na simulação, o programa não permite que a bateria seja descarregada mais profundamente que este limite, porém quanto mais perto desse limite chega à descarga, pior para o sistema. Os resultados dessas figuras mostram claramente essa diferença comparando as quatro configurações.

Na Figura 46 que representa $\mathrm{C} 1$, durante os meses de novembro, dezembro e fevereiro, para algumas horas ou até dias, o limite de descarregamento chega até $20 \%$, o que nos indica que provavelmente deve ter sido uma das causas pelo qual foi encontrado na Tabela 15, 4,3\% de demanda de eletricidade não atendida durante o ano pelo sistema. Esse cenário é o mesmo que acontece nas configurações intensivas da turbina (C2) e da FV e turbina (C4), descargas profundas durante horas ou mesmo dias, porém na C4 a demanda de carga anual não atendida (2,7\%) é menor que na $\mathrm{C} 1$, o motivo pode estar relacionado ao aumento do tamanho da FV já que nessa, a FV passou de 53,2 kW para 57,0 kW. Na Figura 47 que representa C3, só no finalzinho do mês de dezembro teriam algumas poucas horas de descarregamento que pode chegar perto do limite de descarregamento, já durante o ano inteiro o sistema de bateria manteria praticamente sua total carga e talvez seja por isso que o sistema como observado na Tabela 15, a demanda de carga anual não atendida é $0,0 \%$ e assim conseguiria atender toda demanda anual da comunidade sem se preocupar com interrupções inesperadas.

Outro parâmetro importante avaliado é a autonomia do sistema como mostra a Figura 48. As configurações C1, C2 e C4 possuem autonomias iguais e representam 15,8 horas, já C3 possui uma autonomia maior 46,1 horas que significa um aumento de $192 \%$ em relação a C1. As perdas ainda são maiores nas configurações C1, C2 e C4, dessas para C3 a diferença é de 18,49\% como mostra a Figura 49. E por fim são as entradas e saídas de energia para cada configuração em análise como mostra a Figura 50. A configuração C3 possui uma capacidade de armazenamento maior e conseqüentemente consegue libera mais energia. Ela consegue armazena 4,44\% e libera $8,79 \%$ de energia a mais que as outras configurações. E enfim, outro fator importante é a reserva operacional, essa configuração C3 ainda possui uma reserva operacional anual de $7.888 \mathrm{kWh} /$ ano que representa um excesso de eletricidade como mostra a Tabela 15. A reserva é importante porque a carga elétrica às vezes flutua acima da capacidade operacional do sistema, e isso poderia resultar numa interrupção inesperada.

Todos esses detalhes técnicos como, autonomia, perdas, rendimento anual, profundidade de descarga, saídas e entrada de energia elétrica são importantes em termo de viabilidade técnica no sistema. Pelo que tudo indica a avaliação desses detaIhes técnicos já permite deduzir que a configuração intensiva C3 apresenta melhores 
resultados que as outras configurações C1, C2 e C4.

\subsubsection{Análise Econômica}

A Tabela 19 estabelece a relação dos diversos custos do sistema para cada configuração em análise. C4 possui um custo de capital inicial maior, seguido por C2 e logo C3 com uma diferença de 25,42\% para C2, C1 tem o menor custo de capital inicial. Em termos de custos de substituição, C3 tem o maior custo, seguido por C4 e C2 e sem seguida C1. A diferença de C3 para C4 é de 10,2\%, já para C2 a diferença é de 32,9\%. Como mostra a Figura 51, C4 e C2 possuem grandes custos de turbinas enquanto $\mathrm{C} 1$ e $\mathrm{C} 3$ possuem custos baixíssimos. Os custos de baterias e conversor em C3 são maiores do que nas outras configurações.

O NPC representa o custo do ciclo de vida do sistema que é o custo total de instalação e operação ao longo da vida útil do sistema. O sistema é projetado para ter uma vida útil de 25 anos. Na Figura 51, os custos mais altos são os custos de turbinas e do banco de baterias. Na configuração C2 e C4 respectivamente devido ao aumento de turbinas os custos sobem de \$83.744 para \$251.232 e \$418.721 e na C3 devido ao aumento na quantidade de baterias o custo passou de $\$ 64.195$ para $\$ 187.234$. Então, em termos de custos NPC, comparando C1, a configuração escolhida pelo sistema com as configurações intensivas C2, C3 e C4. De C1 para C2 houve um aumento de $78,90 \%$, para C3 o aumento é de $83,50 \%$ e 158,13\% para C4, ou seja, C4 possui maior custo de NPC seguido por C3 e C2. Porém de C3 para C2, a diferença é ligeiramente pequena um total de 2,53\%. A Figura 53 mostra uma clara diferença entre esses custos NPC para todas as configurações simuladas pelo programa.

Shaahid e Elhadidy (2008), na sua pesquisa determinaram a representação da matriz fotovoltaica nos custos de NPC de um sistema FV-diesel-baterias e encontraram que a FV representou $70 \%$ destes custos. Neste trabalho identificamos a representação da FV, da(s) turbina(s), do banco de bateria e do conversor nos custos de NPC para cada configuração em estudo. Percebe-se que na $\mathrm{C} 1$, a turbina tem o maior custo com uma representação de 39,45\% seguido pelo banco de bateria $(30,24 \%)$ e do conversor $(25,59 \%)$, a FV tem a menor participação com 4,71\%. Na C2, as turbinas representam $66,15 \%$ e têm a maior participação. Na C3, o banco de baterias com 48,05\% representa a maior participação, seguido pelo conversor $(27,88 \%)$, da turbina $(21,49)$ e da FV (2,56\%). Já na C4, as turbinas representam 76,41\% de NPC.

Além dos custos de NPC, ainda têm os possíveis custos anuais do sistema que se ocorrer a cada ano da vida útil do projeto, renderia um custo líquido presente equivalente ao de todos os custos e receitas individuais associados a esse componente ao longo da vida útil do projeto. Os cenários acima são os mesmos ao fazer uma comparação entre os custos anuais por componente e dos diversos custos no sistema 
ao observamos a Figura 52 e as Tabelas 21 e 22. Fazendo uma comparação entre os custos inicias e os custos anuais do projeto, percebe-se que os custos anuais são bem menores que os custos iniciais do projeto e isso confirma a teoria de LAMBERT et al. (2006) que diz que "diferente dos projetos de energias convencionais, os projetos de fontes renováveis tendem a ter altos custos de capital iniciais e custos anuais baixos". Estes custos anuais são decorrentes de manutenção, operação e mão-de-obra de todos os componentes do sistema.

Enfim, como mostrado anteriormente, as configurações se diferem por questões técnicas e econômicas, isso mostrou as suas viabilidades que vão ajudar na tomada de decisão a respeito da melhor configuração para o sistema em estudo. Nas configurações C2 e C4, a geração da turbina é pequena, no entanto, elas geram custos altos, ou seja, isso mostra que não é tão viável em termos de custo benefício adicionar mais turbinas no sistema, sem contar da pouca participação no sistema, ainda haveria certo período de tempo durante o ano que a demanda não seria atendida como mostra a Figura 38. A configuração $\mathrm{C} 1$ que possui os menores custos também por detalhes técnicos não se mostra tão viável, haveria em certo período carga não atendida, nos meses de pouca radiação teria esgotamento e descargas prolongadas das baterias. Já C3, mesmo apresentando NPC 83,50\% maior que C1 e uma diferença de NPC de 2,53\% para C2 se mostra mais viável já que possui 0\% de carga anual não atendida, não apresenta descargas profundas e prolongadas mesmo nos dias de pouca radiação $e$ assim conseguiria atender toda demanda da comunidade. Além disso ela apresenta melhor autonomia no banco de baterias, ainda teria uma reserva operacional anual, conseguiria armazenar e liberar mais energia do que as outras configurações.

\subsubsection{Análise de Sensibilidade}

A Figura 54 mostra os resultados da análise de sensibilidade de duas variáveis. Nesta análise foram variadas a média da velocidade do vento e a média da radiação solar do vilarejo em estudo para identificar os seus impactos na produção anual de energia. Para cada variável foram variadas valores em torno de $16 \%$ abaixo e $16 \%$ acima da média de irradiação e da média da velocidade do vento e que são considerados como melhores estimativas como pode observar na Figura 54 abaixo. 


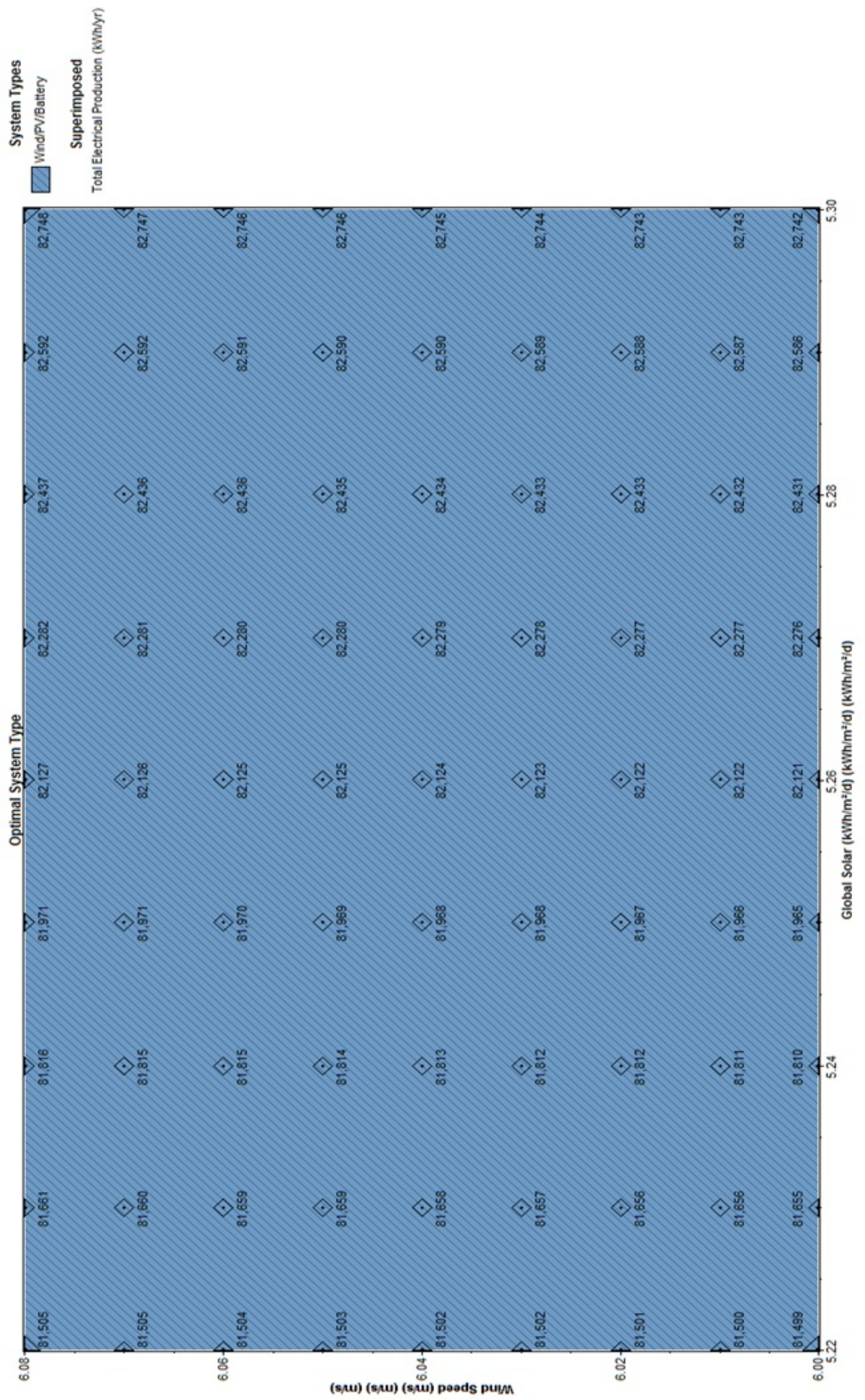

Figura 54 - Análise de sensibilidade de valores relativo à melhor estimativa 
Essa figura mostra o quão sensível a quantidade de energia anual produzida para cada uma das variáveis considerada. Se a velocidade do vento aumenta em torno de $16 \%$ da melhor estimativa, o sistema sofrerá mudanças produzindo anualmente mais eletricidade sem necessariamento um aumento na radiação solar. Se a radiação aumentar a mais de $16 \%$ da melhor estimativa sem que haja aumento na velocidade do vento, o sistema por sua vez também irá produzir mais eletricidade. Dependendo do valor da radiação solar, a quantidade de eletricidade produzida pode ficar abaixo ou acima da estimativa considerada como melhor sem que haja aument na velocidade do vento. O que nos permite a deduzir que se seguirmos essa linha de raciocínio, o sistema produzirá mais ou menos eletricidade dependendo da radiação solar. Radiação solar mais baixas resultam em uma menor produção anual de eletricidade e por outro lado, radiação solar mais fortes resultam em melhor produção anual de eletricidade.

Outras oberservações interessantes, são os aumentos e as diminuições no excesso de eletricidade, no "Unmet Load Factor" ou demanda não atendida e na produção de eletricidade no banco de baterias como observado nas Figuras 55, 56 e 57. A sensibilidade dos valores da radiação solar faz com que a saída do banco de baterias seja maior ou menor assim como o excesso de eletricidade. Valores maiores que a estimativa indicam melhor produção das baterias e mais excesso de eletricidade e consequetemente, valores menores indicam diminuição no excesso de eletricidade e na saída das baterias. Para a carga não atendida, valores mais altos da radiação indicam diminuição na carga não atendida e valores mais baixos indicam aumento na porcentagem de carga não atendida. Enfim, essa análise de sensibilidade nos indica o quão sensível é a produção elétrica do sistema com a variação da velocidade do vento e da radiação solar que é praticamente responsável pelo abastecimento do sistema.

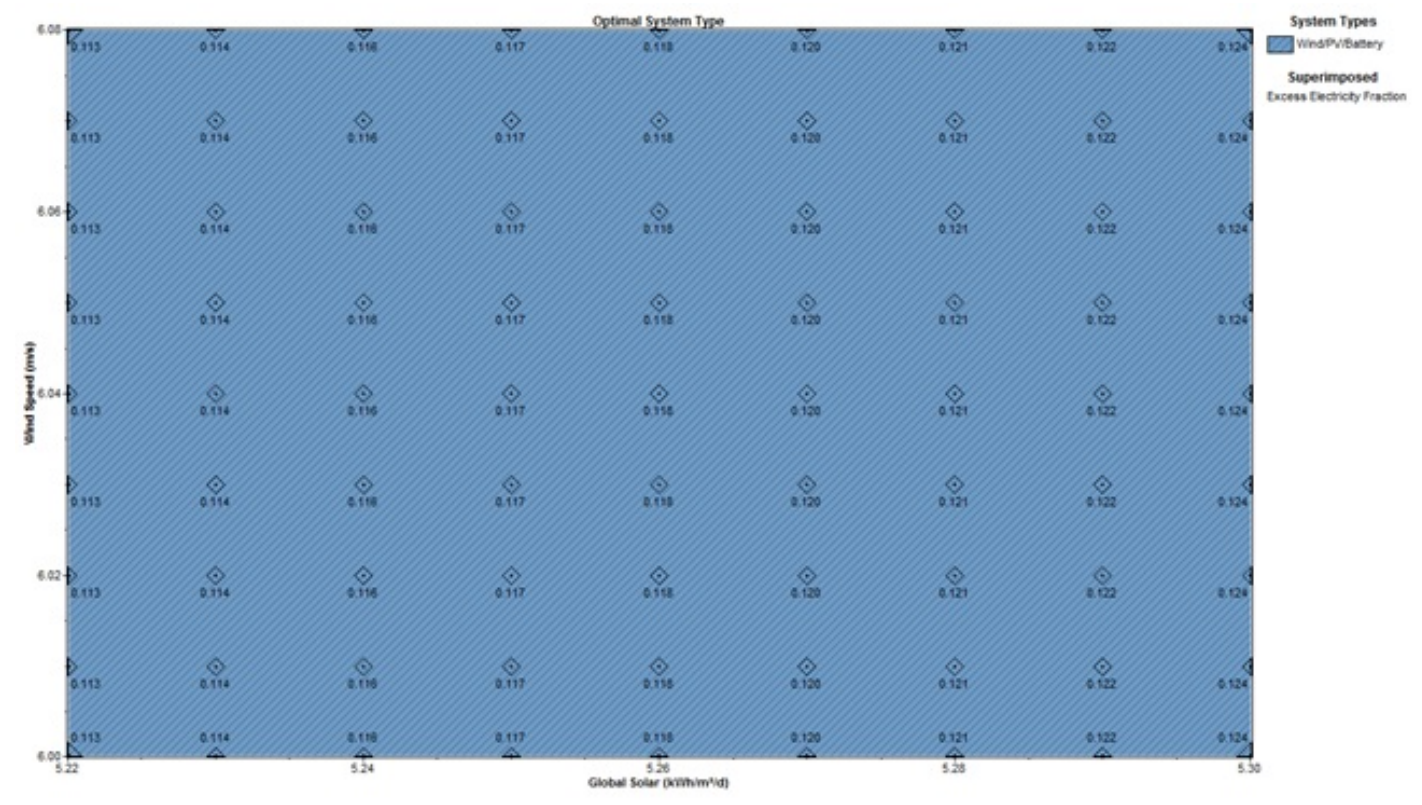

Figura 55 - Variação no excesso de eletricidade 


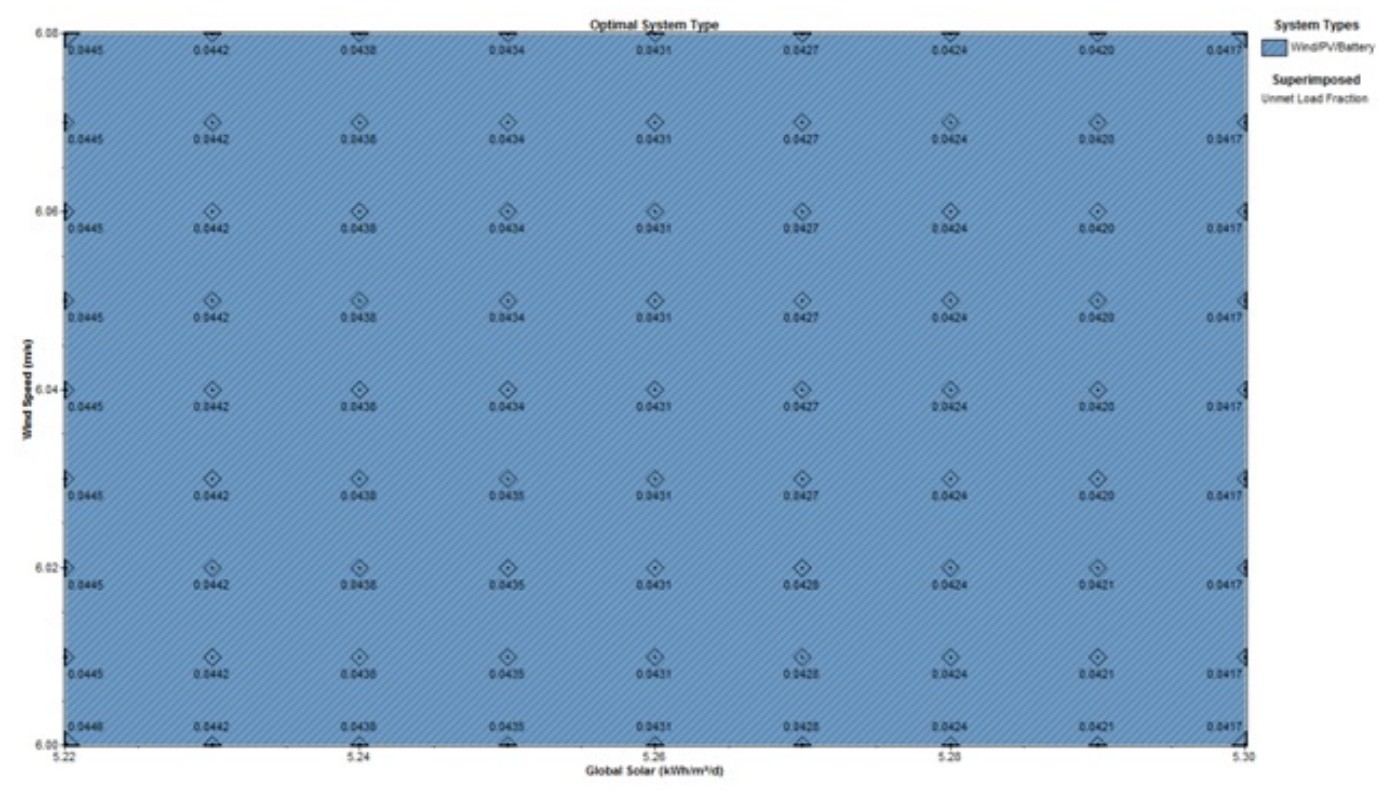

Figura 56 - Variação na carga não atendidade pelo sistema

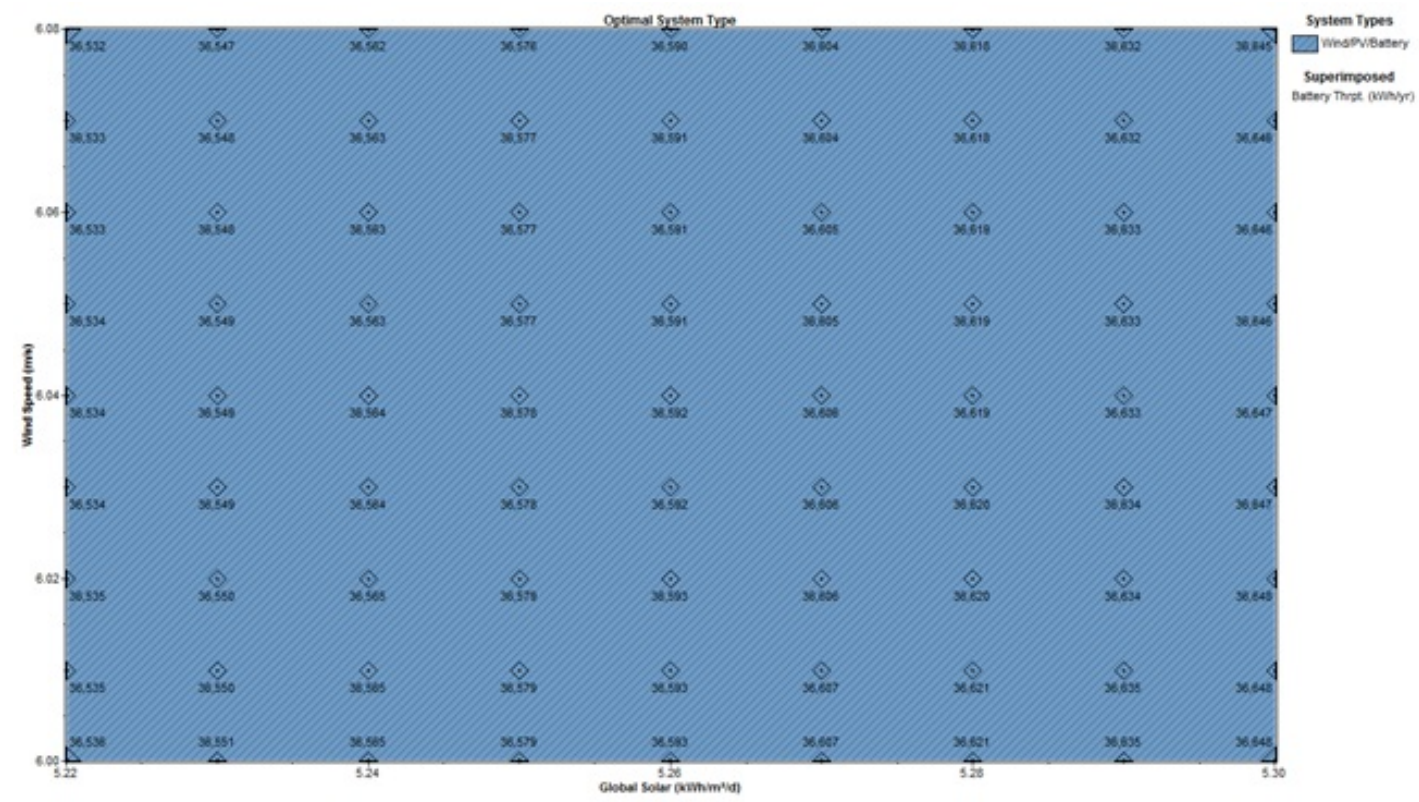

Figura 57 - Variação na saída do banco de baterias 


\section{Conclusão}

A energia representa algo fundamental na vida do homem e um fator essencial para crescimento ou desenvolvimento econômico e social. O acesso a eletricidade é um direito de qualquer cidadão e as fontes alternativas vêm possibilitando que cada vez mais famílias tenham acesso a energia elétrica, permitindo menos desigualdade social. Para satisfazer as necessidades energéticas da pequena comunidade "Paulin" situada no norte da republica do Haiti, esse estudo foi realizado com um sistema de $100 \%$ de energias renováveis aproveitando os recursos (solar e eólico) disponíveis da localidade.

O programa HOMER foi usado para simular e projetar o estudo em questão. HOMER simulou várias configurações e apresentou uma chamada no estudo de (C1) como ideal em razão do seu menor NPC. Consideranrando detalhes técnicos outras configurações que são chamadas no estudo de configurações intensivas (C2, C3 e C4) foram escolhidas para avaliação. De maneira geral os custos projetados pelo programa são bastante interessantes, pois se o projeto for aprovado, o governo deve arcar com os custos. Foi feita uma comparação entre diversas configurações simuladas. Entre as configurações analisadas, $\mathrm{C} 1$ como já tinha sido sinalada pelo HOMER apresenta menor custo NPC (\$212.277), seguida por C2 (\$379.765) e C3 (\$389.647) e por fim C4 (\$547.968). Em termos de detalhes técnicos, C3 tem 0\% de carga anual não atendida, tem $9,60 \%$ de reserva operacional anual, tem um banco de bateria que com a quantidade de energia armazenada e liberada consegue acompanhar a demanda da comunidade nos dias de pouca radiação como vimos nas Figuras 39 e 47 e assim evitar esgotamento das baterias protegendo a vida útil delas. Então por todos esses detalhes, C3 que é a configuração intensiva das baterias é a escolhida para atender a comunidade em estudo. O seu NPC é $83,5 \%$ maior que C1 e 2,6\% maior que C2, porém em termos de avaliação técnica é a configuração mais promissora e apresenta maior confiabilidade para suprimento de energia na comunidade.

Este projeto de sistema fotovoltaico-eólico isolado é uma boa opção de fornecimento de energia elétrica para a comunidade, pois além de sustentavelmente viável, pode custar muito menos em termo de viabilidade econômica que os sistemas convencionais. E ele entra no programa "Banm limyè, banm lavi" do governo haitiano que pretende levar eletricidade às comunidades mais carentes do país. É um programa que pode trazer benefícios tanto para os moradores do vilarejo quanto para o comércio local, pois possibilitaria a compra de mais equipamentos eletrônicos e conseqüentemente aumentar a atividade econômica. Espera-se uma melhora no IDH (Índice de Desenvolvimento Humano) da localidade. 
$\mathrm{Na}$ avaliação do potencial de energia solar e eólica na produção de energia elétrica, a metodologia do modelo apresentada pelo HOMER e os resultados obtidos podem ser aplicados a outras comunidades do arquipélago e assim, aumenta a repartição geográfica da distribuição de energia elétrica.

\subsection{Trabalhos futuros}

Para pesquisas futuras, uma análise dos impactos da implantação desse sistema nessa localidade seria interessante, assim como a remodelagem do sistema de bateria usando bateria de íon-lítio da tesla. Outro idéia interessante para trabalhos futuros, seria otimizar os modelos genéticos do programa para assim aumentar a eficiência do mesmo na projeção de instalações híbridas. 


\section{Referências}

ACKERMANN, T. et al. Distributed generation: a definition. Electric Power Systems Research, n. 57, p. $195-204,2001$.

ACSELRAD, H. Discursos da Sustentabilidade Urbana. REVISTA BRASILEIRA DE ESTUDOS URBANOS E REGIONAIS, n. 1, Maio 1999. ISSN 2317-1529.

ASHOK, S. Optimised model for community-based hybrid energy system. Renewable Energy, n. 32, p. 1155 - 1164, July 2007. Department of Electrical Engineering, National Institute of Technology, Calicut, NIT Campus P.O. 673601, India.

ATHAYDE, M. R.; MARTINS FILHO, J. S. L.; BRASIL JÚNIOR, A. C. P. Avaliação da Sustentabilidade de Sistemas de Energia em Comunidades Isoladas. In: Encontro da ECO-ECO. Brasília, Distrito Federal: [s.n.], 2008.

AYRES, R. U. et al. Energy efficiency, sustainability and economic growth. Energy, Fontainebleau, France, n. 32, p. 634 - 648, 2007.

BARBOSA, C. F. de O. Avaliação Tecnológica, Operacional e de Gestão de Sistemas Híbridos para Geração de Eletricidade na Região Amazônica. 2006. Dissertação (Programa de Pós-Graduação em Engenharia Elétrica) - Universidade Federal do Pará.

BARBOSA FILHO, W. P.; AZEVEDO, A. C. S. de. GERAÇÃO DISTRIBU'DA: VANTAGENS E DESVANTAGENS. In: Simpósio de Estudos e Pesquisas em Ciências Ambientais da Amazônia. [S.I.: s.n.], 2014. Simpósio de estudos e pesquisas em ciências ambientais na Amazônia.

BARROS, A. L. J. F. et al. Análise da Importância da Energia Solar nas Comunidades Rurais: Um estudo de caso. XLIII CONGRESSO BRASILEIRO DE ECONOMIA E SOCIOLAGIA RURAL, Ribeirão Preto, São paulo, Julho 2005. "Instituições, Eficiência, Gestão e Contratos no Sistema Agroindustrial".

BASSETTO, L. I. A incorporação da responsabilidade social e sustentabilidade: um estudo baseado no relatório de gestão 2005 da companhia paranaense de energia COPEL. Universidade Tecnológica Federal do Paraná - UTFPR, Av. Monteiro Lobato, s/n, Km 04, CEP 84016-210, Ponta Grossa - PR, Brasil, v. 17, n. 3, p. 639 - 651, 2010. ISSN 0104-530X. Sustainability business: a study based on the 2005 report of the Paraná state energy management company - COPEL. Disponível em: <http: //www.scielo.br/scielo.php?script=sci_arttext\&pid=S0104-530X2010000300016>.

BURCH, G. D. Hybrid Power Systems Manager Office of Power Technologies. Hybrid Renewable Energy SystemsOffice of Power Technologies, U.S. Department of Energy, Golden, Colorado. 2001. Disponível em: <https://www.netl.doe.gov/publications/ proceedings/01/hybrids/GaryBurch8.21.01.pdf>.

COGEN. Geração Distribuída - Novo Ciclo de Desenvolvimento. [S.I.], 2013. COGEN (ASSOCIAÇÃO DA INDÚSTRIA DE COGERAÇÃO DE ENERGIA). Acesso em 06/02/2017. Disponível em: <http://www.cogen.com.br/workshop/2013/Geracao_ Distribuida_Calabro_22052013.pdf.> 
CORONADO, C. Metodología de evaluación económica para proyectos de eletrificación rural. In: Conferencia Latino-Americana de Eletrificación Rural. Punta del Este, Uruguai: [s.n.], 1993. v. 2, p. $18-1993$.

COSTA, H. S. et al. Análise econômica comparativa da eletrificação rural comercial e fotovoltaica. In: Encontro de Energia no Meio Rural. Campinas, São Paulo: [s.n.], 2000.

DESHMUKHA, M.; DESHMUKH, S. Modeling of hybrid renewable energy systems. Renewable and Sustainable Energy Reviews, Zuari Nagar, Goa 403 726, India, n. 12, p. $235-249,2008$.

DUFFIE, J. A.; BECKMAN, W. A. Solar Engineering of Thermal Processes. 2. ed. Wiley, New York: [s.n.], 1991.

DUFOUR, V. Haiti: Un grand défi pour la coopération internationale et le développement durable. 2011. Dissertação (Centre universitaire de formation en environnement) - Université de Sherbrooke, Sherbrooke, Québec, Canada, essai présenté au Centre Universitaire de Formation en Environnement en vue de l'obtention du grade de maître en environnement (M.Env.). Disponível em: <https://www.usherbrooke.ca/environnement/fileadmin/sites/environnement/ documents/Essais2011/Dufour_V_23-06-2011_.pdf>.

FEDRIZZI, M. C. Sistemas fotovoltaicos de abastecimento de água para uso comunitário : lições apreendidas e procedimentos para potencializar sua difusão. 2003. 174 p. Tese (Programa Interundiades de Pós-Graduação em Energia) - Universidade de São Paulo (USP), São Paulo. Disponível em: <http://www.iee.usp.br//sf/sites/default/files/Doutorado_Cristina_Fedrizzi.pdf>.

GILMAN, P.; LILIENTHAL, P. MICROPOWER SYSTEM MODELING WITH HOMER. In:___. [s.n.], 2006. cap. 15. National Renewable Energy Laboratory. Integration of Alternative Sources of Energy. Disponível em: <http://homerenergy.com/documents/ MicropowerSystemModelingWithHOMER.pdf>.

GOLDEMBERG, J.; JOHANSSON, T. B. Energy as an Instrument for Socio-Economic Development 1 United Nations Plaza, New York, NY, 10017, USA: United Nations Development Programme, 1995. Disponível em: <https://jks-energy.wikispaces.com/file/view/ GoldembergJohansson1995UNDPEnergy InstrumentSocioEconomicDevelopment. pdf>.

GOLDEMBERG, J.; VILLANUEVA, L. D. Energia, Meio Ambiente \& Desenvolvimento. 2. ed. São Paulo: EDUSP, 2003.

GRAHAM, V. A.; HOLLANDS, K. G. T. A method to generate synthetic hourly solar radiation globally. Solar Energ, Waterloo, Ontario Canada, v. 44, n. 6, p. $333-341$, 1990. Solar Energy.

GUPTA, B. Weibull parameters for annual and monthly wind speed distributions for five locations in India. Solar Energy, v. 37, n. 6, p. 469 - 471, 1986.

H.AFGAN, N. et al. Sustainability Assessment of Renewable Energy Systems. New and Renewable Technologies for sustainable Development. Kluwer Academic Publishers, St.Petersburg, Russia, 2002. 
HANLEY, N.; NEVIN, C. Appraising renewable energy developments in remote communities: the case of the North Assynt Estate, Scotland. Energy Policy, Kings Buildings, Edinburgh EH9 3JG, Scotland, UK, v. 27, p. 527 - 547, 1999.

HIMRI, Y. et al. Techno-economical study of hybrid power system for a remote village in Algeria. Elsevier, October 2007.

HOLDREN, J. P. Energy and Sustainability. v. 315, p. - 737, 2007. Disponível em: $<$ http://science.sciencemag.org/content/sci/315/5813/737.full.pdf>.

IEA. Photovoltaic Power Systems. [S.I.], 2013. Annaul report - International Energy Agency (IEA), Fribourg, Switzerland. Disponível em: <http://apvi.org.au/wp-content/ uploads/2014/06/IEA-PVPS-Annual-Report-2013.pdf>.

IHSI. Enquête sur les conditions de vie em Haiti - Volume II. 1, Angle rue Joseph Janvier et Blvd Harry Truman, 2015. Republique D'Haiti, Ministère de l'Économie et des Finances, Institut Haïtien de Statistique et d'Informatique (IHSI). Disponível em: $<$ http://www.ihsi.ht>.

INATOMI, T. A. H.; UDAETA, M. E. M. Análise dos impactos ambientais na produção de energia dentro do planejamento integrado de recursos. In: UNIVERSIDADE DE SÃO PAULO. 2011. Disponível em: <http://seeds.usp.br/portal/uploads/INATOMI_TAHI_ IMPACTOS_AMBIENTAIS.pdf>.

JHON, R. R. La Lutte Contre la Pauvreté dans les Sections Communale de Jean Rabel: Conditions de Développement Rural. [S.I.], 1999. Licence. Disponível em: <http://www.memoireonline.com/10/09/2815/

La-lutte-contre-la-pauvrete-dans-les-sections-communales-de-Jean-Rabel-Conditions-de-develop html\#_Toc233432357>.

JUSTUS, C. G.; HARGRAVES, W. R.; YALCIN, A. Nationwide assessment of potential output from wind-powered generators. Journal of Applied Meteorology, v.15, n. 7, p. $673-678,1976$.

KEATING, W. Computer Simulation and Expert Systems for Photovoltaic Applications. University College Cork, Ireland, 1991. Tese de doutorado.

KRENZINGER, A. Desenvolvimento de Modelos para Simulação de Sistemas de Energia Solar Fotovoltaica. Centro de Investigaciones Energéticas Medioambientales y Tecnológicas, CIEMAT - Epanha., 1994.

LAMBERT, T. et al. Micropower System Modeling with HOMER. In:___. [S.I.: s.n.], 2006. cap. 15. Mistaya Engineering Inc. and National Renewable Energy Laboratory. Integration of Alternative Sources of Energy.

MARINI, J. A. DESENVOLVIMENTO DE PROGRAMA COMPUTACIONAL PARA PROJETO DE SISTEMAS FOTOVOLTAICOS NO SUPRIMENTO DE ELETRICIDADE A PEQUENAS COMUNIDADES RURAIS. 2001. Dissertação (Programa de Pós-Graduação em Engenharia Agrícola) - Universidade Estadual de Campinas, Campinas.

MARNDR. Recensement Général de l'agriculture: Enquête Communautaire, Résultats Définitifs. Route Nationale No. 1, Damien Port-au-Prince, Haiti, 2015. Disponível em: $<$ https://agriculture.gouv.ht/>. 
MESSENGER, R. A.; VENTRE, J. Photovoltaic Systems Engineering. 2. ed. Blvd., Boca Raton, New York, Washington, D.C.: [s.n.], 2004. ISBN 0-8493-1793-2.

NEMA, P. et al. A current and future state of art development of hybrid energy system using wind and PV-solar: A review. Renewable and Sustainable Energy Reviews, Bhopal 462007, M.P., India, v. 13, p. 2096 - 2103, 2013.

OLIVEIRA, A. J. C. Viabilidade econômica de alternativas energéticas para o meio rural. 1991. Dissertação (Departamento de Economia Agrícola) Universidade Federal do Ceará, Fortaleza, Ceará. Disponível em: <http: //www.iplance.ce.gov.br/publicacoes/perfil_basico/2000/Pentecoste.pdf>.

OLIVEIRA, A. S. de. Análise das Modalidades Procedimentos Simplificados do Mecanismo de Desenvolvimento Limpo" - "Os projetos de Pequena Escala e a Geração de Energia Renovável para o Atendimento das Residências Rurais e Isoladas. 2003. Dissertação (Mestrado) - Universidade Federal do Rio de Janeiro, COPPE, Rio de Janeiro. Disponível em: <http://www.ppe.ufrj.br/ppe/production/tesis/asoliveira.pdf>.

OXFORD, U. Oxford Poverty and Humain development Initiative (OPHI): Country briefing: Haiti. [S.I.], 2010. Disponível em: <http://www.ophi.org.uk/policy/ multidimensional-poverty-index/mpi-country-briefings/>.

PETRY, A. A Pobreza e a Exclusão social na América Latina. In: UNIVERSIDADE DO VALE DO RIO DOS SINOS. [S.I.], 2007. Eixo: América Latina. UNISINOS.

PINHO, J. T. et al. Sistemas Híbridos: Soluções Energéticas para a Amazônia. 1. ed. Brasília : Ministério de Minas e Energia: [s.n.], 2008. Projeto BRA 99/011, Ministério de Minas e Energia. ISBN 978-85-98341-02-6. Disponível em: <http://www.ufpa.br/inct-ereea/LivroHibridosFinal.pdf>.

PLANIFICATEUR, L. Météo et Climat à Port-de-paix. 2016. Consultado no dia 15/12/2016. Disponível em: <https://planificateur.a-contresens.net/amerique-du-nord/ haiti/nord_ouest/port_de_paix/3718420.html>.

RAMAKUMAR, R.; CHIRADEJA, P. DISTRIBUTED GENERATION AND RENEWABLE ENERGY SYSTEMS. IECEC, Oklahoma State University. Stillwater, OK USA, n. 20027, 2002. 37th Intersociety Energy Conversion Engineering Conference (IECEC).

RAMANI, K. Rural Electrification and Rural Development. In: SAUNIER, G. (Ed.). Rural Electrification Guidebook for Asia and Pacific. Bangkok, Tailandia: [s.n.], 1992.

REDDY, A. K. et al. Energy after Rio - Prospects and Challenges. 1 United Nations Plaza, New York, NY, 10017 USA, 1997. United Nations Development Programme in collaboration with International Energy Initiative and Energy 21 Stockholm Environment Institute and in consultation with Secretariat of the UN Commission for Sustainable Development.

REN21. RENEWABLES 2016 GLOBAL STATUS REPORT. [S.I.], 2016. REN21 (Renewable Energy Policy Network for the 21st Century). National Technical University of Athens (NTUA).

RIBEIRO, T. B. S. et al. IMPLEMENTAÇÃO DE SISTEMAS FOTOVOLTAICOS EM COMUNIDADES ISOLADAS: REFLEXÕES SOBRE ENTRAVES ENCONTRADOS. Revista Brasileira de Energia, v. 19, n. 1, p. 269 - 283, 2013. 
RíO, P. del; BURGUILLO, M. Assessing the impact of renewable energy deployment on local sustainability: Towards a theoretical framework. Renewable and Sustainable Energy Reviews, Madrid, Spain, v. 12, p. 1325 - 1344, Março 2007.

ROBERTO SCHAEFFER AND Claude Cohen AND Mauro Araújo Almeida AND Carla Costa Achão AND Fernando Monteiro Cima. Energia e Pobreza: Problemas de desenvolvimento energético e grupos sociais marginais em áreas rurais e urbanas do Brasil. Santiago, Chile, 2003. División de Recursos Naturales e Infraestructura. Disponível em: <http://repositorio.cepal.org/bitstream/handle/11362/6421/S038528_pt. pdf;jsessionid=F4538B6D1CD9AE9B68555D11E8D99C11 ?sequence $=1>$.

ROSÁRIO, L. T. R. do; ELS, R. V.; BRASIL JÚNIOR, A. C. P. ALTERNATIVAS ENERGÉTICAS PARA COMUNIDADES ISOLADAS DA AMAZÔNIA: A ENERGIA HIDROCINÉTICA NO MARACÁ, SUL DO AMAPÁ. In: ECOECO. Brasília, Distrito Federal, 2005. Disponível em: <http://www.ecoeco.org.br/conteudo/publicacoes/ encontros/vi_en/artigos/mesa4/Alternativas_energeticasparacomunidades.pdf>.

SAHEB-KOUSSA, D.; HADDADI, M.; BELHAMEL, M. Economic and technical study of a hybrid system (wind-photovoltaic-diesel) for rural electrification in Algeria. Applied Energy, Algiers, Algeria, n. 86, p. 1024 - 1030, 2009.

SAMAAN, M. M. et al. Using simulation tools for optimizing cooling loads and daylighting levels in Egyptian campus buildings. HBRC Journal, January 2016. Disponível em: <BienroderWeg.97,R149,Braunschweig38106, Germany>.

SHAAHID, S.; ELHADIDY, M. Economic analysis of hybrid photovoltaic-diesel-battery power systems for residential loads in hot regions-A step to clean future. Renewable and Sustainable Energy Reviews, Dhahran 31261, Saudi Arabia, n. 12, p. 488 - 503, July 2008.

SILVA, M. J. et al. Energia Solar Fotovoltaica para Geração Descentralizada de Eletricidade no Brasil: A Necessidade de Subsídio por parte do Governo. Congresso Latino Americano de Generacion y Transporte de Energia Electrica, p. 7 -, 2000.

TRIGOSO, F. B. M. DEMANDDA DE ENERGIA ELÉTRICA E DESENVOLVIMENTO SOCIOECONÔMICO: O caso das comunidades rurais eletrificadas com sistemas fotovoltaicos. 2004. Tese (Programa Interunidades de Pós-Graduação em Energia) Universidade de São Paulo, São Paulo.

UDAETA, M. E. M. Planejamento integrado de recursos energéticos-PIR-para o setor elétrico (pensando o desenvolvimento sustentável). 1997. Tese (Engenharia de Sistemas de Potência) - Universidade de São Paulo (USP). Disponível em: <http://seeds.usp.br/portal/uploads/8f6b04ca-53f8-492c.pdf>.

VERA, L. H. Programa Computacional para dimensionamento e Simulação de sistemas Fotovoltaicos Autônomos. 2004. Dissertação (Mestrado), Universidade Federal do Rio Grande do Sul.

WANDERLEY, B.; NAZARETH, M. de. A ruralidade no Brasil moderno por um pacto social pelo desenvolvimento rural. In: GIARRACA, N. (Comp.) Una nueva ruralidad in America Latina? . In: NORMA GIARRACCA. CLACSO, CONSEJO LATINOAMERICANO DE CIENCIAS SOCIALES. Ciudad Autónoma 
de Buenos Aires, Argentina, 2001. ISSN 950-9231-58-4. Disponível em: $<$ http://bibliotecavirtual.clacso.org.ar/ar/libros/rural/wanderley.pdf >.

WICHERT, B. PV-DIESEL HYBRID ENERGY SYSTEMS FOR REMOTE AREA POWER GENERATION-A REVIEW OF CURRENT PRACTICE AND FUTURE DEVELOPMENTS. Renewable and Sustainable Energy Reviews, Perth 6102, Western, Australia, v. 1, n. 3, p. $209-228,1997$.

WINDFINDER. Prévisions \& rapports météo et de vent. 2016. Disponível em: $<$ https://fr.windfinder.com/forecast/port-au-prince>.

WORLDWATCH INSTITUTE AND MTPTEC. Feuille de Route pour um système énergétique durable em Haiti: Exploiter les ressources énergétiques nationales pour mettre en place um système électrique fiable, abordable et adapte aux changements climatiques. [S.I.], 2014. WORLDWATCH INSTITUTE \& Ministère des Travaux Publics, Transports, Énergie et Communications (MTPTEC ). Disponível em: <http://www.worldwatch.org/system/files/Haiti-Roadmap-French.pdf>. 